\title{
AN EXPERIMENT ON INTEGRATED THERMAL MANAGEMENT USING METALLIC FOAM
}

\author{
A Thesis \\ Presented to the \\ Aerospace Engineering Department \\ California Polytechnic State University, San Luis Obispo \\ In Partial Fulfillment of Requirements for the \\ Degree of Master of Science in Aerospace Engineering
}

By

Derek Geiger

May 2009 
(C) 2009

Derek Geiger

ALL RIGHTS RESERVED 


\section{COMMITTEE MEMBERSHIP}

Title:

Author:

Date Submitted:

COMMITTEE CHAIR:

COMMITTEE MEMBER:

COMMITTEE MEMBER:

COMMITTEE MEMBER:
An Experiment on Integrated Thermal Management

Using Metallic Foam

Derek Geiger

May 2009

Dr. Jin Tso, Professor

Y.H. Bill Ho, Northrop Grumman Technical Fellow

Dr. Dianne DeTurris, Professor, Co-Chair

Dr. Eltahary Elghandour, Lecturer 


\begin{abstract}
An Experiment on Integrated Thermal Management Using Metallic Foam

Derek Geiger
\end{abstract}

This report details an approach to using metal foam heat exchangers inside an integrated thermal management system on a variable cycle engine. The propulsion system of interest is a variable cycle engine with an auxiliary, variable flow rate fan. The feasibility of utilizing an open-celled metallic foam heat exchanger in the ducting between the constant and variable-fans on this variable cycle engine to cool the avionics was explored using an experimental approach. Two heat exchangers, 6.3 inch width by 6.3 inch length by 0.5 inch thickness, were constructed from 20 and 40 pores per inch (PPI) metal foam and tested. Both were constructed using 6061-T6 aluminum open-cell metal foam with a relative density of $8 \%$ and brazed using 4047 aluminum braze to 0.02 inch thick sheet metal made of 6061-T6 aluminum. Both models were subjected to internal forced convection using heated air with flow rates of 4, 8, 12, 16, and 20 standard cubic feet per minute (SCFM). They were also subjected to external forced convection using blowers to supply cooling air to simulate the variable cycle engine's fans. One duct was supplied with a constant $34 \mathrm{ft} / \mathrm{s}$ cooling flow, while the other cooling flow velocity was varied between $0 \%$ and $100 \%$ of this $34 \mathrm{ft} / \mathrm{s}$, in $25 \%$ increments. The temperature and pressure of the flow internal to the metal foam, as well as the heat exchanger external surface and cold flow temperatures, were recorded. A hot-flow Reynolds number range of 1,300 to 6,400 was tested.

Results showed expected trends for the hydraulic performance of both heat exchangers. The form factors were 50.4 and $54.8 \mathrm{ft}^{-1}$ and the permeabilities were $9.11 \mathrm{E}-7$ and $6.32 \mathrm{E}-7 \mathrm{ft}^{2}$ for the 20 and 40 PPI heat exchangers, respectively. Due to a defect on one side of the 40 PPI heat exchanger, the thermal results are based only on the 20 PPI heat exchanger. While the present study examines a different metal foam heat transfer configuration than most other studies, the metal foam Nusselt numbers were comparable to past studies. In addition, the pumping power required was not excessive and would allow the thermal management system to be realized without an unreasonable energy input. Therefore, a metal foam heat exchanger integrated within the ducting of a variable cycle engine is deemed feasible. The pumping power and thermal resistance were used to create a performance predicting model of the 20 PPI heat exchanger. From this model, the optimized 20 PPI heat exchanger has a hot-flow rate of 10.5 SCFM. The resulting pumping power and thermal resistance are estimated to be $6.7 \mathrm{BTU} / \mathrm{hr}$ and 0.036 $\frac{{ }^{\circ} R}{B T U / h r}$, respectively. 


\section{ACKNOWLEDGMENTS}

I would like to thank Dr. Jin Tso, my advisor, for his support, knowledge, and assistance throughout all phases of this project. I also thank Bill Ho for his guidance and his combined effort within Northrop Grumman for making this project possible. I thank Dan Powell for his time and effort with the test apparatus design and especially construction. I thank Dr. Eltahary Elghandour and Dr. Kurt Colvin for their help with test setup issues. Finally, I would like to thank my family for their continued encouragement and support. 


\section{TABLE OF CONTENTS}

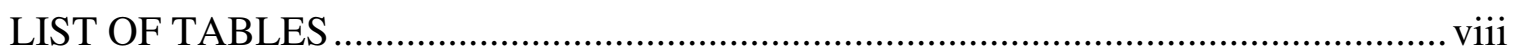

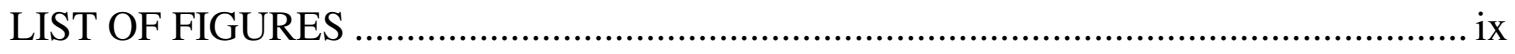

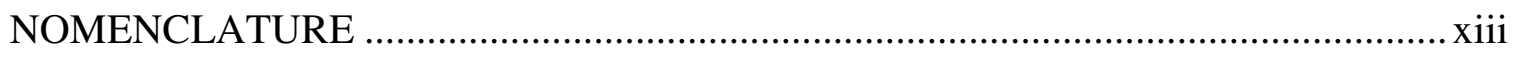

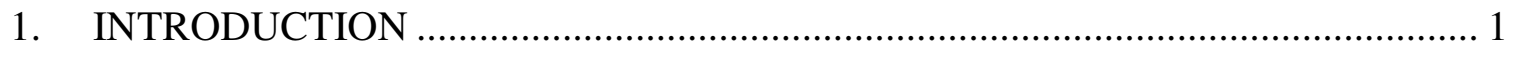

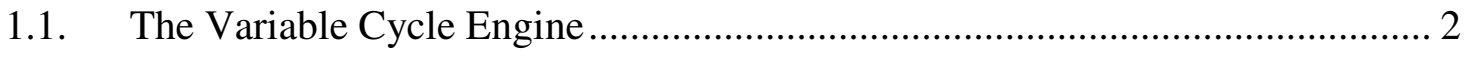

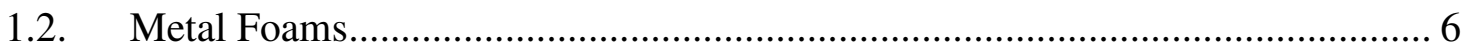

1.3. Variable Cycle and Integrated Thermal Management ..................................... 10

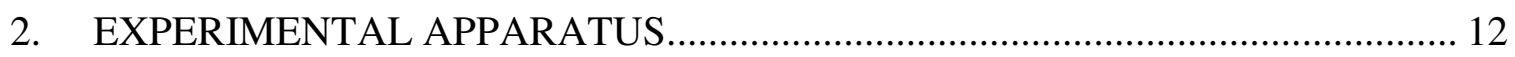

2.1. System Design ................................................................................... 12

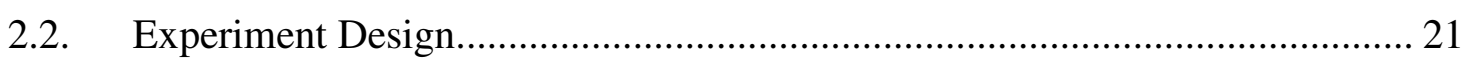

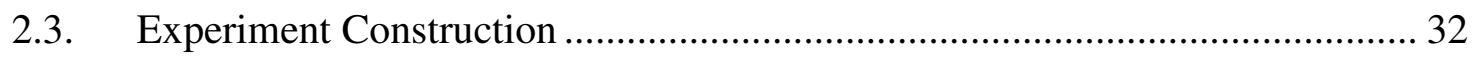

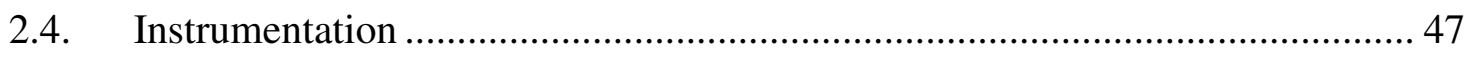

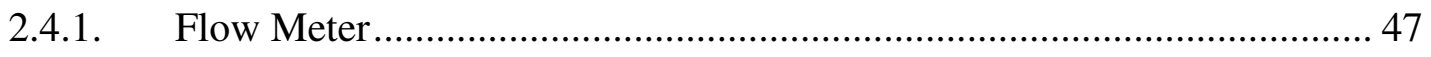

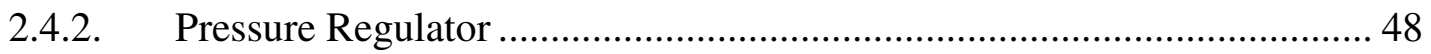

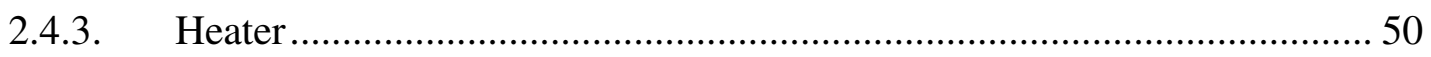

2.4.4. Blowers, Motors, and Controllers …………………………………....... 52

2.4.5. Pitot Probes and Manometer.................................................................. 54

2.4.6. Thermocouples and Amplifiers................................................................. 55

2.4.7. Scanivalve and RadLink ..................................................................... 57

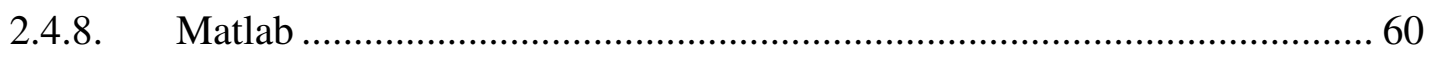

2.4.9. Data Acquisition PC Card and Accessories ............................................... 60

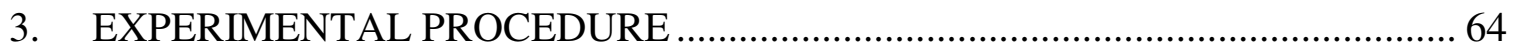




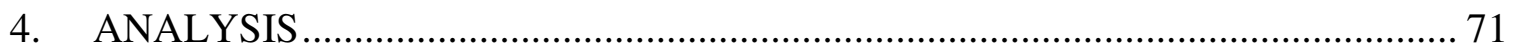

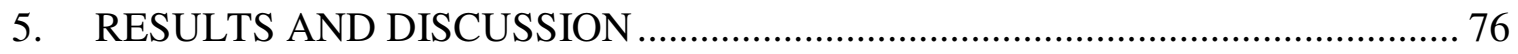

5.1. Metal Foam Cross-flow Variation ........................................................ 76

5.2. Flow Properties at Metal Foam Inlet and Outlet........................................... 79

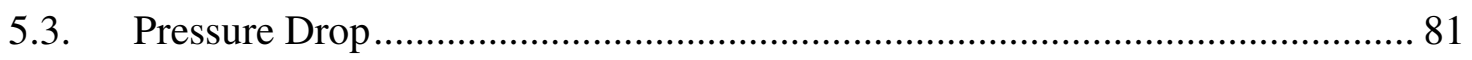

5.4. Heat Transfer Performance ..................................................................... 85

5.4.1. Forty PPI Heat Exchanger Anomaly ............................................... 85

5.4.2. Heat Transfer Performance of 20 PPI Heat Exchanger .......................... 92

5.5. Overall Heat Exchanger Performance ....................................................... 98

5.6. Error Estimation ............................................................................. 103

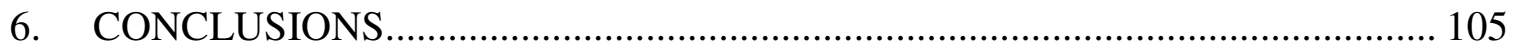

APPENDIX A: ERROR CALCULATIONS ......................................................... 108

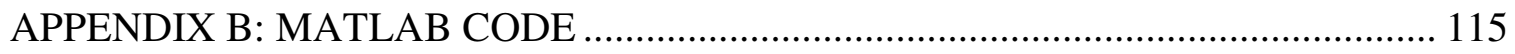

APPENDIX C: 40 PPI HEAT EXCHANGER RESULTS ........................................ 120

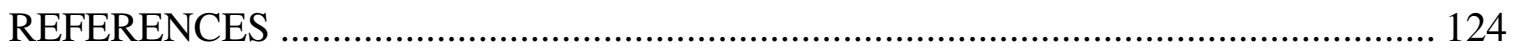




\section{LIST OF TABLES}

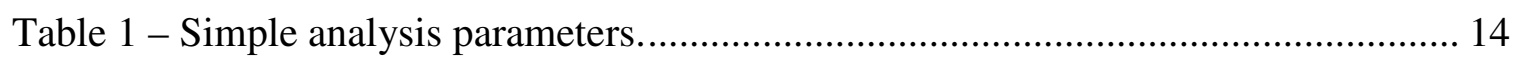

Table 2 - Test matrix. ................................................................................... 70

Table 3 - Permeability and form factor results..................................................... 83

Table 4 - Most probable error estimation in significant results. ................................. 104 


\section{LIST OF FIGURES}

Figure 1 - Duocel open-cell metal foam structure ................................................... 7

Figure 2 - Convective cooling experimental setup.................................................... 9

Figure 3 - Heat sink experimental setup............................................................. 10

Figure 4 - Metal foam integration with variable cycle engine concept......................... 12

Figure 5 - Simple analysis results for mean parameter values................................... 15

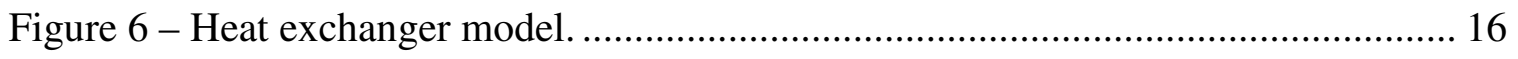

Figure 7 - Depiction of an open-cell created by the staggered bank of cylinders........... 16

Figure 8 - Estimated metal foam heat exchanger performance................................... 20

Figure 9 - Schematic of circumferentially oriented metal foam heat exchanger within

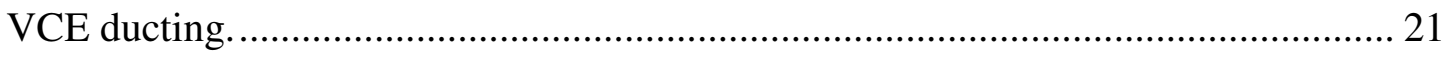

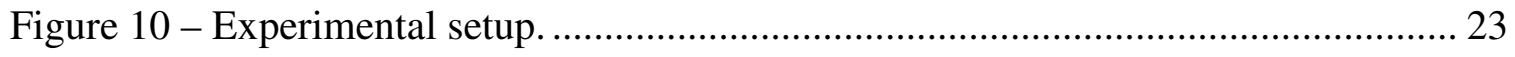

Figure 11 - Metal foam heat exchanger drawing (dimensions in inches). ..................... 26

Figure 12 - Cold flow duct and metal foam insertion point drawing (dimensions in

inches)

Figure 13 - Hot-flow diffuser and delivery ducting drawing (dimensions in inches)..... 28

Figure 14 - Hot-flow outlet drawing (dimensions in inches)................................... 29

Figure 15 - Drawing of complete test bed design (dimensions in inches).................... 30

Figure 16 - Hot-flow measurement locations.................................................... 31

Figure 17 - Surface thermocouple locations for side with measurement ports............... 32

Figure 18 - 20 PPI metal foam heat exchanger................................................... 33

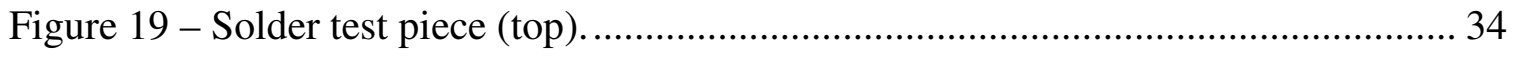

Figure 20 - Solder test piece (bottom) …........................................................ 35 
Figure 21 - Measurement tube bond type test specimen. 36

Figure 22 - Hot flow bulk temperature thermocouple insertion location (not to scale)... 37

Figure 23 - 20 PPI metal foam heat exchanger with thermocouples and pressure tubes assembled. 38

Figure 24 - Surface thermocouples on the constant-fan side of the 20 PPI heat

exchanger. 38

Figure 25 - Surface thermocouple on the variable-fan side of the 20 PPI heat

exchanger. 39

Figure 26 - Cold flow inlet and start of duct. 40

Figure 27 - Connection plates assembled with heat exchanger inside cold flow duct.... 41

Figure 28 - Connection plate cutout for mounting and securing the heat exchanger....... 42

Figure 29 - Hot-flow inlet to connection plate flange............................................. 43

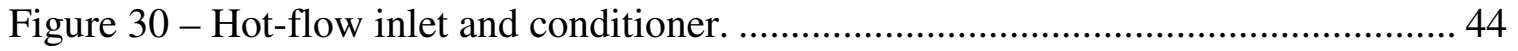

Figure 31 - Honeycomb flow straightener assembled into hot-flow inlet ducting.......... 44

Figure 32 - Hot-flow outlet duct which exhausts out the lab roll-up door..................... 45

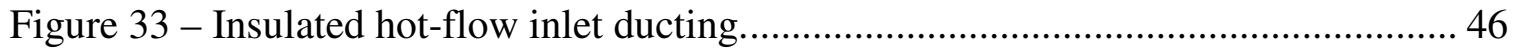

Figure 34 - Final assembled test bench ready for testing...................................... 46

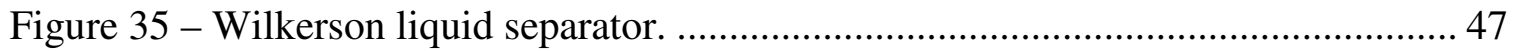

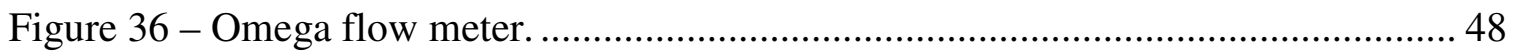

Figure 37 - Norgren pressure regulator and supplied pressure gauge.......................... 49

Figure 38 - Pressure regulator flow characteristics................................................ 49

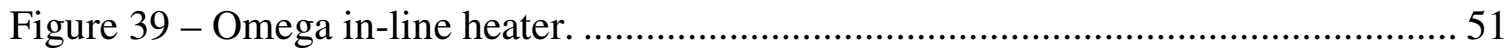

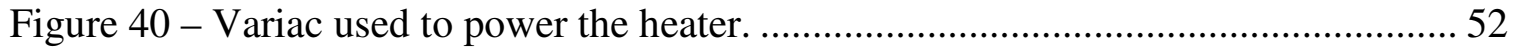


Figure 41 - Cold air flow delivery system............................................................. 53

Figure 42 - Blower and motor casing ............................................................... 53

Figure 43 - Pitot tubes mounted externally to the cold flow duct............................... 54

Figure 44 - Manometer used to measure cold flow velocity ..................................... 55

Figure 45 - Thermocouple connected to Omega converter used to amplify the

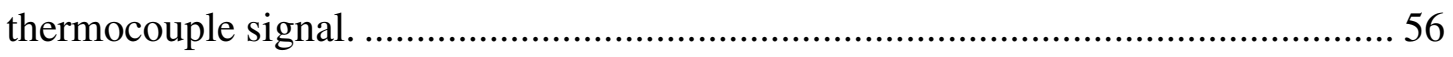

Figure 46 - Scanivalve system configuration.................................................. 58

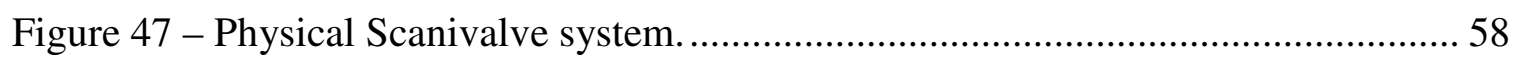

Figure 48 - RadLink GUI used to operate Scanivalve system.................................. 59

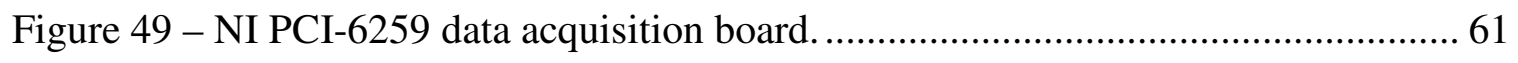

Figure 50 - SCC-68 data acquisition box outfitted to acquire thermocouple and flow

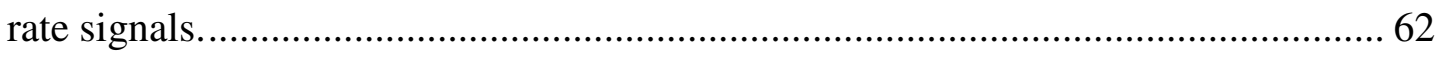

Figure 51 - Screenshot from DAQ computer during a test run.................................. 63

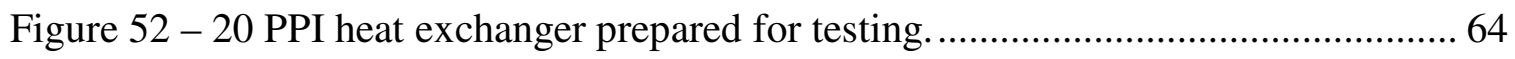

Figure 53 - DAQ box ready to measure flow temperature in the hot-flow direction....... 65

Figure 54 - Scanivalve ZOC33 module with hot-flow pressure tubes connected........... 66

Figure 55 - Hot-flow temperature for $4 \mathrm{SCFM}, \mathrm{VF}=100 \% \mathrm{CF}$ velocity test case........ 68

Figure 56 - Pressure check for 2-D flow (20 PPI model)......................................... 77

Figure 57 - Pressure check for 2-D flow (40 PPI model) ....................................... 77

Figure 58 - Temperature check for 2-D flow (20 PPI model) .................................. 78

Figure 59 - Temperature check for 2-D flow (40 PPI model).................................... 79

Figure 60 - Example of inlet and outlet pressure determination............................... 80

Figure 61 - Example of inlet and outlet temperature determination. ............................ 81 
Figure 62 - Pressure drop per unit length for both 20 and 40 PPI models..................... 82

Figure 63 - Fanning friction factor for both 20 and 40 PPI models............................. 84

Figure 64 - Flow temperatures within metal foam for 20 SCFM, VF $=100 \%$ CF test

case.

Figure 65 - Heat transfer modes from the hot-flow to the cold flow. ........................... 89

Figure 66 - Internal Nusselt number for the 20 PPI heat exchanger. .......................... 92

Figure 67 - External Nusselt number for the 20 PPI heat exchanger........................... 95

Figure 68 - Colburn j factor for the 20 PPI internal flow......................................... 96

Figure 69 - Comparison of $100 \%$ variable fan velocity test case to data from Salas and Waas.

Figure 70 - Pumping power and internal thermal resistance for the 20 PPI heat

exchanger.

Figure 71 - Normalized pumping power and thermal resistance for the 20 PPI heat exchanger. 101

Figure 72 - 20 PPI heat exchanger performance model used for optimization. 102 
NOMENCLATURE

\begin{tabular}{|l|l|l|}
\hline Symbol & \multicolumn{1}{|c|}{ Definition } & Units \\
\hline A & Cross-sectional area & $\mathrm{ft}^{2}$ \\
\hline $\mathrm{A}_{\text {con }}$ & Convective heat transfer surface area & $\mathrm{ft}^{2}$ \\
\hline $\mathrm{a}$ & Cell size & $\mathrm{ft}$ \\
\hline $\mathrm{b}$ & Metal foam sandwich height & $\mathrm{ft}$ \\
\hline Bi & Biot Number, $\frac{h L}{k_{s}}$ & - \\
\hline $\mathrm{C}$ & Form factor & $\mathrm{ft}^{-1}$ \\
\hline $\mathrm{C}_{\mathrm{p}}$ & Specific heat at constant pressure & $\mathrm{ft}-\mathrm{lbf} /\left(\mathrm{slug}-{ }^{\circ} \mathrm{R}\right)$ \\
\hline $\mathrm{D}_{\mathrm{h}}$ & Hydraulic diameter, $\frac{4 A}{P}$ & $\mathrm{ft}$ \\
\hline $\mathrm{d}$ & Ligament diameter & $\mathrm{ft}$ \\
\hline $\mathrm{F}$ & Force & $\mathrm{lbf}$ \\
\hline$f$ & Fanning friction factor, Fuel flow ratio & - \\
\hline $\mathrm{H}$ & Duct height & $\mathrm{ft}$ \\
\hline $\mathrm{h}$ & Convective heat transfer coefficient & $\mathrm{BTU} /\left(\mathrm{hr}-\mathrm{ft}^{2}-{ }^{\circ} \mathrm{R}\right)$ \\
\hline$\Delta \mathrm{h}$ & Manometer deflection & $\mathrm{ft}$ \\
\hline $\mathrm{j}$ & Colburn j factor, $\frac{h}{\rho U C_{p}}\left(\frac{C_{p} \mu}{k}\right)^{2 / 3}$ & - \\
\hline $\mathrm{K}$ & Permeability & \\
\hline $\mathrm{k}$ & Thermal conductivity & $\mathrm{ft}{ }^{2}$ \\
\hline $\mathrm{L}$ & Length & $\mathrm{BTU} /\left(\mathrm{hr}-\mathrm{ft}-{ }^{\circ} \mathrm{R}\right)$ \\
\hline $\mathrm{l}$ & Transfer length & $\mathrm{ft}$ \\
\hline $\mathrm{M}$ & Mach number & $\mathrm{ft}$ \\
\hline $\mathrm{m}$ & Experimental coefficient & - \\
\hline$\dot{m}$ & Mass flow rate & - \\
\hline $\mathrm{Nu}$ & Nusselt number, $\frac{h L}{k_{f}}$ & $\mathrm{slugs} / \mathrm{s}$ \\
\hline $\mathrm{P}$ & Perimeter & $\mathrm{ft}$ \\
\hline $\mathrm{p}$ & Pressure & $\mathrm{lbf} / \mathrm{ft}^{2}$ \\
\hline$\Delta \mathrm{p}$ & Pressure drop $/ \mathrm{ft}^{2}$ \\
\hline $\mathrm{Q}$ & Volumetric flow rate & $\mathrm{ft} / \mathrm{min}(\mathrm{CFM}$ \\
\hline $\mathrm{q}$ & Heat transfer & \\
\hline & & \\
\hline
\end{tabular}




\begin{tabular}{|l|l|l|}
$\mathrm{R}_{\mathrm{th}}$ & Thermal resistance, $\frac{\Delta T}{q}$ & o $\mathrm{R} /(\mathrm{BTU} / \mathrm{hr})$ \\
\hline $\mathrm{Re}$ & Reynolds number, $\frac{\rho U D_{h}}{\mu}$ & - \\
\hline $\mathrm{T}$ & Temperature & ${ }^{\circ} \mathrm{R}$ \\
\hline $\mathrm{U}$ & Mean velocity, $\frac{Q}{A}$ & $\mathrm{ft} / \mathrm{s}$ \\
\hline $\mathrm{V}$ & Velocity & $\mathrm{ft} / \mathrm{s}$ \\
\hline$\dot{W}$ & Pumping power, $\Delta p Q$ & $\mathrm{BTU} / \mathrm{hr}$ \\
\hline $\mathrm{x}$ & Distance & $\mathrm{ft}$ \\
\hline $\mathrm{y}$ & Distance in cross-flow direction & $\mathrm{ft}$ \\
\hline
\end{tabular}

\begin{tabular}{|l|l|l|}
\hline \multicolumn{2}{|l|}{ Greek Symbols } \\
\hline$\alpha$ & Thermal diffusivity & $\mathrm{ft}^{2} / \mathrm{s}$ \\
\hline$\beta$ & Bypass ratio & - \\
\hline$\gamma$ & Specific weight & $\mathrm{lbf} / \mathrm{ft}^{3}$ \\
\hline$\Delta$ & Difference & - \\
\hline$\mu$ & Dynamic viscosity & $\mathrm{lbf}-\mathrm{s} / \mathrm{ft}^{2}$ \\
\hline $\mathrm{v}$ & Kinematic viscosity & $\mathrm{ft}^{2} / \mathrm{s}$ \\
\hline$\xi$ & Experimental coefficient & - \\
\hline$\eta$ & Coefficient, $1-0.22 \tilde{\rho}$ & - \\
\hline$\eta_{H X}$ & Heat exchanger efficiency & - \\
\hline$\rho$ & Density & slugs/ $/ \mathrm{ft}^{3}$ \\
\hline$\tilde{\rho}$ & Relative density, $\frac{\rho_{m f}}{\rho_{s}}$ & - \\
\hline
\end{tabular}

\begin{tabular}{|l|l|}
\hline \multicolumn{2}{|l|}{ Subscripts } \\
\hline a & air \\
\hline atm & Atmospheric \\
\hline avg & Average \\
\hline CF & Constant-fan property \\
\hline c & Cold flow property \\
\hline eff & Effective metal foam property \\
\hline ext & Property external to the metal foam \\
\hline f & Fluid \\
\hline HX & Heat exchanger \\
\hline in & Inlet \\
\hline
\end{tabular}




\begin{tabular}{|l|l|} 
int & Property internal to the metal foam \\
\hline $\mathrm{Im}$ & Logarithmic mean \\
\hline $\mathrm{mf}$ & Metal foam \\
\hline out & Outlet \\
\hline s & Solid \\
\hline std & Standard \\
\hline VF & Variable-fan property \\
\hline w & Wall \\
\hline$\infty$ & Freestream \\
\hline
\end{tabular}




\section{INTRODUCTION}

As current generation propulsion systems are pushed to their limits, many organizations, especially the United States Air Force (USAF), are looking to the future. To propel future aircraft, next generation power plants will need increased performance at a lower operating cost. To achieve this, the propulsion system as a whole will have to advance. The propulsion system can no longer be examined as an engine with peripherals, such as bleed air pumps and ducting used for cooling and auxiliary power generation systems. All components of the system will have to be designed simultaneously to achieve the best performance possible. While improved performance is possible, this system design process will force the sub-systems and components to become highly integrated and most likely more complex than current solutions.

One prime example, examined in this paper, is a thermal management system integrated with the engine itself. By integrating these two sub-systems, the overall propulsion system may provide increased performance as compared to a current engine without tight sub-system integration. Of course, this integrated thermal management system will not be installed on today's aircraft engines. The integrated thermal management system will be employed on tomorrow's power plant: a variable cycle engine (VCE). The VCE concept shows promise for greatly increasing performance and efficiency, but to reach the USAF's goals, this concept will need to be combined with other performance enhancements.

To build on the VCE advancement, an integrated thermal management system utilizing heat exchangers contained in the VCE structure is proposed here. The type of VCE examined here is a variable bypass ratio turbofan. The bypass ratio is varied 
through the use of an auxiliary, variable inlet area fan. To further utilize advancing technology, the proposed heat exchangers are constructed using open-cell metal foam, a porous medium that offers many advantages for heat transfer applications. The proposed concept utilizes heat exchangers constructed from metal foam that are structurally integrated into the ducting between the constant and variable-flow fan ducts to cool fan bleed air for use in cooling the avionics.

\subsection{The Variable Cycle Engine}

To meet the challenging demands put on next generation aircraft engines, engine developers have tried many different configurations, with one of the more current being the Variable Cycle Engine (VCE). Until recently, aircraft power plants had been designed around a single mission segment, giving optimum performance during only one flight condition. With this design philosophy, the power plant will experience performance degradation during all other mission segments. The basic goal of a VCE is to design the engine around more than one flight condition, allowing efficient operation throughout many flight regimes. This is essentially accomplished by an engine that can be reconfigured during operation to change at least one of its characteristics, such as bypass ratio, flow rate, and/or pressure ratio. The key difference between a VCE and a current turbofan is that for off-design point operation the current turbofan must match thrust requirements by changing throttle setting. The VCE, however, will change an engine characteristic, thereby gaining the ability to tailor the engine for optimal performance around multiple design points.

This type of reconfigurable engine is desirable because designers will be able to tailor an engine for an entire mission, rather than just one segment. One example of an aircraft 
type that could benefit from a VCE is a supersonic transport (SST). In the case of a SST, designers desire low takeoff noise, since the SST will most likely take off from commercial airports, and high specific thrust during transonic acceleration and supersonic cruise to provide supersonic cruising speed efficiently. So, taking a mixed exhaust turbofan as an example, simple cycle analysis gives the specific thrust as

$$
\frac{F}{\dot{m}_{a}}=\frac{(1+\beta+f)}{(1+\beta)} V_{\text {exit }}-V_{\infty}
$$

where $\mathrm{F}$ is the thrust produced by the engine, $\dot{m}_{a}$ is the mass flow rate of air, $f$ is the ratio of fuel to core air mass flow rate, $\mathrm{V}_{\text {exit }}$ is the mixed exhaust flow velocity, $\mathrm{V}_{\infty}$ is the freestream air velocity, and $\beta$ is the bypass ratio, the ratio of fan to core air mass flow rate.

Since the specific thrust is proportional to the velocity difference between the exhaust and freestream velocities, the smaller this difference is, the smaller the specific thrust. Also, the noise caused by this exhaust velocity increases as the exhaust speed increases, so the low takeoff noise requirement translates into a requirement for low specific thrust at takeoff. Therefore, a VCE concept that allows large specific thrust during supersonic cruise and low specific thrust for takeoff and landing would be ideal for a SST. However, it should be noted that while this low takeoff noise is an important requirement, so is the static thrust the engine produces. Without enough static thrust from the engine, the SST would be unable to takeoff. So another benefit the VCE could offer using a variable air mass flow rate is to increase the static thrust at takeoff for a given specific thrust.

There are many different ways to reconfigure the power plant mid-mission, but consider just one: variable bypass ratio. As was seen in Equation 1, the bypass ratio has a 
direct effect on the specific thrust. As the bypass ratio increases, the specific thrust decreases. This can be seen from the ratio $\frac{(1+\beta+f)}{(1+\beta)}$ directly, however the specific thrust is actually decreased more than this ratio shows. For the mixed exhaust turbofan, the core and fan exhaust flows are mixed in the nozzle. As the bypass ratio increases there is more fan exhaust, which travels at a slower velocity compared to the core exhaust, added to the mixture with the core exhaust. Since a larger percentage of the final mixed exhaust flow is traveling slower, the exhaust velocity will be slower, thereby decreasing the specific thrust.

While there are many ways to change the bypass ratio, this report examines an engine with an auxiliary, variable area fan flow path. With the auxiliary flow path open, the fan mass flow rate will increase, the bypass ratio will increase, and the specific thrust will decrease. This would be the takeoff engine configuration for the SST. Then, during the thrust pinch point, the auxiliary flow path would be fully closed, the bypass ratio would decrease, and the specific thrust would increase. This would be the SST's transonic acceleration and cruise engine configuration. With this engine setup both mission segments would have adequate performance as compared to an engine optimized for a particular flight segment, which would have a severe performance reduction for the other mission segment. In addition, an advanced control system could operate the engine with greater flexibility and most likely produce an overall more efficient engine.

The VCE concept is not new. In the 1970s and '80s, General Electric actually explored an experimental VCE test engine, the YJ101. ${ }^{1}$ Then in the 1980s, GE converted this work into the F120 engine: a power plant with limited cycle variability for use on the advanced tactical fighter, the result of which was the Lockheed Martin YF-22 and 
Northrop Grumman YF-23. While GE's engine was not used on the YF-22, GE learned a great deal about VCEs and other technologies that will be necessary to produce a VCE. GE carried this knowledge to the Defense Department's integrated high-performance turbine engine technology (IHPTET) initiative during the early '90s. Advances were made in support of this power plant program, especially in the area of materials, which will allow current VCE concepts to be more realizable and reliable in the eyes of the Air Force. $^{2}$

More currently, to promote power plant improvements similar to the IHPTET initiative, the Air Force Research Lab, Propulsion Directorate (AFRL/PR), released a Broad Agency Announcement (BAA) in April of 2007. Entitled Adaptive Versatile Engine Technology (ADVENT), this effort is housed within the national Versatile, Affordable Advanced Turbine Engines (VAATE) Program. ${ }^{3}$ The goal of the ADVENT Program is to "develop and demonstrate inlet, engine, exhaust nozzle, and integrated thermal management technologies that enable optimized propulsion system performance over a broad range of altitude and flight velocity." ${ }^{, 4}$ When ADVENT was first drafted, it was primarily viewed as a program that would improve supersonic aircraft, giving them larger supersonic range and increased subsonic loiter. However, with increasing fuel costs, the program is now viewed as a method for decreasing total fuel and operational costs across the board. ${ }^{1}$

Like the previous GE VCEs, the YJ101 and F120, it is expected that demonstrator engines for the ADVENT program will utilize two separate fan flow paths and have a method for varying mass flow and/or pressure ratio in one of the paths. ${ }^{1}$ With this focus in mind, there are two technologies addressed in the BAA this project concentrates on: 
"Separate, variable-flow and pressure ratio auxiliary fan streams" and "integrated thermal management. ${ }^{4}$ The first point was addressed above in that an auxiliary fan stream is one way to reconfigure the power plant during flight. To explore integrated thermal management, another technology must be examined: metal foam heat exchangers.

\subsection{Metal Foams}

To obtain integrated thermal management, there will be a highly integrated, highly coupled nature between the power plant and some form of heat exchanger. While traditional fin-type heat exchangers have proven their worth, to reach the goals of the ADVENT Program advances must be made. This is where metal foam heat exchangers may fit. Metal foam, basically a sponge made of metal (although metal foam comes in many other forms), offers interesting advantages such as a large surface area to volume ratio. With the proper design tools, a smaller, lighter, more efficient metal foam heat exchanger could be designed to replace a fin-type heat exchanger for use in a VCE.

The type of metal foam that could be used for the concept proposed here is open-cell, meaning the cellular structure of the foam is porous and allows a fluid to flow through. Specifically, Duocel® open-celled foam will be examined here. Open-cell metal foam has many pertinent parameters that directly affect heat transfer performance and pressure drop characteristics. The relative density relates the density of the metal foam to the density of the constituent metal:

$$
\tilde{\rho}=\frac{\rho_{m f}}{\rho_{s}}
$$


where $\rho_{\mathrm{mf}}$ is the density of the metal foam and $\rho_{\mathrm{s}}$ is the density of the solid metal it was made from. For most common applications, this parameter typically varies between 3$10 \%$. Relative density has a direct effect on the metal foam's thermal conductivity, stiffness, and foam ligament cross-section. ${ }^{5}$

Another important parameter is pores per inch (PPI). The pore referred to here is the polygon opening of the open-cell metal foam, as seen in Figure 1. PPI is basically a measure of how "open" the metal foam structure is. By looking at the foam structure on a linear scale, the number of openings per inch defines how compact the structure will look. For example, a 5 PPI foam will look much more open than a 20 PPI foam because there are fewer, larger pores per inch in the 5 PPI foam. Metal foam's PPI has a direct effect on the surface area to volume ratio and the resistance the foam structure has against any internal flow. Duocel metal foams typically fall within the range of 5 to 40 PPI. ${ }^{5}$

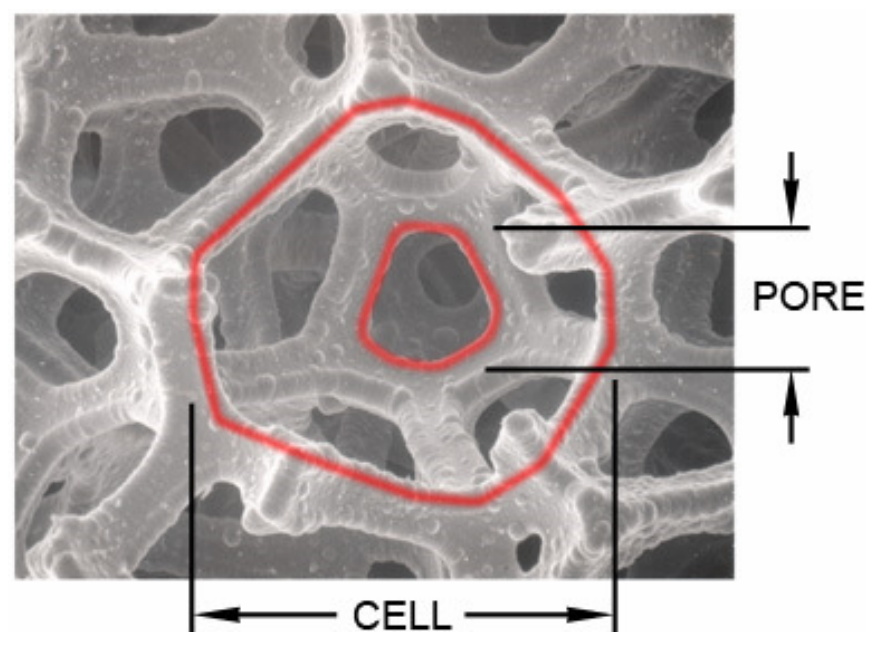

Figure 1 - Duocel open-cell metal foam structure. ${ }^{5}$

Open-cell metal foams are well suited to heat exchanger applications in aircraft because they: 
- Offer a large surface contact area to volume ratio, increasing the contact area between a cooling fluid and a hot surface.

- Increase mixing of the fluid through the metal matrix shape, ensuring efficient exposure of the fluid to the metal surface area.

- Provide highly conductive multiple heat flow paths to transfer heat from one internal fluid to another external fluid when made from conductive metals, such as aluminum.

- Provide an increase in heat transfer performance with a decrease in weight, compared to the solid metal the foam is made from.

While a heat exchanger utilizing metal foam may provide performance enhancements, there are still many unknowns when it comes to metal foam. Predicting metal foam heat exchanger performance is more complicated than for a simple fin-type heat exchanger. Reliable, accurate, and easy to implement design tools are required to create an integrated thermal management system utilizing metal foam.

Metal foam heat exchangers have been extensively studied, however none for this particular application. The two comparable types of experiments are concerned with metal foam sandwiches. In one case, one or both solid faces of the sandwich are supplied with a constant heating load while cooling flow travels through the metal foam, as in Figure 2. Here, metal foam is used to increase the heat transfer performance to the cooling flow using the complex metal matrix to create turbulence and a large surface area. Many different fluids have been examined for use as the cooling flow in this setup, with much research focused on air and water. ${ }^{6}$ 


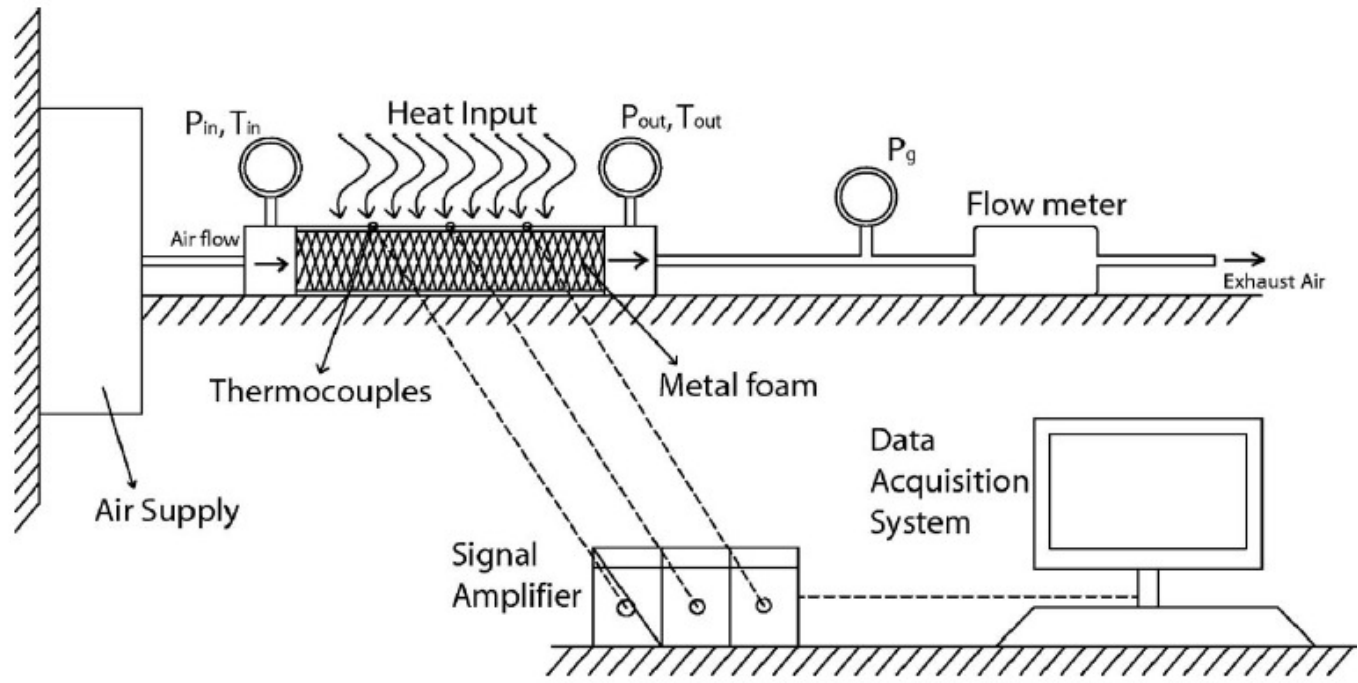

Figure 2 - Convective cooling experimental setup. ${ }^{6}$

The other type of experiment utilizes the metal foam as a heat transport device, pulling heat from a source to a cooling flow on the opposite side of the metal foam, as seen in Figure 3. Here, metal foam is used to increase the heat transfer rate from an internal source to an external cooling flow, such as would be seen for an electronics heat sink. These heat exchangers have potential for applications such as electronics cooling where they could replace fin-type heat exchangers. 


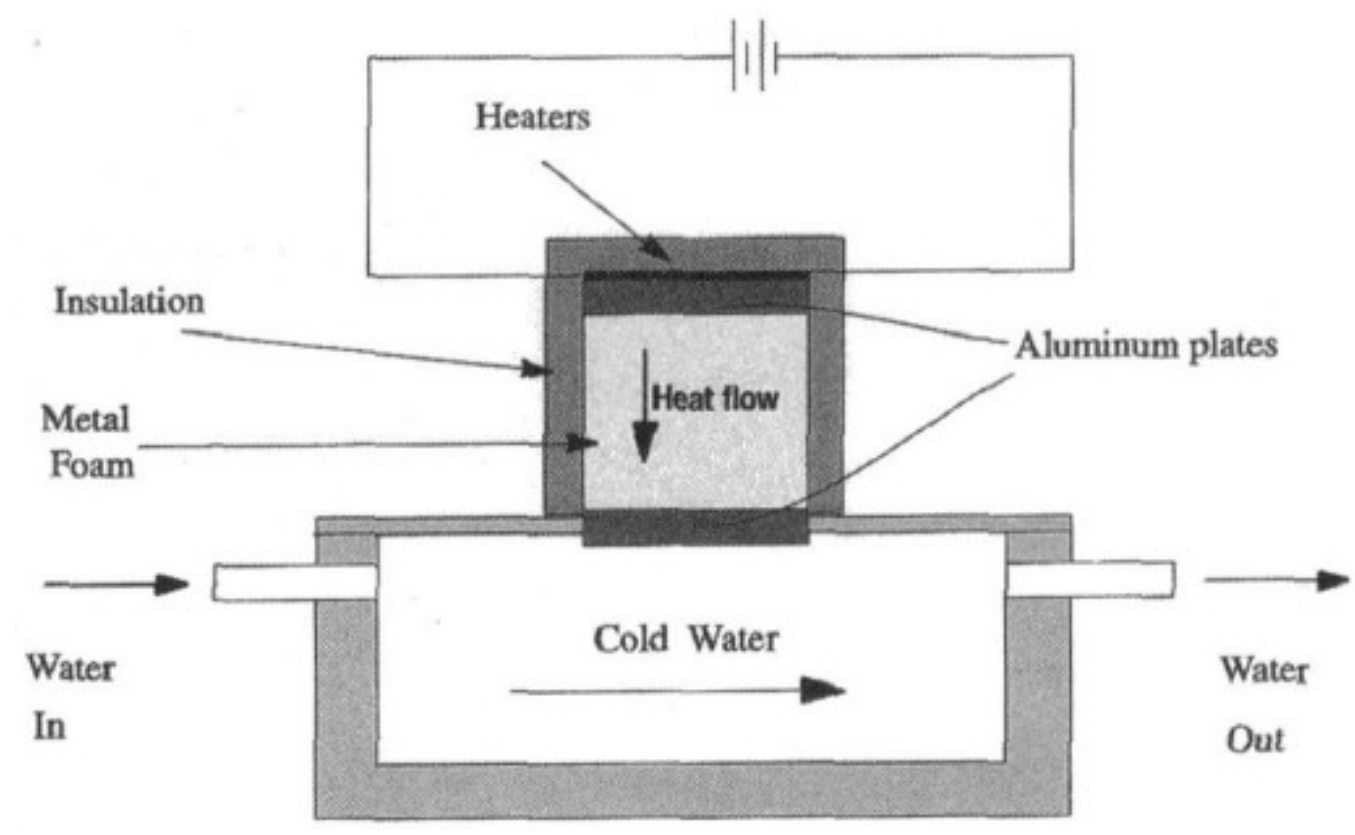

Figure 3 - Heat sink experimental setup. ${ }^{7}$

\subsection{Variable Cycle and Integrated Thermal Management}

Metal foam has a place inside a VCE as a structurally integrated heat exchanger, helping to create an integrated thermal management system while increasing overall system integration with possible performance enhancements. Many studies have been

conducted recently, ranging from experimental studies conducted by Salas and $\mathrm{Waas}^{6}$ and Calmidi et. al. ${ }^{7}$ to numerical studies conducted by Boomsma et. al. ${ }^{8}$ However, all of these studies concentrate on metal foams with a constant heat flux on the heat exchanger outer face. None of these studies have examined the implications of relying on convection to transfer heat to or from the metal foam encasing, especially if the convection is highly variable. So, the effect the variable-fan flow could have on the metal foam heat exchanger is unknown.

The objective of this investigation is to determine the effectiveness of a metal foam heat exchanger integrated in the ducting between constant and variable-flow fans by 
experiment. The heat exchanger will be used to cool air for use in cooling the avionics in a thermal management system integrated with a turbofan utilizing a variable-fan flow rate. A metal foam heat exchanger will be tested with varying cooling flow velocities to determine the effect of the variable-fan flow velocity on the heat transfer performance. In addition, the effect of the hot air flow rate and the foam's PPI will be examined. Both the heat transfer performance and the pumping power requirements will be documented to assess the performance of the metal foam heat exchanger. 


\section{EXPERIMENTAL APPARATUS}

To perform this experiment, a baseline system to be modeled must first be explored. From this baseline system, a representative experimental apparatus can be designed to model, as best as possible, the baseline system.

\subsection{System Design}

A clear definition of the system to be tested is required to begin the design of the experimental setup. An overall schematic of this system concept can be seen in Figure 4. Note the metal foam heat exchangers will be contained in the duct separating the outermost, variable fan and the inside, non-variable fan. This feature is the key reason for testing: the metal foam heat exchangers will have two separate convective cooling flow streams, one of which will be variable. This feature also allows the metal foam to be structurally integrated to the engine ducting, providing the opportunity for a combined engine and thermal management system weight reduction.

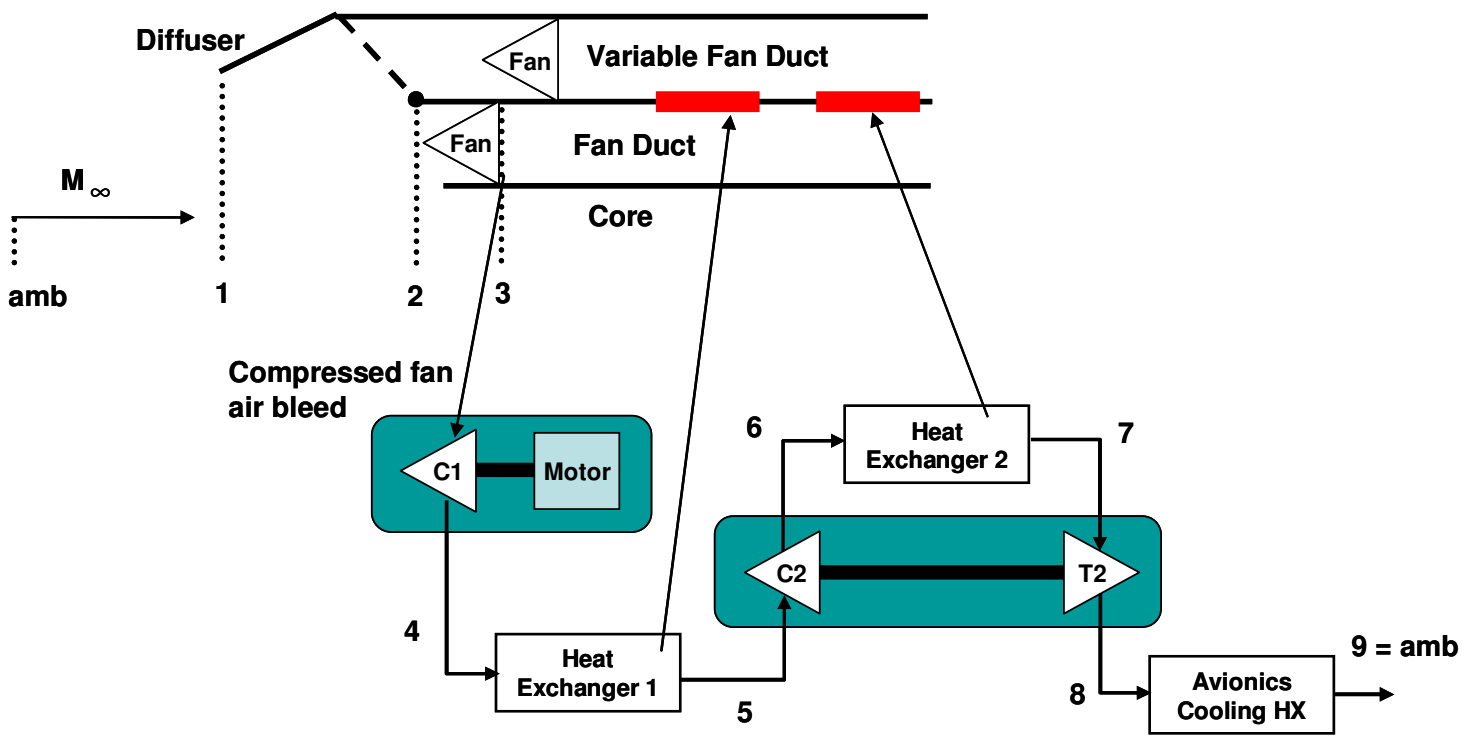

Figure 4 - Metal foam integration with variable cycle engine concept. 
The ultimate goal of the system is to supply cooling air to the avionics. The avionics themselves will be cooled by an oil flow, and then the oil will be cooled by the outlet air from this system. As seen in Figure 4, fan bleed will be compressed using an auxiliary power driven compressor to help overcome the pressure drop of the system. Depending on actual system losses and the fan pressure ratio, this compressor can have a relatively low pressure ratio (1.2-1.4) and power input. From there, the air flows through the first metal foam heat exchanger to reduce the temperature prior to reaching the second compressor. This compressor will be directly driven by the turbine downstream of the second heat exchanger. While the turbine does power the second compressor, its primary goal is to reduce the cooling air flow temperature so that it is capable of pulling heat from the avionics cooling oil. From the avionics heat exchanger, the cooling air would be exhausted to ambient.

To begin the design of this system, flight conditions and representative parameters were defined using general knowledge and advice from Bill Ho of Northrop Grumman. To start, the oil is assumed to enter the avionics heat exchanger at a temperature of roughly $160^{\circ} \mathrm{F}(344 \mathrm{~K})$ and have a goal exit temperature of $40^{\circ} \mathrm{F}(278 \mathrm{~K})$. The representative flight conditions are an altitude of 35,000 feet (10,668 m), a cruise Mach number of 0.85 , and a dash Mach number of 1.5 . In the cruise configuration, the variablefan flow path will be full open to give a large bypass ratio and improve fuel economy. In the dash configuration, the variable-fan flow path will be fully closed to increase the specific thrust and achieve the dash Mach number.

To get an idea of the scale of the required heat exchangers, a simple cycle analysis was performed for the cooling air stream. Some parameters had to be assumed and their 
mean values are shown in Table 1. The metal foam heat exchanger pressure drop was assumed to be $30 \%$. This assumption was driven by the fact that the metal foam provides the air with a complex structure to navigate around, which will cause a significant pressure drop. Obviously all of these parameters will truly be variable in the actual system, but representative values were required in order to provide an input to a test system design. Figure 5 shows the temperature and pressure of the cooling air stream at each station labeled in Figure 4. These results are for a motor driven compressor pressure ratio of 1.4, oil mass flow rate of $50 \mathrm{lbm} / \mathrm{sec}(23 \mathrm{~kg} / \mathrm{s})$, and avionics heat transfer rate of $50 \mathrm{~kW}(171,000 \mathrm{BTU} / \mathrm{hr})$.

Table 1 - Simple analysis parameters.

\begin{tabular}{|l|r|c|}
\hline Diffuser Efficiency $\left(\mathrm{M}_{\infty}=0.85\right)$ & 0.9 & - \\
\hline Diffuser Efficiency $\left(\mathrm{M}_{\infty}=1.5\right)$ & 0.8 & - \\
\hline Fan Pressure Ratio & 1.7 & - \\
\hline Fan efficiency & 0.8 & - \\
\hline Motor Driven Compressor Pressure Ratio & 1.4 & - \\
\hline Motor Driven Compressor Efficiency & 0.8 & - \\
\hline Compressor 2 Pressure Ratio & 1.4 & - \\
\hline Compressor 2 Efficiency & 0.7 & - \\
\hline Turbine 2 Efficiency & 0.8 & - \\
\hline Metal Foam Heat Exchanger Pressure Drop & 0.3 & - \\
\hline Oil Mass Flow & 50 & $\mathrm{lbm} / \mathrm{sec}$ \\
\hline Oil Inlet Temperature & 160 & ${ }^{\circ} \mathrm{F}$ \\
\hline Avionics Heat Transfer & 50 & $\mathrm{~kW}$ \\
\hline
\end{tabular}




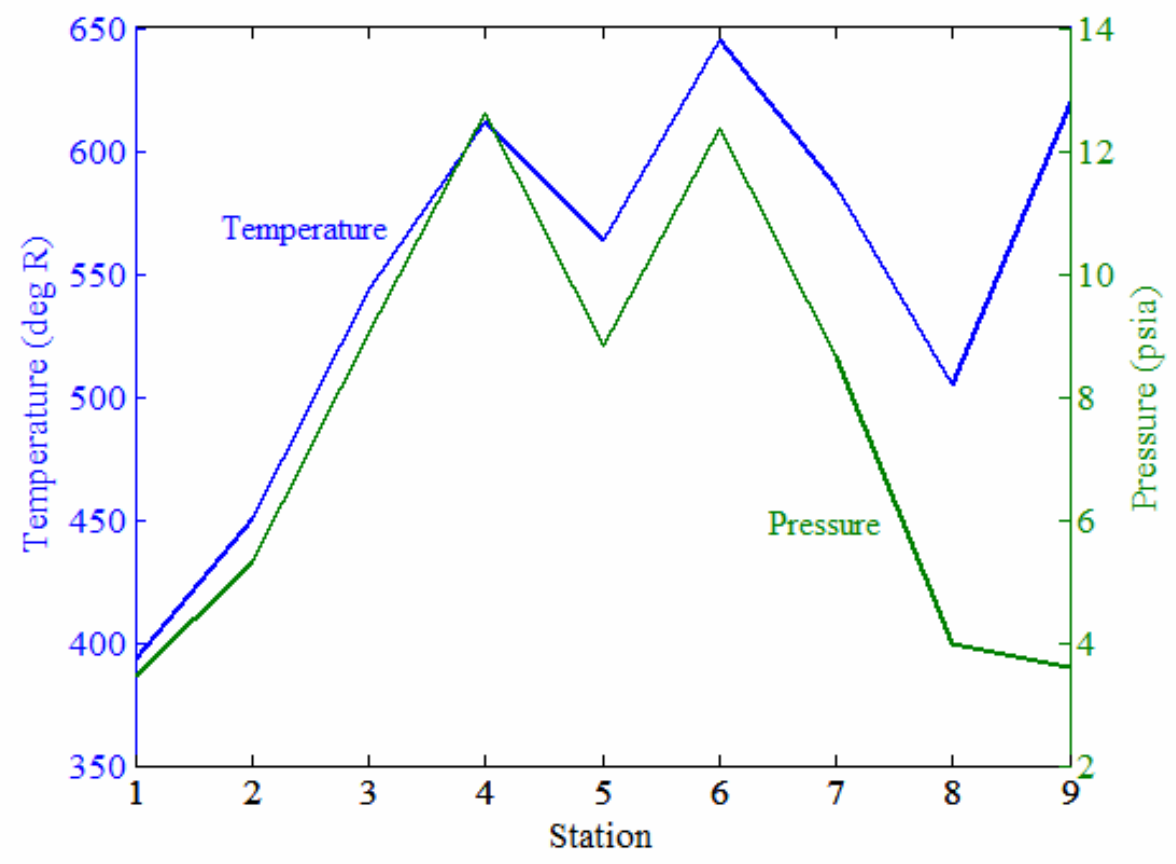

Figure 5 - Simple analysis results for mean parameter values.

These results gave an estimate of required heat exchanger performance. Since the metal foam heat exchangers are working as intercoolers, the thermal efficiency will be defined in the same way, namely

$$
\eta_{H X}=\frac{\text { Heat taken by heat exchanger }}{\text { Heat added by compressor }}
$$

which, for an ideal gas, can be reduced to

$$
\eta_{H X}=\frac{T_{H X, \text { in }}-T_{H X, \text { out }}}{T_{\text {compressor, out }}-T_{\text {compressor, }, \text { in }}}
$$

This efficiency allows for a comparison of the temperature reduction done by the heat exchanger to the temperature increase as a result of the non-ideal compression. As can be seen, with an efficiency of $100 \%$, the heat exchanger would reduce the air temperature back to its original value before entering the compressor. The simple system analysis 
results in required heat exchanger efficiencies of about $70 \%$. With this information, a rough sizing of the metal foam heat exchanger could be initiated.

To gage the performance of the metal foam heat exchangers, a model based on the heat transfer performance of a staggered bank of cylinders was employed. The cylinders are oriented normal to the metal foam internal flow and empirical correction factors are used to relate the idealized geometry to the actual metal foam. ${ }^{9}$ The model is formulated based on a cooling fluid traveling through the porous structure created by the cylinders. The cylinders are assumed to be connected with a zero thermal resistance bond to two infinitely thin plates that supply a uniform heat transfer at a uniform temperature. This configuration can be seen in Figure 6 with a single open-cell depicted in Figure 7.

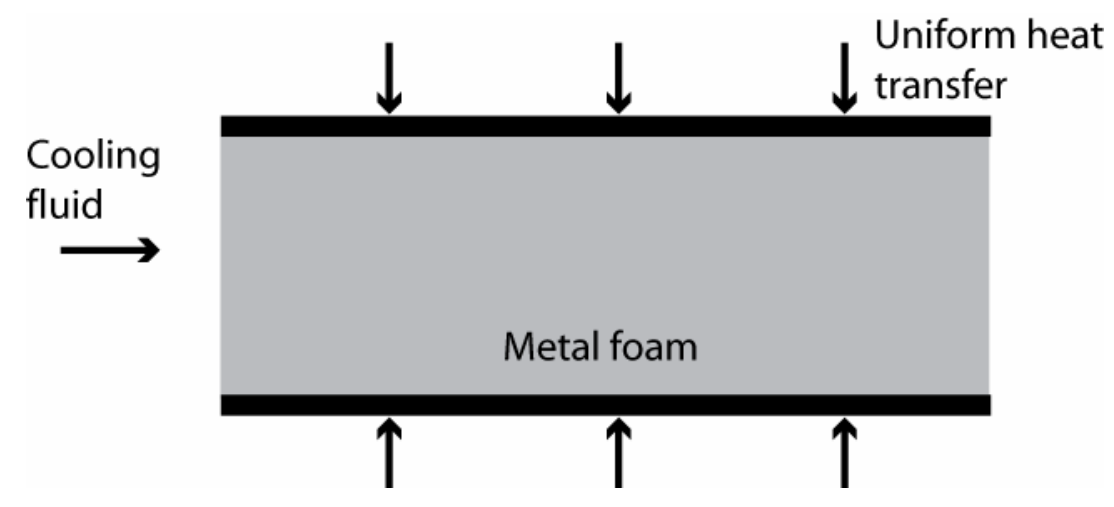

Figure 6 - Heat exchanger model. ${ }^{9}$

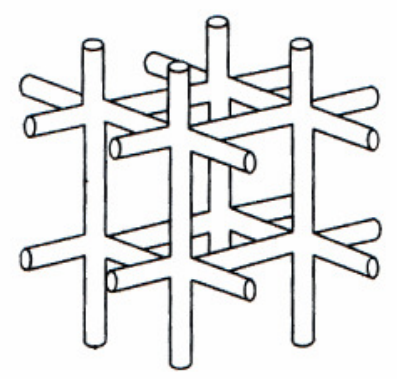

Figure 7 - Depiction of an open-cell created by the staggered bank of cylinders. ${ }^{9}$ 
All of the following relations for the metal foam are from Ashby et. al. ${ }^{9}$ From this model, the effective heat transfer coefficient is

$$
h=\frac{2 \tilde{\rho}}{d} k_{\text {eff }} \sqrt{B i_{\text {eff }}} \tanh \left(\frac{2 b}{d} \sqrt{B i_{\text {eff }}}\right)
$$

where $d$ is the ligament diameter, $k_{\text {eff }}$ is the effective thermal conductivity of the metal foam, $\mathrm{Bi}_{\text {eff }}$ is the effective Biot number, and $\mathrm{b}$ is the internal height of the metal foam sandwich. In Equation 5, $\mathrm{k}_{\mathrm{eff}}$ and $\mathrm{Bi}_{\mathrm{eff}}$ are determined using semi-empirical methods.

The heat transfer per unit width is

$$
q=L h \Delta T_{l m}
$$

where $\mathrm{L}$ is the length of the metal foam sandwich and $\Delta T_{l m}$ is the logarithmic mean temperature. The logarithmic mean temperature is a function of the heated wall temperature and fluid inlet and outlet temperatures. So, to correctly evaluate the logarithmic mean temperature, the fluid temperature at the exit of the metal foam is required. This usually must be measured, but the model does have a method for determining the temperature of the fluid along the flow direction

$$
T_{f}=T_{w}-\left(T_{w}-T_{m f, i n}\right) e^{-x / l}
$$

where $T_{w}$ is the temperature of the heated sandwich wall, $T_{m f, i n}$ is the fluid inlet temperature, and $l$ is the metal foam transfer length. The length of the metal foam can then be plugged into Equation 7, which will yield the fluid exit temperature.

The model provides the following expression for this transfer length 


$$
l=\frac{\rho_{f} C_{p} b V_{f}}{2 \eta k_{\text {eff }} \sqrt{B i_{\text {eff }}}}\left[1+\frac{\tilde{\rho}}{1.5 \eta} \tanh \left(\frac{2 b}{d} \sqrt{B i_{\text {eff }}}\right)\right]^{-1}
$$

where $\rho_{f}$ is the fluid density, $\mathrm{C}_{\mathrm{p}}$ is the fluid specific heat at constant pressure, $\mathrm{V}_{\mathrm{f}}$ is the fluid velocity, and $\eta$ is a function of the relative density.

Finally, the pressure drop per unit length is

$$
\frac{\Delta p}{L}=\xi\left(\frac{1}{a}\right)\left[\frac{v_{f}^{m} \rho_{f}}{\left(1-\alpha_{f}\right)^{2-m}}\right] V_{f}^{2-m} d^{-m}
$$

where $\xi$ and $m$ are experimentally determined coefficients, a is the cell size, $v_{f}$ is the kinematic viscosity of the fluid flowing through the metal foam, and $\alpha_{f}$ is the fluid thermal diffusivity.

To initially examine the metal foam for use as a heat exchanger, it was assumed the heat exchanger would resemble a metal foam sandwich and its characteristics would be 2-D, i.e. per unit width. The simple analysis results from above were used as inputs for the heat exchanger, with a metal foam inlet fluid temperature of $645^{\circ} \mathrm{R}(358 \mathrm{~K})$. The temperature of the sandwich plates was assumed to be larger than the actual temperature of the fan flow and was a constant $597^{\circ} \mathrm{R}(332 \mathrm{~K})$ for this study. The air inlet pressure was $12.4 \mathrm{psia}(85,500 \mathrm{~Pa})$ and it was assumed that multiple metal foam heat exchangers existed along the fan ducting, so that the entire air mass flow rate required for cooling the avionics was not pushed through a single metal foam channel. This assumption is necessary to achieve reasonable flow speeds through the metal foam but could also resemble a system where the required avionics cooling air is pulled from more than one 
engine. The overall air mass flow rate was $101 \mathrm{lbm} / \mathrm{min}(0.764 \mathrm{~kg} / \mathrm{s})$, the required flow found from the simple analysis to cool the avionics.

The relative density was kept constant at a representative value of $8 \%$ while the foam's PPI and duct height were varied to produce the results seen in Figure 8. As expected, as the foam's PPI is increased, the heat transfer is also increased, but at the price of a larger pressure drop. This is expected because as PPI increases so does the foam's surface-area-to-volume ratio, which provides more convective surface area but also more skin friction. As the foam height decreases, the heat transfer by ligament increases, but again at the price of a larger pressure drop. With a constant flow rate, as the metal foam height increases, the flow speed decreases and there is a smaller pressure drop. However, the fluid must travel farther through the metal foam to achieve the same drop in temperature, thereby decreasing the heat transfer performance. 


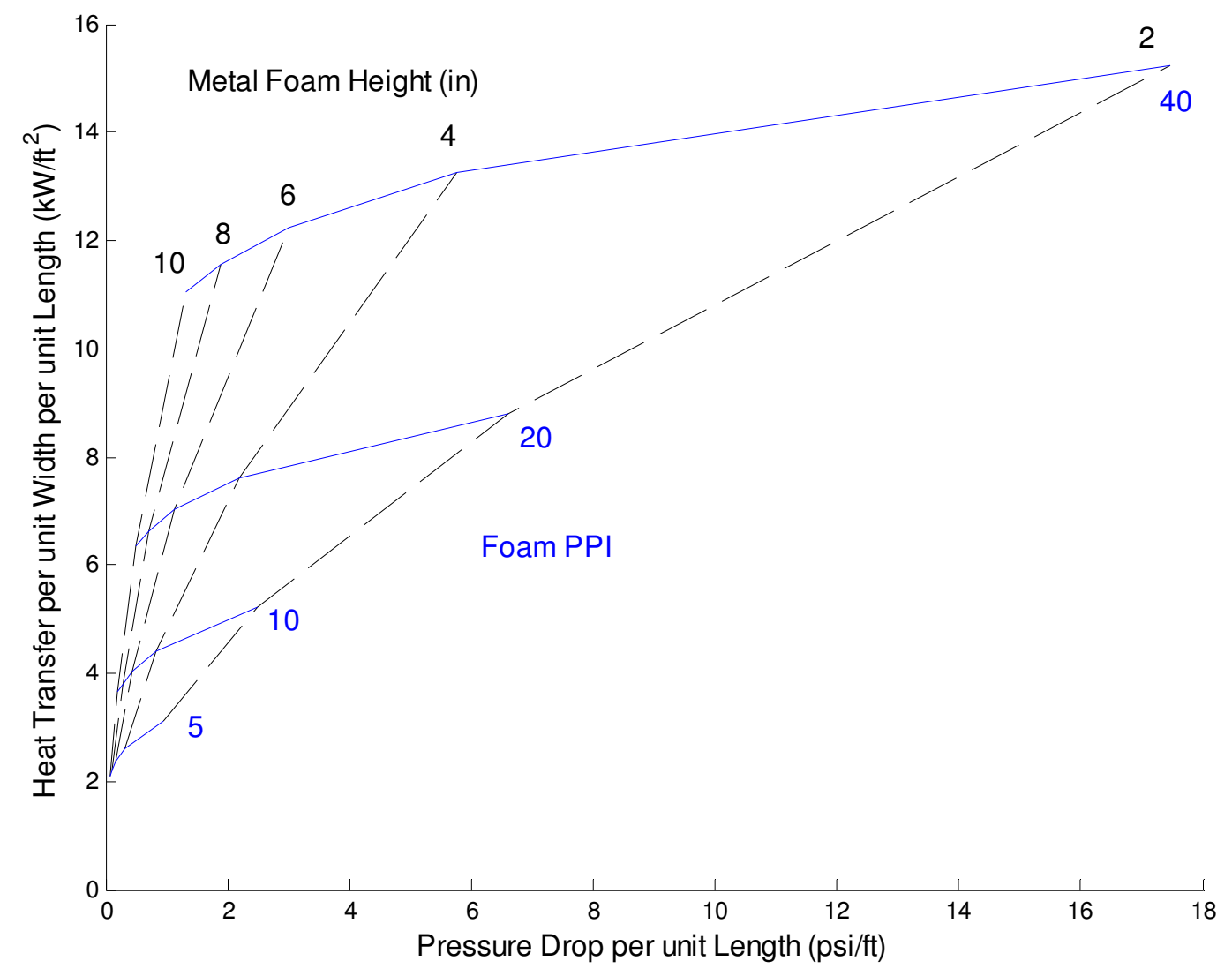

Figure 8 - Estimated metal foam heat exchanger performance.

From the above results, it was found that the heat exchanger length would need to be longer than practically possible if the heat exchanger was oriented axially along the engine. So, a circumferential heat exchanger, with the hot-flow traveling around the fan duct circumference, was explored. This configuration can be seen in Figure 9, where a portion of the ducting between the constant and variable fans is idealized with hot flow traveling through the metal foam heat exchanger in the circumferential direction. 


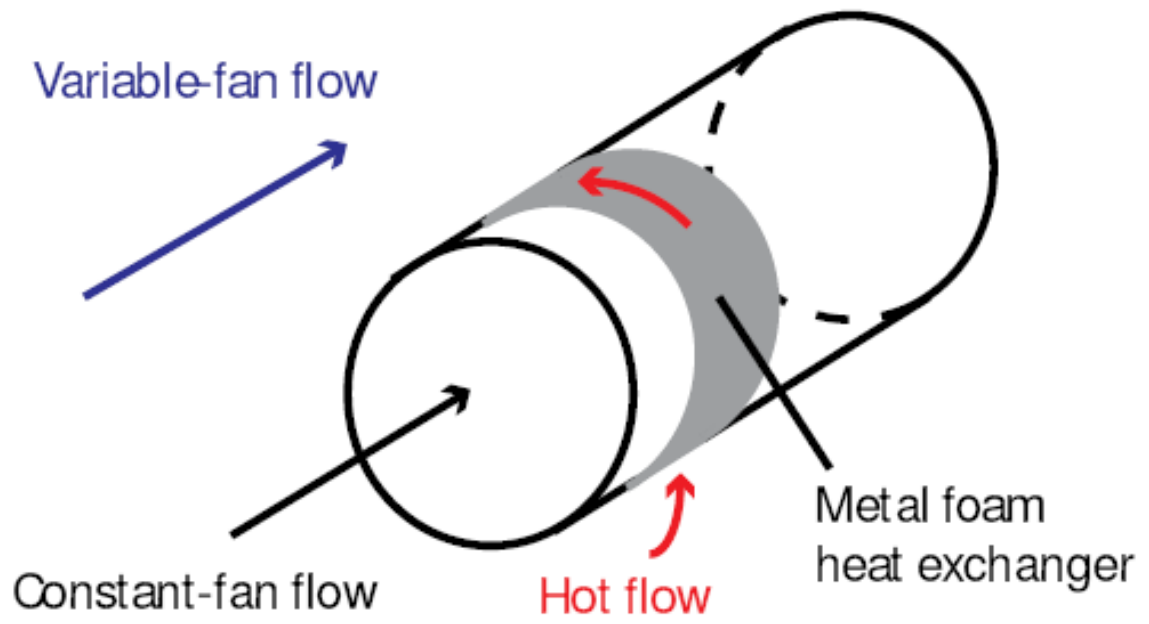

Figure 9 - Schematic of circumferentially oriented metal foam heat exchanger within VCE ducting.

This configuration allowed for an increase in heat transfer length while also distributing the heat in a more circumferentially uniform pattern to the fan flow and allowing less complicated and loss creating ducting from the engine cowling to other parts of the aircraft. Since the air flowing through the metal foam will eventually be directed to cool the avionics, it will have to leave the engine cowling. If the metal foam was arranged axially along the engine, the air flow path could only be as long as the distance between the fan and the end of the engine connection to the airframe. In addition, with an axial configuration, different metal foam paths arranged axially around the engine would need a collection chamber that turned the flow from axial to circumferential in order to direct all of the air through one connection between the engine and airframe.

\subsection{Experiment Design}

With a better understanding of the metal foam heat exchanger characteristics required for the variable-fan flow concept, an experimental heat exchanger could be designed to 
evaluate its performance. Much like the engine does to the actual heat exchanger, the lab setup put constraints on the experimental heat exchanger design. The primary constraints were available airflow and physical space. One of the original concepts utilized Cal Poly's three foot by four foot wind tunnel to test the heat exchanger. However, this idea could not be implemented because the amount of available airflow for the hot stream could not be provided. In addition, the wind tunnel was designed with a single flow passage, so a physical blockage would have to be used to create two separate flow paths, and then some sort of throttle would be needed for one of the passages. This throttle would need to be a flow blockage device, since controlling the wind tunnel fan directly would change the flow rate for both cold streams. The flow blockage concept was deemed too inexact for control of the flow inside the variable-flow path and so it was avoided.

While Cal Poly's wind tunnel could not be used, the experiment would still be conducted within the wind tunnel lab space. It was decided early on that the hot air flow supplied to the metal foam would be supplied by the building compressed air. This put a limitation on the air flow rate with a maximum of about 25 SCFM (708 SLPM). This also put a limitation on where the experimental setup could be located, since there are only two feasible compressed air delivery points within the lab. Given this, the experiment was placed in an area near the exhaust door for the big wind tunnel to allow air to exhaust outside the lab. This location only had about 5 feet by 8 feet $(1.5$ by $2.4 \mathrm{~m})$ of available floor space, leaving a finite amount of space to place the metal foam test bed. To utilize as much of the space as possible, the hot-flow path was oriented perpendicular to the cold flow paths to allow the heater and flow conditioning duct sections to be as long as 
necessary without obstructing any walkways. This left greater flexibility in locating equipment for the cold flow, such as fans, motors, and controllers. It also was an attempt to simulate the circumferential heat exchanger design seen in Figure 9.

A schematic of the experimental setup can be seen in Figure 10 and highlights the fact that three independent and controllable flows will be required for testing. Figure 10 also highlights an admitted problem with the test setup: to measure fluid properties within the metal foam, measurement devices will need to obstruct one of the cold flow paths. This was a persistent problem through the experimental process, but the blockage caused by any instruments is unavoidable.
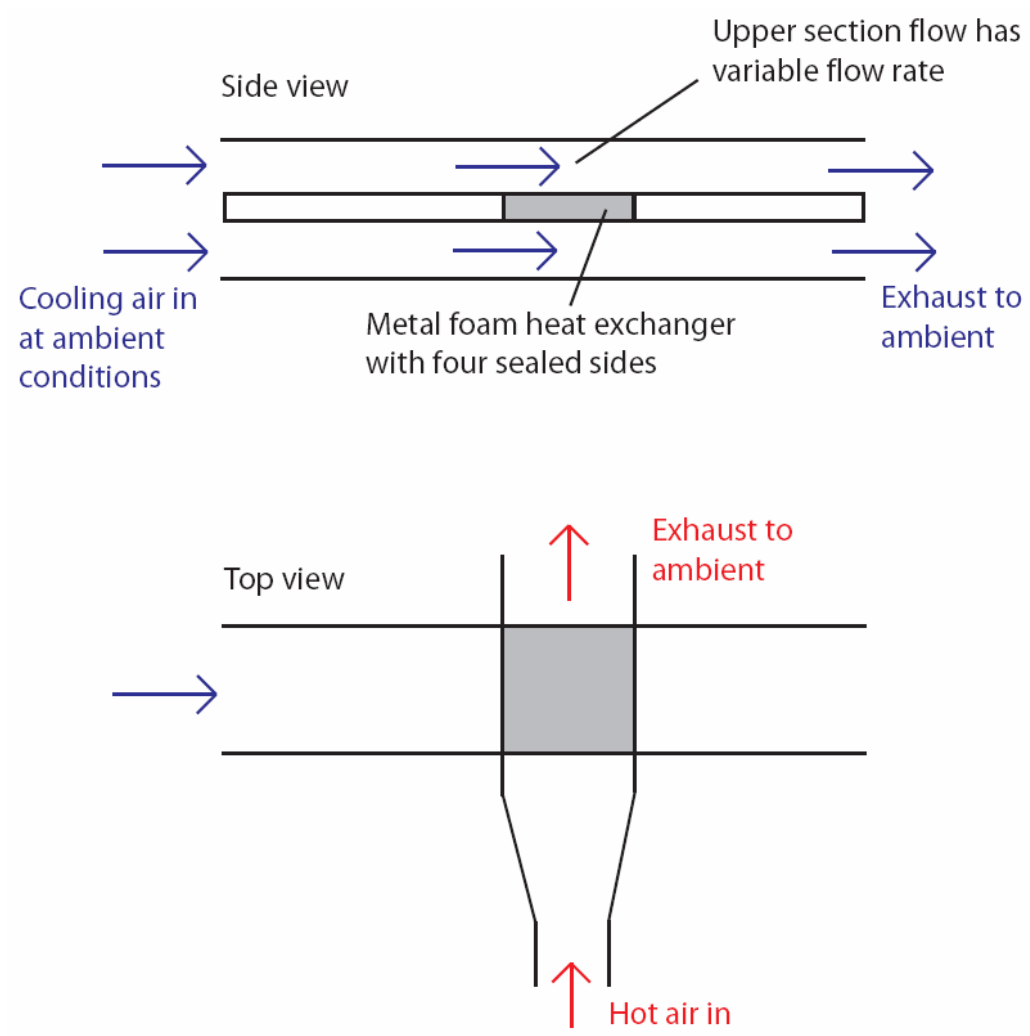

Figure 10 - Experimental setup.

With the general setup determined, the actual ducting had to be designed. The approach taken to this design was modular, and so each individual duct section was 
relatively simple but combined they could provide the required flow path. By designing straight duct sections with only one dimension changing per section, the ducting could be easily manufactured with sheet metal. Then, mating flanges could be welded to the sheet metal to allow connection between different duct sections. This approach, while somewhat labor intensive, was deemed more economical and could be completed in a shorter amount of time than other options, such as machining large duct pieces from one solid block of metal.

To start the physical design, the metal foam heat exchanger was investigated. The goal air inlet temperature was selected as $160^{\circ} \mathrm{F}(344 \mathrm{~K})$. This will create a temperature difference between the hot-flow inlet and the cooling fan flow inlet temperatures close to the predicted temperature difference for the second heat exchanger in the system analysis. Since the hot air will be exhausted to ambient, the pressure at the inlet to the metal foam will be just enough to overcome pressure losses and create the required flow rate. With this information and the desired range of standard flow rates, the metal foam crosssection could be designed to provide similar flow velocities as the actual system. Assuming a 5 psig (34,500 Pa gage) inlet pressure, the design 6.3 by 0.5 inch (16 by 1.3 $\mathrm{cm})$ metal foam cross-section provides an air velocity of about 8 feet per second $(2.4 \mathrm{~m} / \mathrm{s})$ with 10 SCFM (283 SLPM) delivery air.

To simplify the design, the heat exchanger was designed as a square. This square design is how the 6.3 inch $(16 \mathrm{~cm})$ width was determined. As explained below, the cold flow duct is 6 inches $(15 \mathrm{~cm})$ in width, so a metal foam length of 6.3 inches allows 0.15 inches $(0.38 \mathrm{~cm})$ on each side of the heat exchanger to support and mount it to the cold flow duct. The square design allowed the hot-flow to travel 6.3 inches through the metal 
foam while the cold flow traveled 6.3 inches across the outer surface. To make the raw metal foam into a heat exchanger it is sandwich between pieces of sheet metal. As recommended by ERG Aerospace, the company who built the heat exchangers, the 6.3 by 6.3 inch faces were brazed to the metal foam while the 0.5 by 6.3 inch faces were only bonded. The brazed faces are the convection surfaces, where the cold fan flow will take heat from the hot air within the metal foam. A drawing of the metal foam heat exchanger can be seen in Figure 11. To measure temperature and pressure within the metal foam, 0.0625 inch $(1.588 \mathrm{~mm})$ diameter holes were drilled 0.3 inches $(0.76 \mathrm{~cm})$ deep. These holes were drilled through the sheet metal face on one side and the metal foam to allow insertion of thermocouples. These thermocouples could then measure the air flow bulk temperature at the center of the heat exchanger without risking the sensing element coming into contact with the metal foam ligaments. The 25 holes are arranged 0.5 inches apart along the hot-flow direction and also perpendicular to it. The holes perpendicular to the hot-flow direction are for checking the hot-flow pressure and temperature variation in the cross-flow direction. The pressure is not expected to vary in the cross-flow direction, while the temperature is expected to vary because of the cooling cross-flow. 


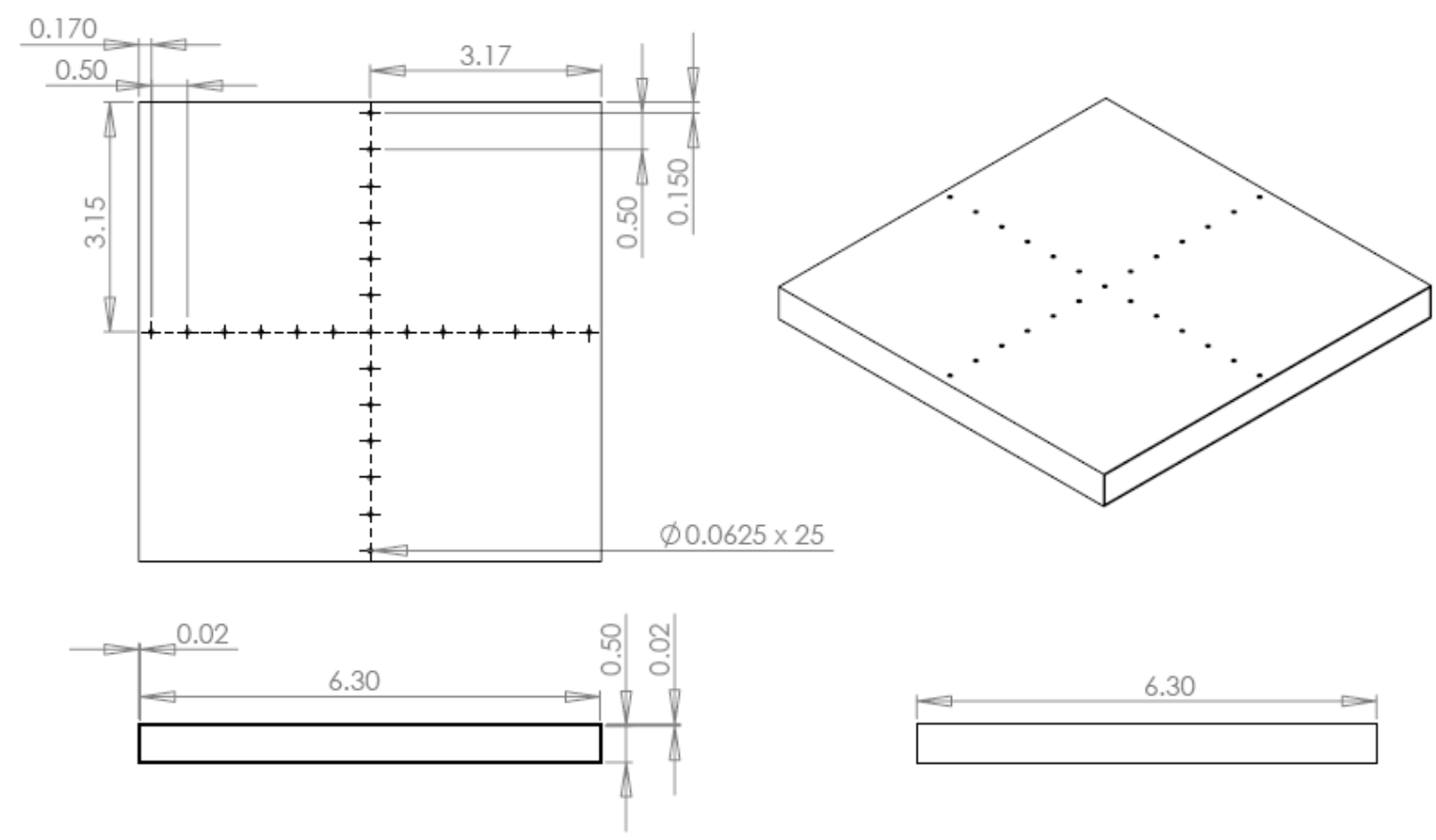

Figure 11 - Metal foam heat exchanger drawing (dimensions in inches).

The metal foam heat exchanger is contained within the cold flow, with the hot-flow traveling at a right angle. To obtain a reasonable cold flow to hot-flow velocity ratio, the overall cold flow was designed with a 6 by 8 inch $(15$ by $20 \mathrm{~cm})$ test section with a separation plate to create two separate flow streams. These flow streams have crosssections measuring 6 by 3.73 inches $(15$ by $9.47 \mathrm{~cm}$ ) and are outfitted with their own blower and controller so independent control of the flow rate through each section can be attained. The separation plate was designed with the same thickness as the external metal foam dimensions so the metal foam heat exchanger could be arranged as almost an extension of the separation plate. This allowed the metal foam heat exchanger to be integrated into the separation plate as well as the cold flow ducting. A drawing of the wind tunnel test section showing the cold flow ducting and cutout for the metal foam can be seen in Figure 12. There is a straight lead-in section roughly 8 hydraulic diameters in 
length prior to the convection surfaces of the metal foam to allow the cold flow air to fully develop.
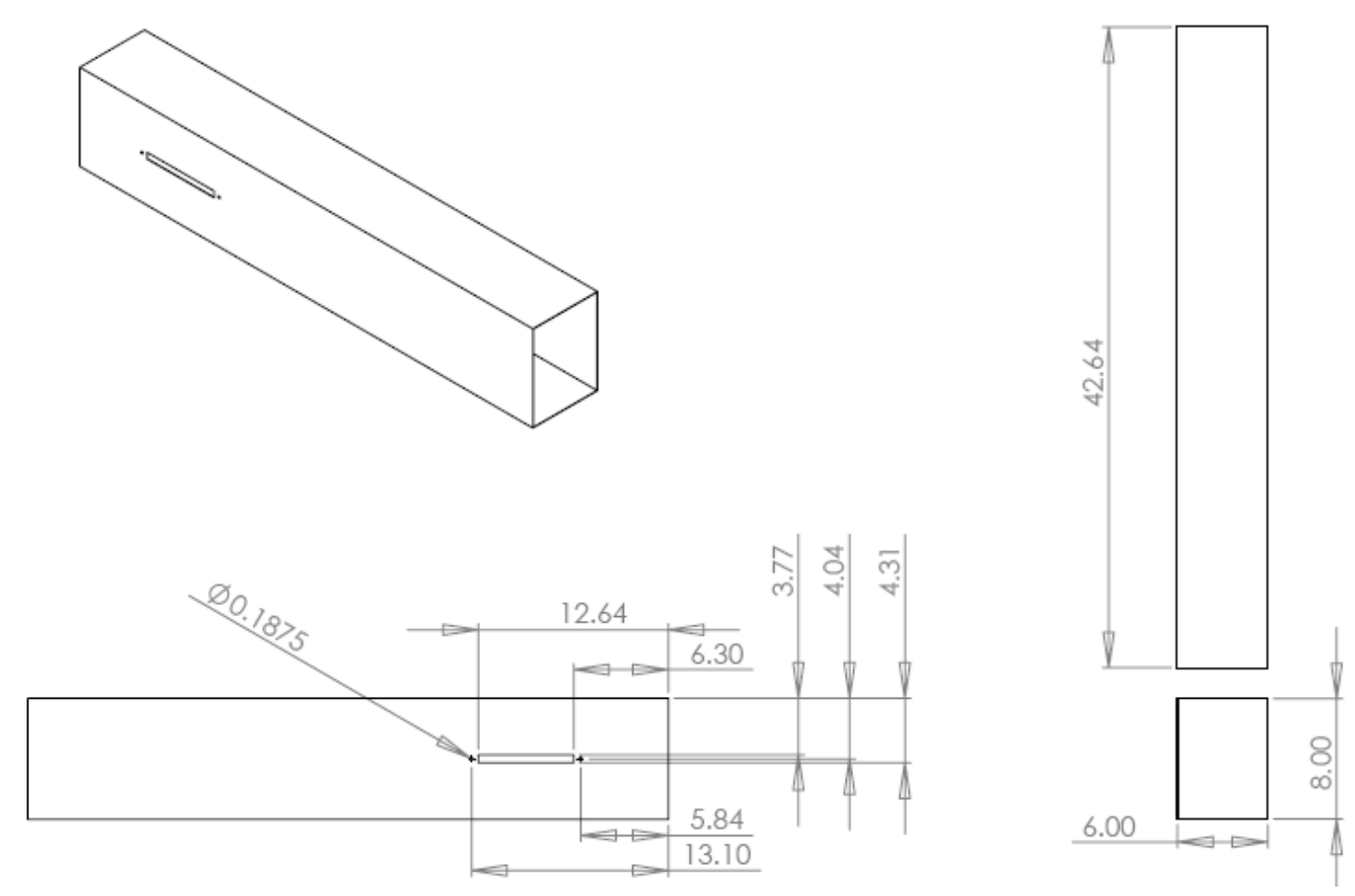

Figure 12 - Cold flow duct and metal foam insertion point drawing (dimensions in inches).

To provide the heat exchanger with hot air flow, the building compressed air was used. To provide uniform flow, the hot air supply was routed through a diffuser and flow conditioner seen in Figure 13. The first three inches of the flow conditioner contain a metal honeycomb, followed by a straight lead-in section nine duct thicknesses in length. 

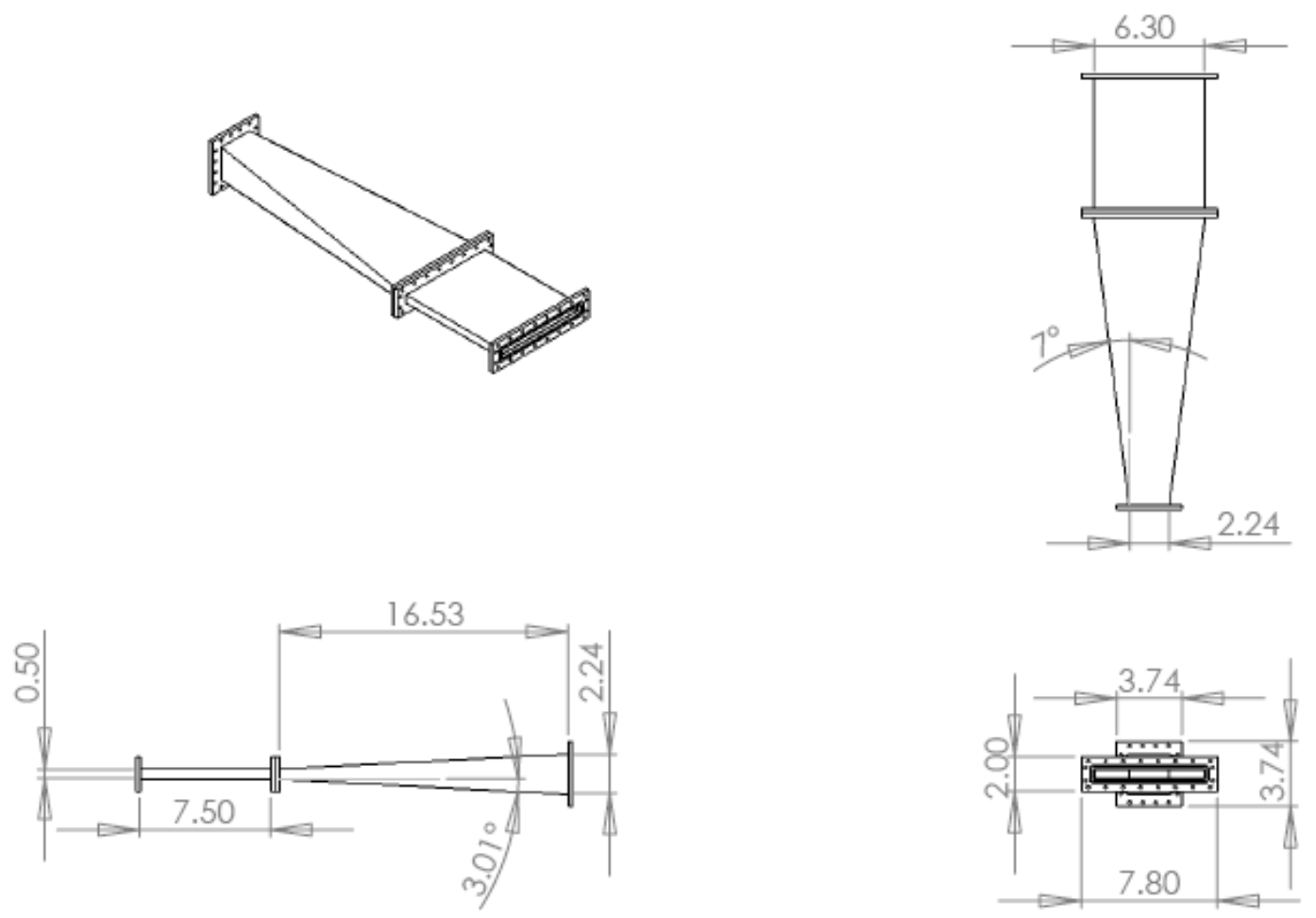

Figure 13 - Hot-flow diffuser and delivery ducting drawing (dimensions in inches).

The outlet for the hot air was designed to allow both the cold and hot-flows to exhaust in the same direction. With this strategy, the wind tunnel exhaust could be directed outside the lab to prevent interference with any instruments. To achieve this, the hot-flow outlet contained a 90 degree bend, seen in Figure 14. The outlet also increased the flow cross-sectional area by a factor of about 3.5 to slow the outlet flow. 

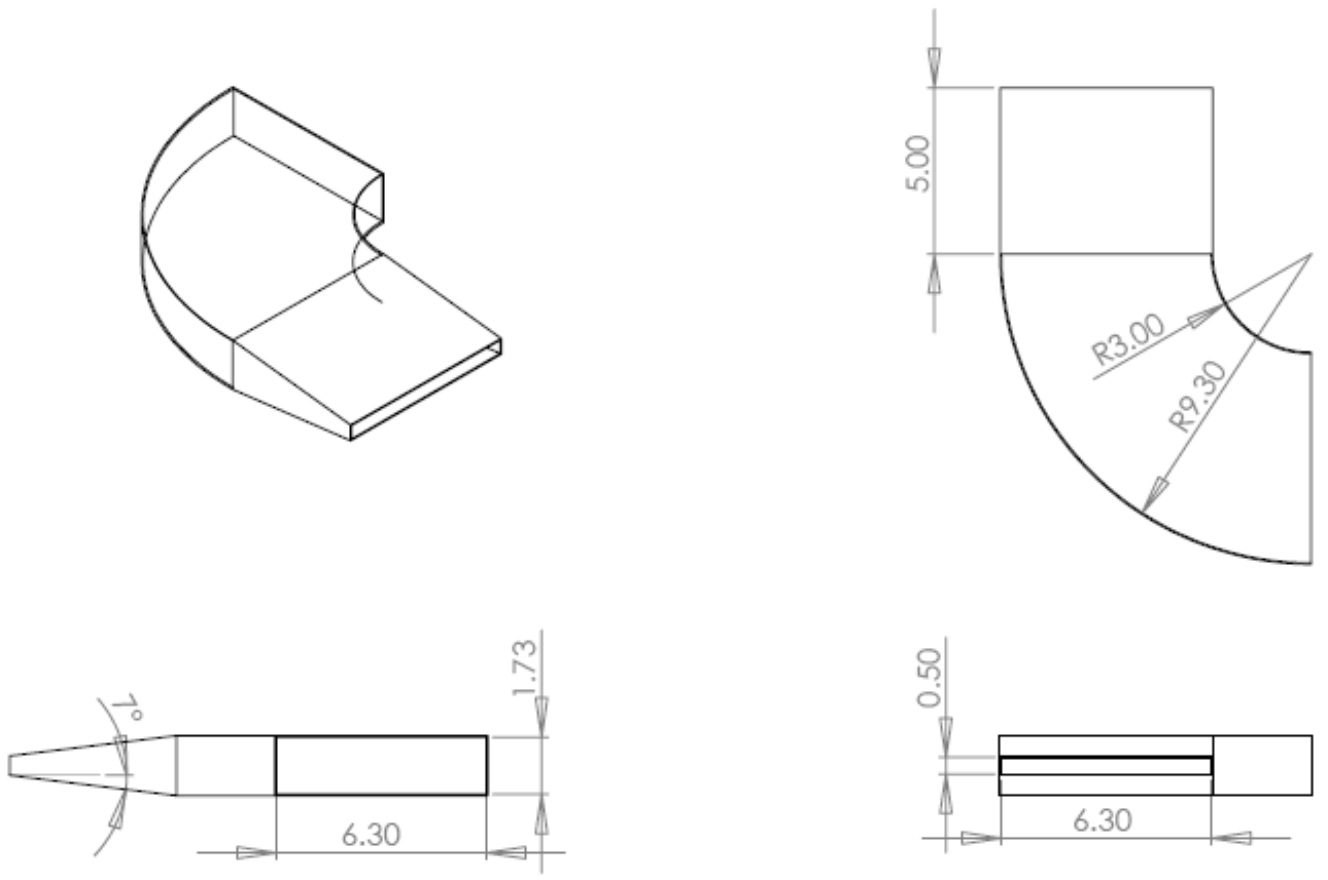

Figure 14 - Hot-flow outlet drawing (dimensions in inches).

A drawing of the complete designed test bed can be seen in Figure 15. It is about 6 feet long and 4 feet tall which makes it well suited for table-top operation. Note these dimensions do not include any heaters, blowers, or their related equipment. 

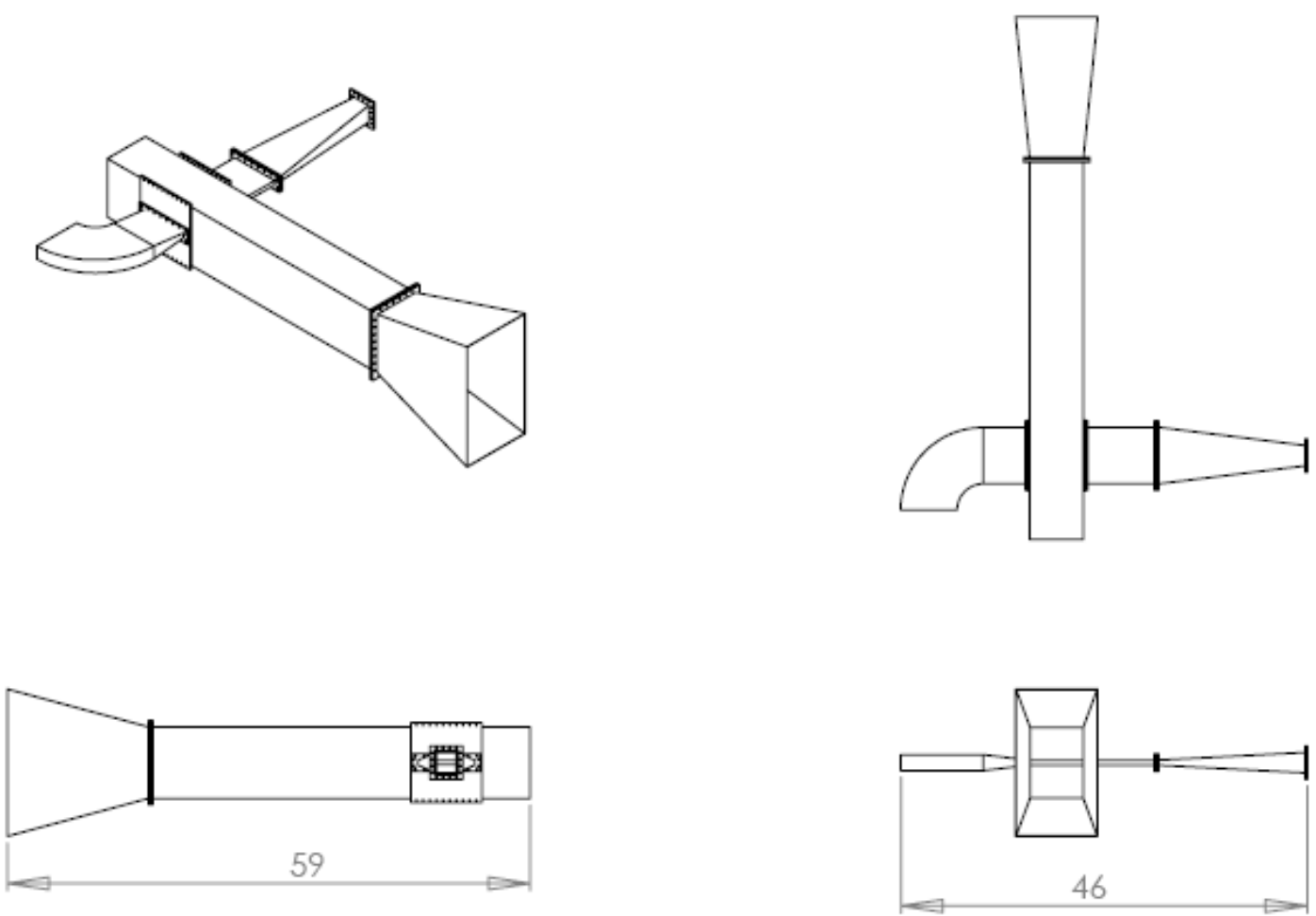

Figure 15 - Drawing of complete test bed design (dimensions in inches).

The measurement locations along the hot-flow can be seen in Figure 16. The measurement ports on the metal foam are alternating temperature and pressure to acquire both during one test run. This will allow the metal foam heat exchanger to be assembled in the test rig less often than if separate temperature and pressure tests had to be conducted. It also allows for less overall cold flow blockage by the measurement devices. Since the thermocouple lead wires and pressure tubing must be routed through one of the cold flow paths they will create a blockage. If a separate pressure measurement test run was conducted with all ports outfitted to measure pressure, the blockage would be much larger than if the same was done to measure temperature, and the two may not be comparable. So, by measuring both during the same test run, the effect of the blockage can be reduced while also reducing the number of test runs required. 


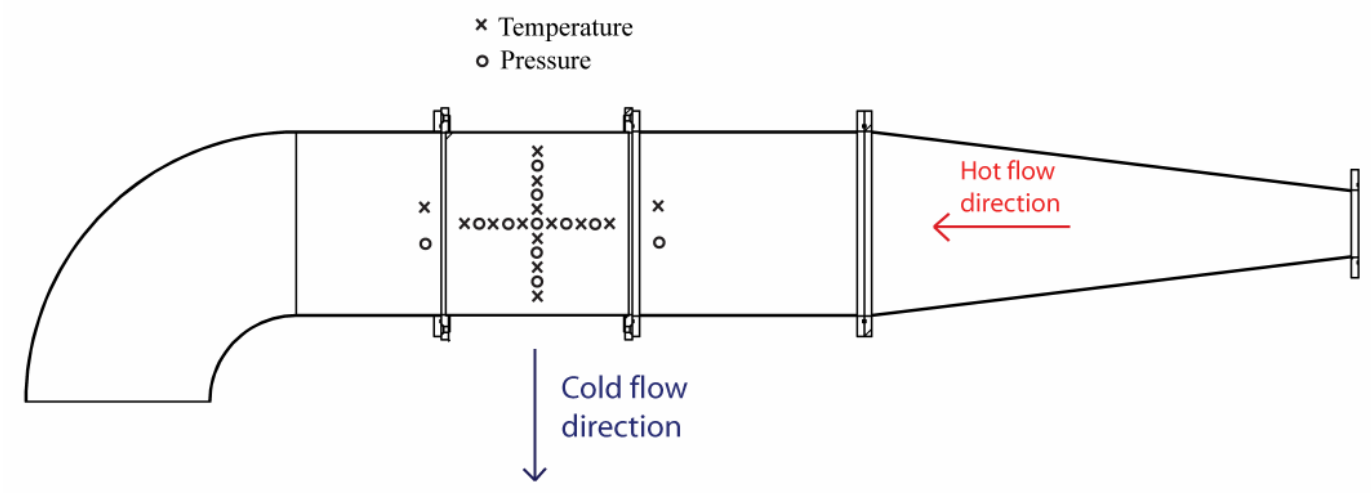

Figure 16 - Hot-flow measurement locations.

In addition to hot-flow bulk temperature measurements, both variable and constantfan flows' inlet and outlet temperatures will be measured at the middle of the duct. This will allow for determination of the cooling flow freestream temperature. The inlet and outlet temperature measurements are located five inches $(12.7 \mathrm{~cm})$ upstream and downstream of the heat exchanger, respectively.

After initial testing had occurred, it was obvious the temperature on the heat exchanger external surface was also required. So, surface thermocouples were added to the external surfaces of the metal foam heat exchanger. On the side without measurement ports, a single surface thermocouple was mounted to the center of the metal foam outside surface. The center was chosen as a representative location because the internal temperature will be measured along the centerline. Also, it would be impractical to measure the surface temperature at many locations along this centerline because the surface thermocouple provides insulation to the heat exchanger surface and the thermocouple wires obstruct the cold flow. On the side of the heat exchanger with measurement ports, the surface temperature needs to be measured in four places. Because of the measurement ports, a surface thermocouple cannot be located at the center of the 
surface. In addition, it was expected that the temperature profile on the surface would be two-dimensional, so a square of thermocouples was applied around the center point of the surface. The nominal arrangement can be seen in Figure 17. The sensing location of the thermocouples was set 0.75 inches $(1.91 \mathrm{~cm})$ from the horizontal and vertical centerlines.

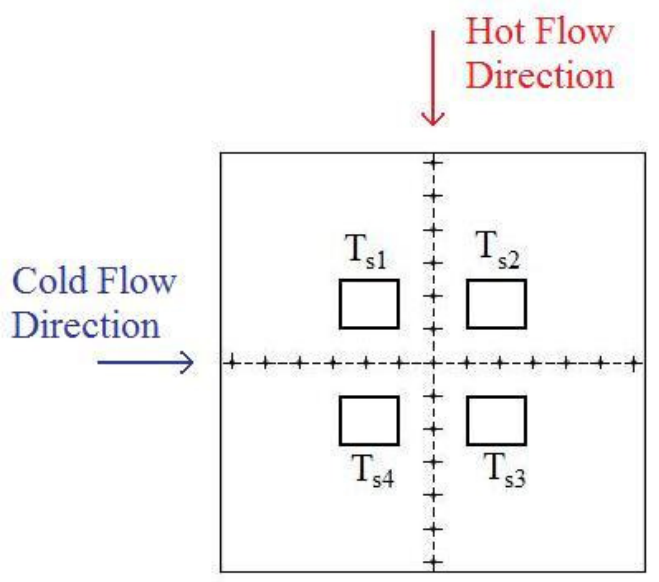

Figure 17 - Surface thermocouple locations for side with measurement ports.

\subsection{Experiment Construction}

The final metal foam heat exchanger, built by ERG Materials and Aerospace Corp., is encased in 0.020 inch $(0.51 \mathrm{~mm})$ thick aluminum 6061-T6 sheet metal brazed to the top and bottom and bonded to the sides. The metal foam dimensions are 6.3 by 0.5 inch (16 by $1.3 \mathrm{~cm}$ ) cross-section and 6.3 inches $(16 \mathrm{~cm})$ in length, with the aluminum sheet metal wrapped around these dimensions. A 20 and a 40 PPI heat exchanger were built from 6061-T6 aluminum with the 20 PPI test specimen pictured in Figure 18. The metal foam was brazed to the sheet metal on the convection surfaces ( 6.3 by 6.3 inch faces) using 4047 aluminum braze. 


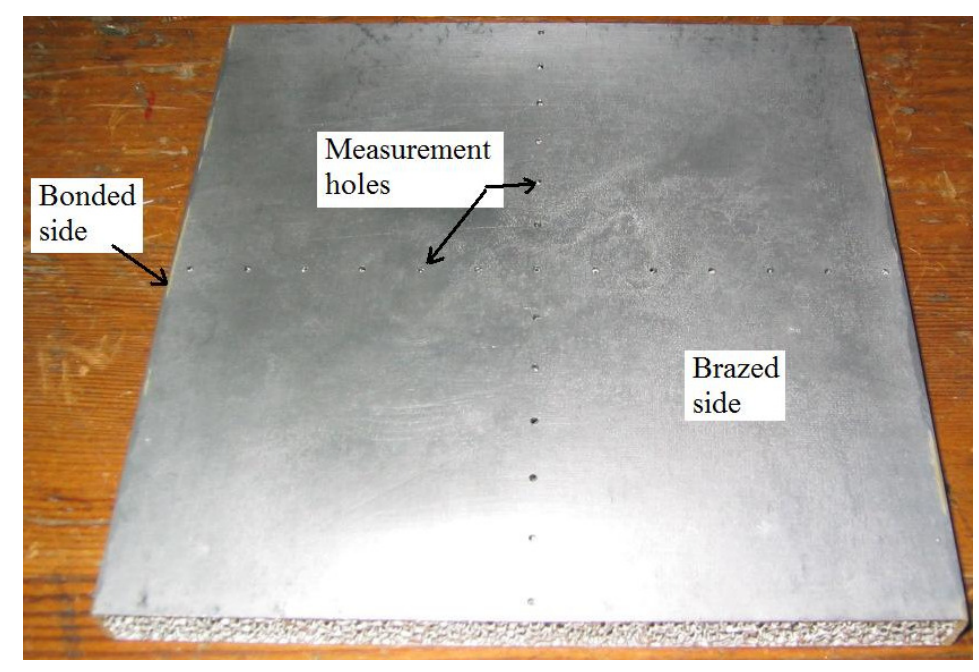

Figure 18 - 20 PPI metal foam heat exchanger.

As mentioned above, holes were drilled in the heat exchanger to measure temperature and pressure. Since the outer surface of the heat exchanger is a convection surface, the method of bonding is important. Ideally, the measurement tubes and their bond would have no effect on the convection. Obviously the measurement tubes will cause a blockage, thereby affecting the cooling air flow, but this is necessary in order to measure the internal hot-flow properties. However, with the right kind of bond, the bond area could act as an extension of the heat exchanger surface; with a very small bond area, the bond would have minimal effect on the experiment. To create this best case bond, aluminum braze and solder were explored. While similar processes, a brazing process occurs at temperatures greater than $850{ }^{\circ} \mathrm{F}$ while soldering occurs at lower temperatures. Since the metal foam was brazed to the internal face of the aluminum, great care had to be taken to ensure this bond was not affected at all by any external bonding. In addition, while aluminum does not melt until about $1,200{ }^{\circ} \mathrm{F}$, it can warp at much lower temperatures. This warping would not only cause a shape change to the external surface 
of the heat exchanger, but could also damage the bond to the metal foam. Because of this, brazing was out of the question.

To explore a soldered bond, aluminum solder with a melting temperature around 400 ${ }^{\circ} \mathrm{F}$ was tested with 6061 aluminum sheet metal and 3003 aluminum tubing. When applying the solder with a soldering iron, the aluminum solder would not melt well and did not flow like a liquid as it should. It was thought that an oxy-acetylene torch would help heat the solder to a more appropriate temperature and it would flow better. However, as seen in Figure 19 and Figure 20, this result was unsatisfactory. This testing showed that it would be nearly impossible to solder measurement tubes to the heat exchanger surface without running the risk of damaging the internal brazed connection to the metal foam. This meant a more traditional type of bond would be necessary.

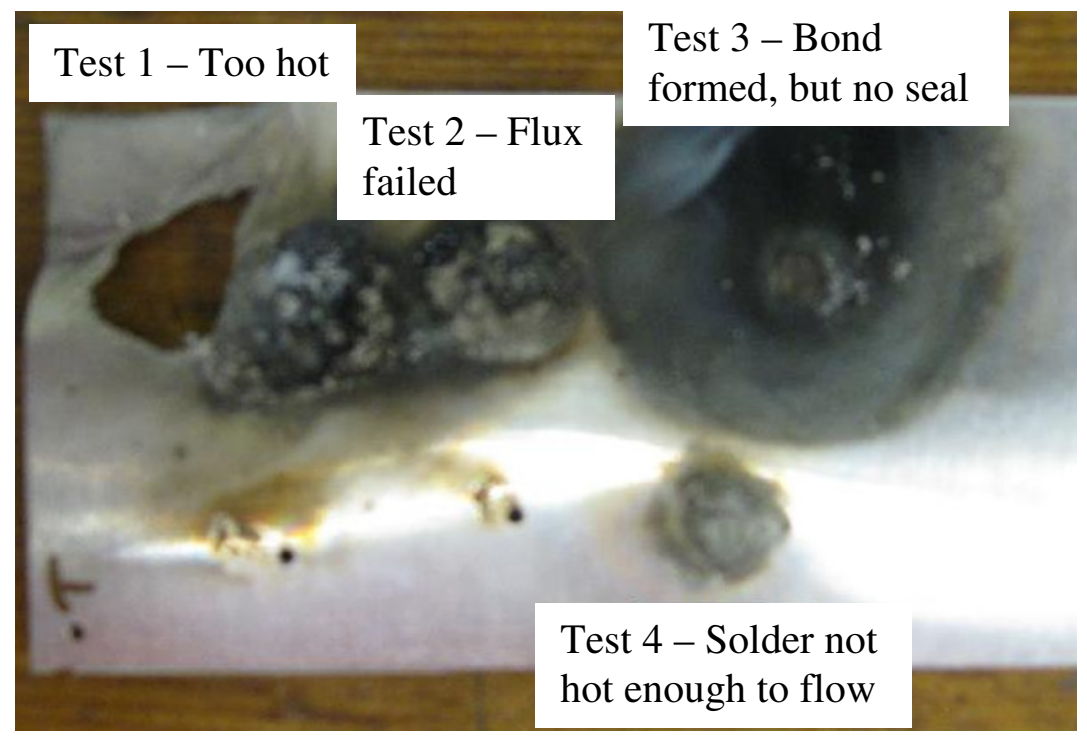

Figure 19 - Solder test piece (top). 


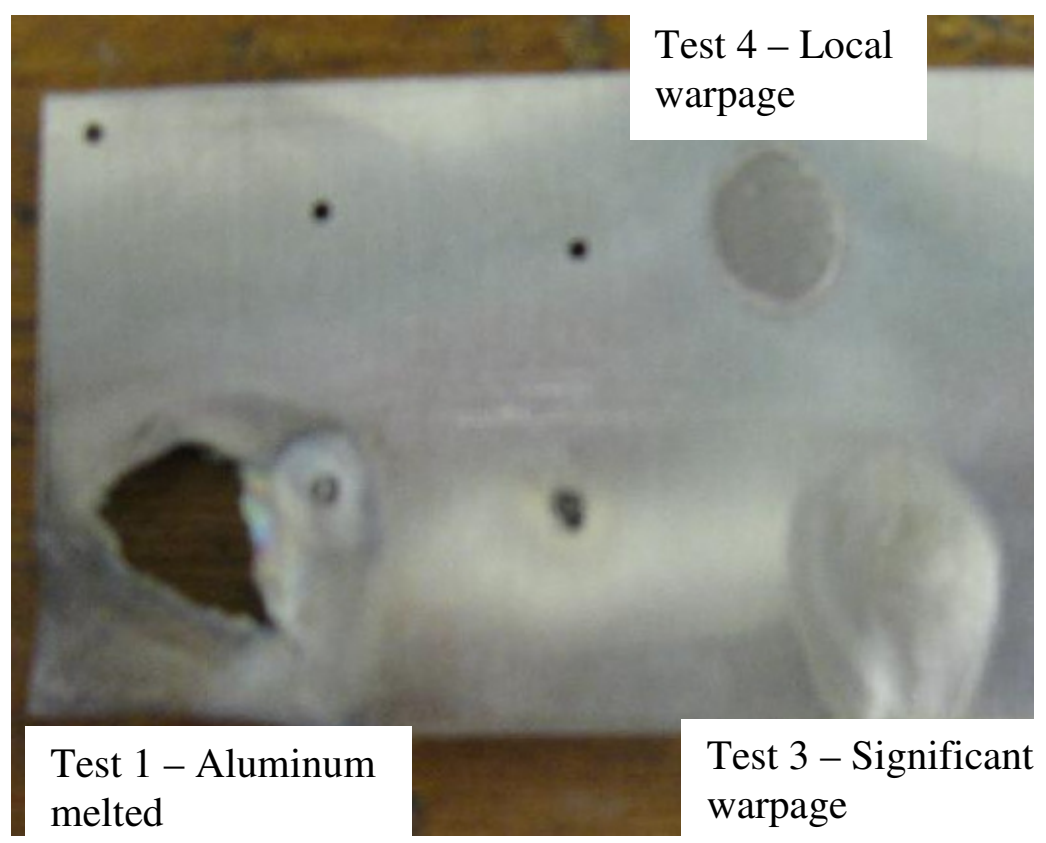

Figure 20 - Solder test piece (bottom).

Additional testing was conducted using different adhesives. While so called thermally conductive adhesives were explored, these materials only had thermal conductivities around $1-5 \%$ of $6061-\mathrm{T} 6$ aluminum's thermal conductivity. So, while this bonding is necessary, the bonded surface area will act like an insulator and affect the experimental results. Again, this bonding is necessary to allow for measurement of the internal hotflow properties. Building off experience gained by Ballestas ${ }^{10}$ and Sheridan ${ }^{11}$, Resbond 907GF adhesive and sealant, Omegabond 700 high temperature chemical set cement, and Duralco 4525 epoxy were tested, as seen in Figure 21. All bond testing was conducted on aluminum 6061-T6 sheet metal, the same alloy as the heat exchanger surface. The result of this test was the Resbond $907 \mathrm{GF}$ bond was the weakest, failing due to moderate shaking of the measurement tube. The Omegabond 700 was adequate in strength, but was difficult to apply. The Duralco 4525 was easier to apply because it was more liquid-like 
and flowed to seal any gaps while also exhibiting adequate strength, so it was chosen to bond the measurement tubes.

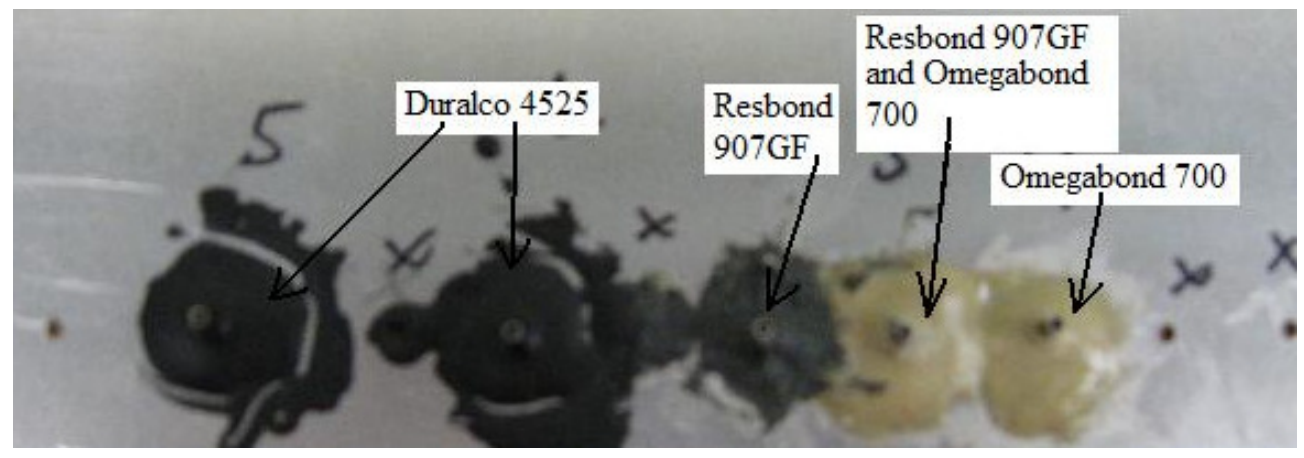

Figure 21 - Measurement tube bond type test specimen.

To attach pressure tubes and thermocouples, stainless steel tubes were bonded to the measurement holes using Duralco 4525. The tubes had an outer diameter of 0.0625 inches $(1.59 \mathrm{~mm})$, inner diameter of 0.0425 inches $(1.08 \mathrm{~mm})$, and nominal length of 0.3 inches $(0.76 \mathrm{~cm})$. To measure pressure, 0.0625 inch inner diameter tubing was fit over the metal tubes; to measure temperature, thermocouples were inserted through the metal tubes. Great care was taken to ensure the thermocouples were inserted to the middle of the metal foam channel, not in contact with the foam, to ensure an accurate fluid bulk temperature was measured. A schematic of the nominal thermocouple location within the heat exchanger can be seen in Figure 22. 


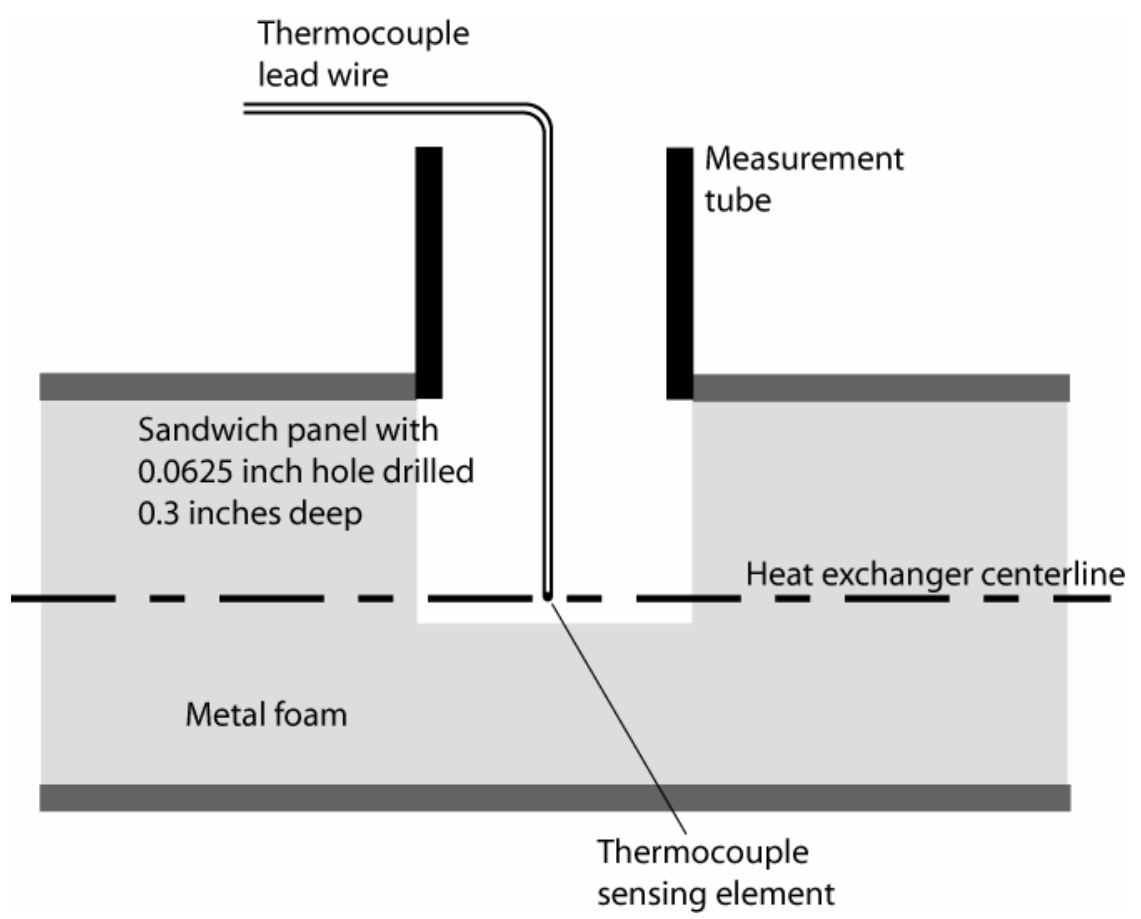

Figure 22 - Hot flow bulk temperature thermocouple insertion location (not to scale).

A heat exchanger with all pressure tubes and thermocouples attached is pictured in Figure 23. Originally, there were 25 measurement locations, as was seen in Figure 11. However, once the rest of the test setup was constructed, the outermost holes had to be plugged because they interfered with assembly. A small amount of high temperature silicone sealant was applied to the end of the pressure tubes to ensure a tight seal. Silicon was also applied to seal the end of the stainless steel tubes for the temperature measurement locations. 


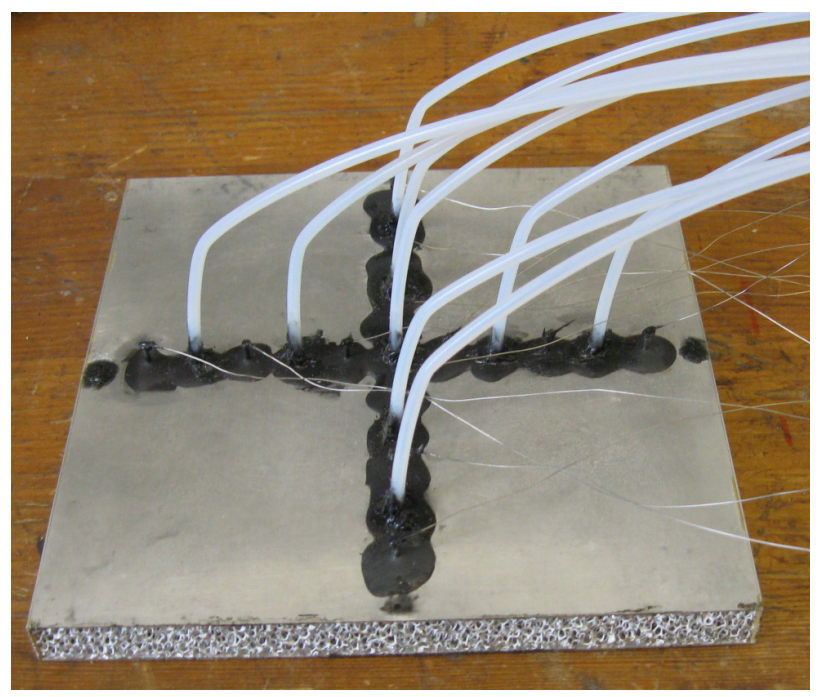

Figure 23 - 20 PPI metal foam heat exchanger with thermocouples and pressure tubes assembled.

As mentioned above, after initial testing it was apparent the heat exchanger surface temperatures would be required. On the side with the thermocouple wires and pressure tubes, which is the side subjected to the constant-fan flow, four surface thermocouples were applied in a square pattern around the surface center point, as seen in Figure 24. The measurement point of each surface thermocouple is 0.75 inches $(1.91 \mathrm{~cm})$ off both the horizontal and vertical centerlines.

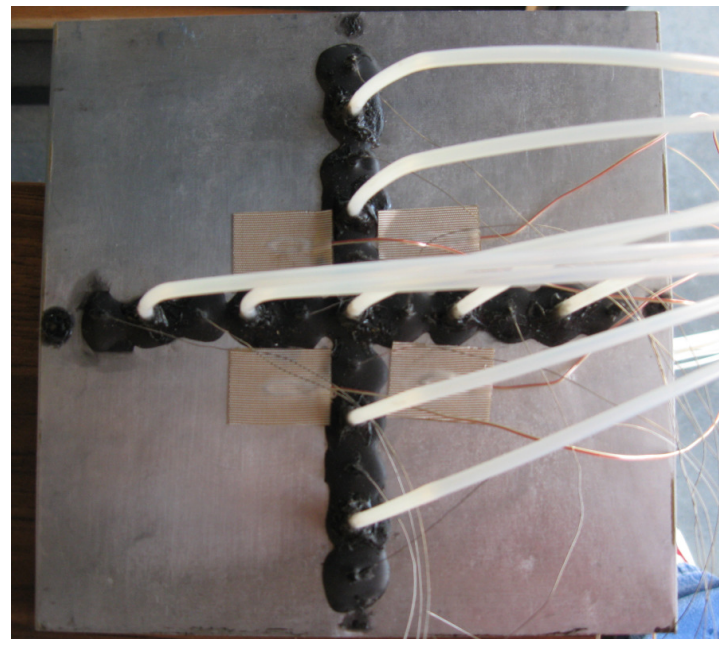

Figure 24 - Surface thermocouples on the constant-fan side of the 20 PPI heat exchanger. 
The other side of the heat exchanger, which is subjected to the variable-fan flow, only required a single surface thermocouple since the center point of the surface was not blocked. The thermocouple location can be seen in Figure 25.

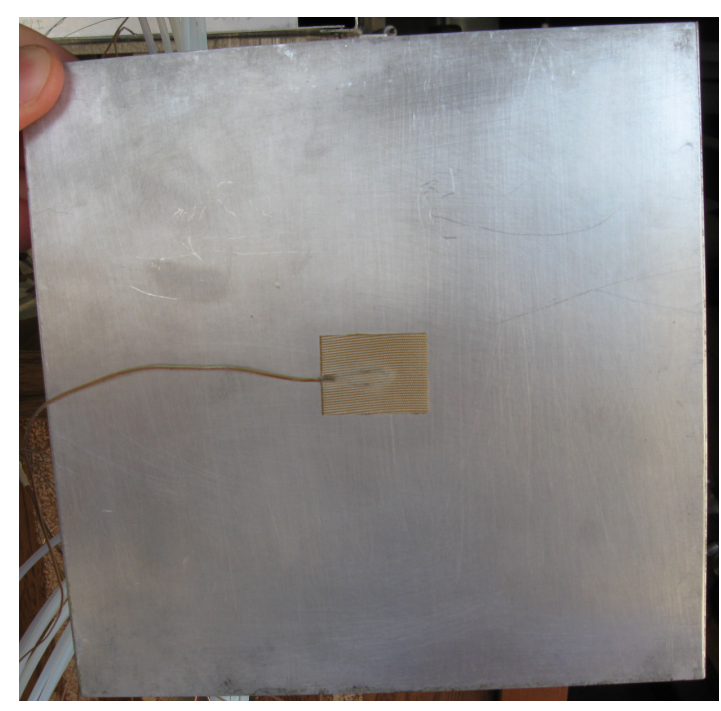

Figure 25 - Surface thermocouple on the variable-fan side of the 20 PPI heat exchanger.

A picture of the constructed cold flow ducting and blower inlet can be seen in Figure 26. The cold flow duct was built using sheet metal and was riveted using flush rivets on one corner of the duct. The cold flow inlet was constructed from two separate ducts and then welded together along with a flange which, with the separation plate, provided the necessary independent and controllable cold flow paths. Starting just after the inlet, 0.1 inch $(2.5 \mathrm{~mm})$ diameter holes were drilled 2.25 inches $(5.72 \mathrm{~cm})$ apart on the side of the wind tunnel to accommodate screws that would hold the 0.54 inch $(1.37 \mathrm{~cm})$ thick separation plate. The separation plate piece spanning from the inlet to the start of the metal foam was attached and treated as permanent. 


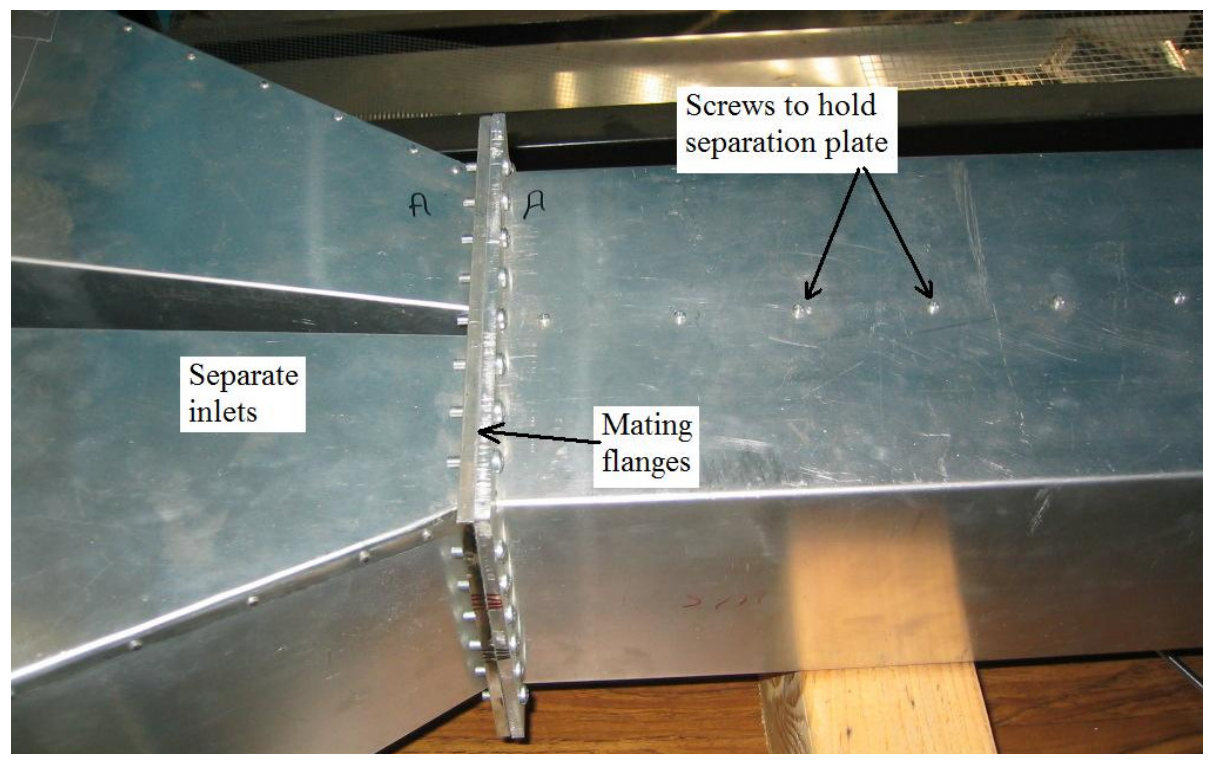

Figure 26 - Cold flow inlet and start of duct.

To secure the heat exchanger within the cold flow duct, two 0.25 inch $(0.64 \mathrm{~cm})$ thick connection plates were constructed. One of the connection plates was permanently attached to the cold flow duct with flush rivets while the other was made removable. With this configuration, the heat exchanger could be assembled inside the permanent connection plate and the other connection plate could be placed over the heat exchanger to secure it. Four threaded rods 7.25 inches $(18.4 \mathrm{~cm})$ in length were then used to tighten the connection plates, providing a seal so the hot-flow would not leak to the cold flow duct. An external view of the assembled connection plates can be seen in Figure 27. 


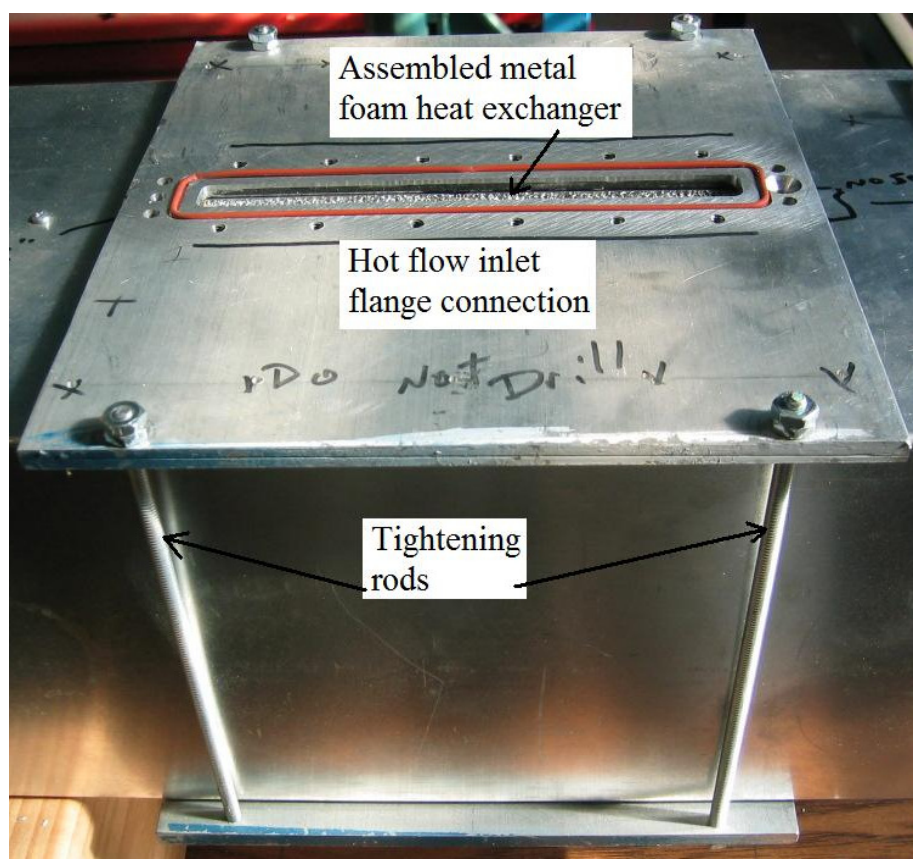

Figure 27 - Connection plates assembled with heat exchanger inside cold flow duct.

The connection plates contain an open slot with dimensions matching the metal foam dimensions. In addition, another slot which matched the dimensions of the heat exchanger was machined 0.15 inches $(3.8 \mathrm{~mm})$ deep into the plate. This allowed the connection plates to provide a flow path for the hot air internal to the heat exchanger while also holding the heat exchanger inside the cold flow duct. These machined slots can be seen in Figure 28. In addition to tapped holes for mounting the hot-flow inlet and outlet flanges, the connection plates both had two additional holes. These holes were used to mount the connection plate to the separation plate, external to the cold flow duct. The connection plate could then serve as a mounting location for the hot-flow ducting. 


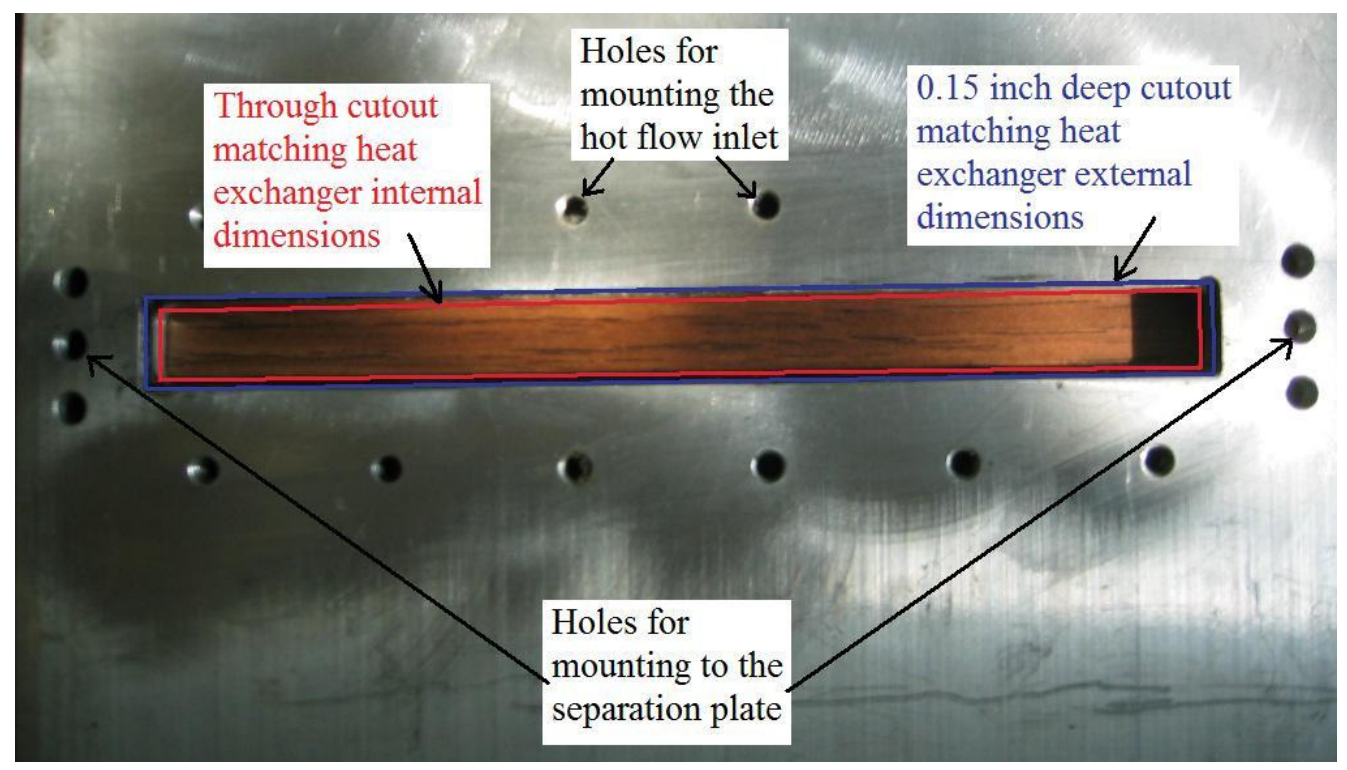

Figure 28 - Connection plate cutout for mounting and securing the heat exchanger.

To mate removable sections of ducting, a generic flange design was created. While the flanges had different internal dimensions at different segments of ducting, they all had the same characteristics. For example, the flange for the hot-flow inlet has different dimensions than for the cold flow inlet, but they are both derived from the same generic design. All of the flanges were constructed by Dan Powell using a CNC mill. To seal the flanges, an o-ring slot was machined into one of each mating pair of flanges, and silicone o-ring material was placed in the slot. This silicone gasket is 0.0625 inches $(1.59 \mathrm{~mm})$ in diameter and can withstand temperatures up to $400{ }^{\circ} \mathrm{F}$. To connect the flanges, screw holes were machined in one inch $(2.54 \mathrm{~cm})$ increments along the edge of the flange, roughly 0.25 inches $(0.64 \mathrm{~cm})$ away from the o-ring slot. One of the mating flanges had just holes drilled while the other had drilled and tapped holes so screws alone could secure two flanges. The flange and o-ring used to mate the hot-flow inlet to the connection plate can be seen in Figure 29. 


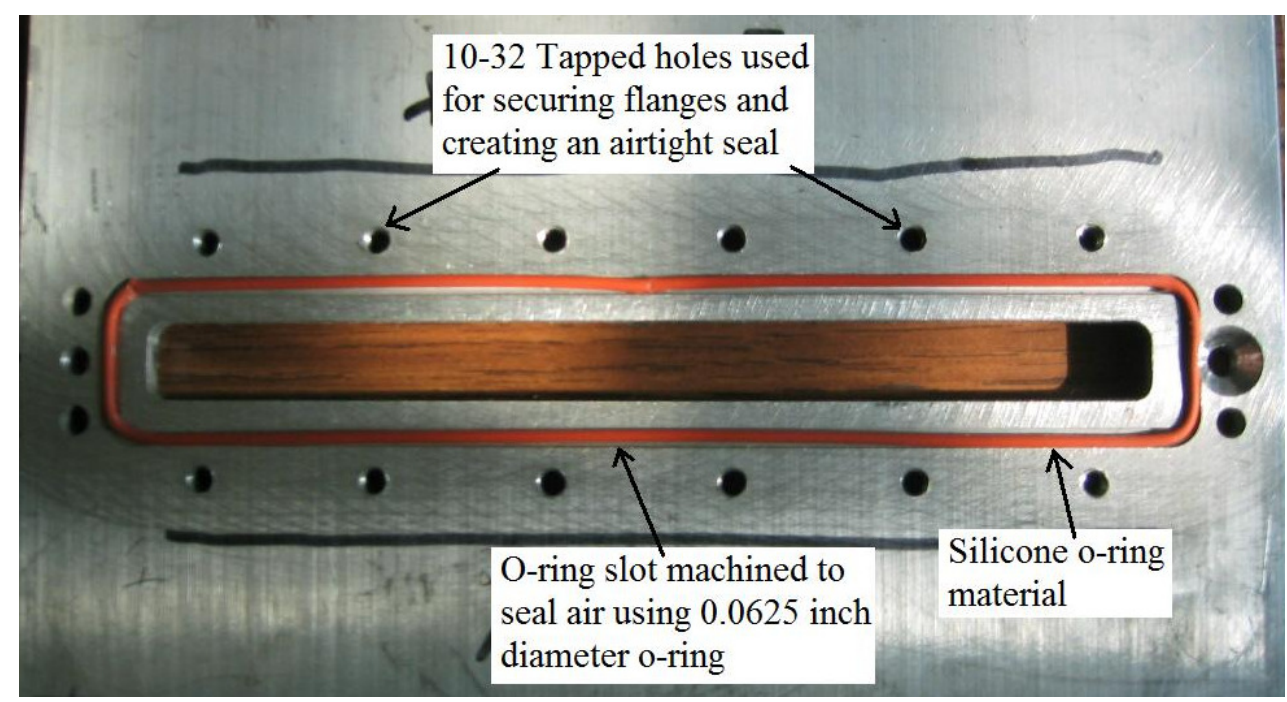

Figure 29 - Hot-flow inlet to connection plate flange.

The hot-flow delivery ducting, pictured in Figure 30, was constructed from two separate ducts. Both were created from sheet metal built to the required internal dimensions and then flanges were welded to the resulting duct. Two 0.0625 inch (1.59 $\mathrm{mm}$ ) diameter holes were drilled at the delivery end of this ducting for measuring the metal foam inlet temperature and pressure. The same steel tubing used on the heat exchanger was bonded to these holes using Duralco 4525. Attached at the inlet to this ducting is a custom build round to square transition duct. This was necessary to transition from the heater's round cross-section to the metal foam rectangular cross-section. 


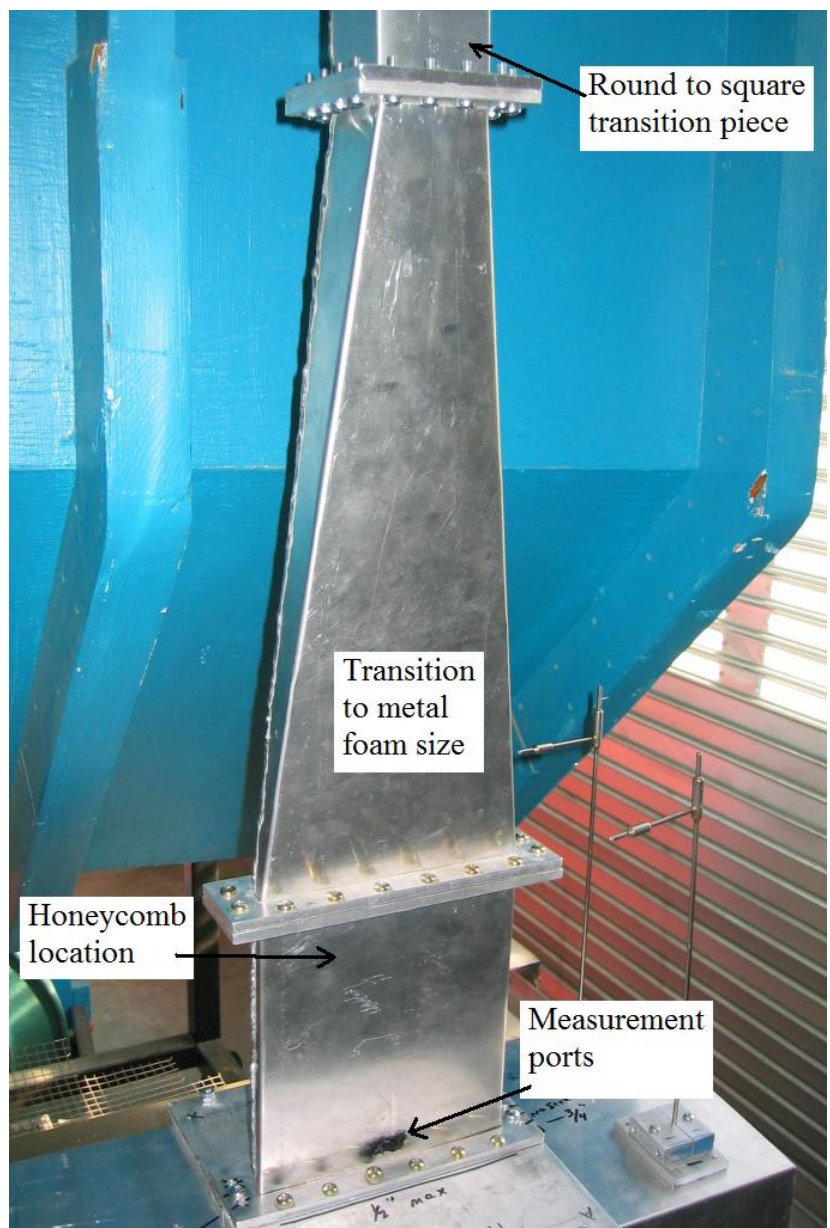

Figure 30 - Hot-flow inlet and conditioner.

Once the straight portion of this delivery ducting was constructed, a metal honeycomb 3 inches $(7.6 \mathrm{~cm})$ in length was cut to the dimensions of the duct and inserted, as seen in Figure 31.

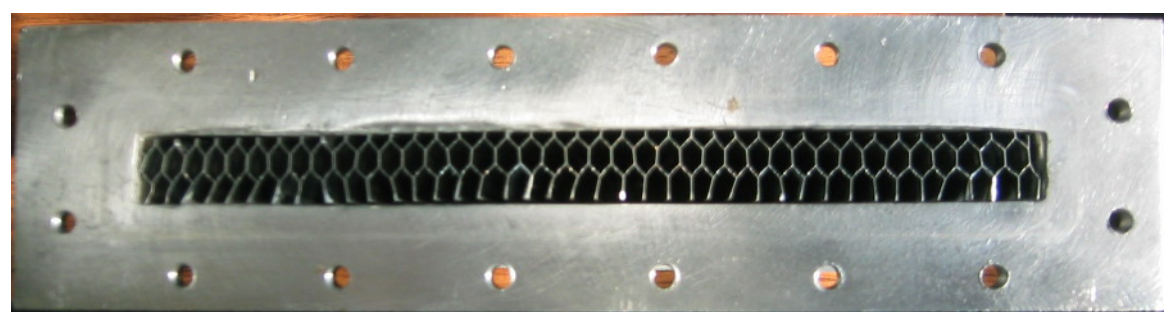

Figure 31 - Honeycomb flow straightener assembled into hot-flow inlet ducting. 
The hot-flow outlet was constructed from four separate pieces of sheet metal and then welded together on the external surfaces to form the complex shape. Two 0.0625 inch $(1.59 \mathrm{~mm})$ diameter holes were drilled and the steel tubing was attached using Duralco 4525 for metal foam outlet temperature and pressure measurement. The outlet duct assembled in the custom build test bench can be seen in Figure 32.

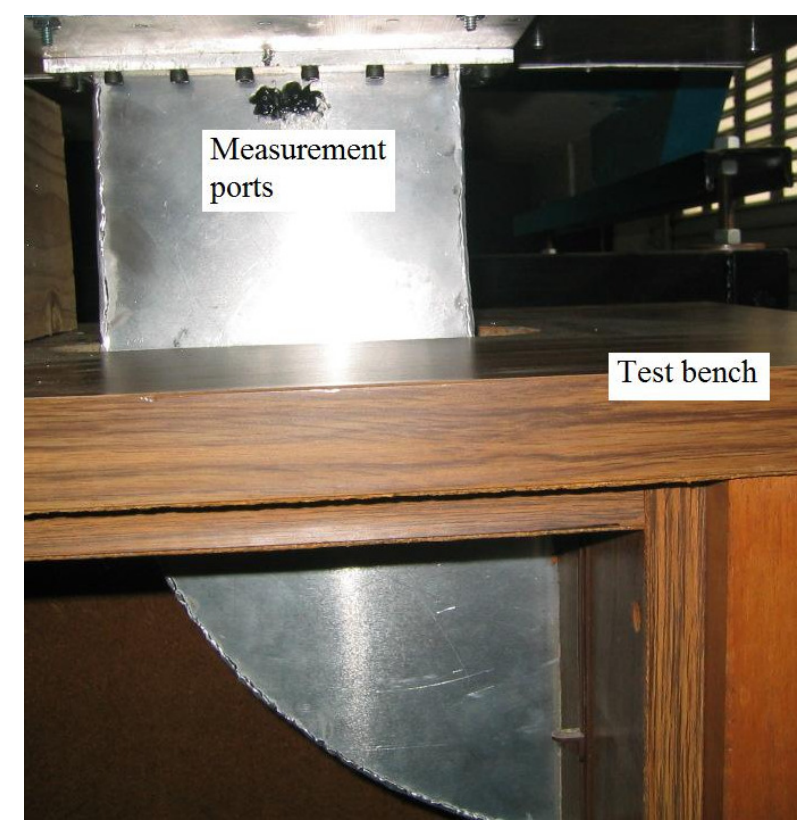

Figure 32 - Hot-flow outlet duct which exhausts out the lab roll-up door.

Before testing could begin, the hot-flow inlet and outlet ducting were covered in insulation. This was done to minimize any heat loss, avoid a rise in ambient temperature, and avoid any effect the hot-flow could have on the cold flows outside of the heat exchanger test area. To insulate the ducting 0.125 inch $(3.18 \mathrm{~mm})$ thick Cotronics' 390 ceramic paper was layered up to 0.375 inches $(9.53 \mathrm{~mm})$ on all of the inlet ducting downstream of the heater and on the hot-flow outlet duct. Duralco 4525 epoxy was used to bond the ceramic paper to the ducting. Because this bond was permanent, the flanges connecting different ducts had to be insulated using a different method. A reflective water 
heater insulation blanket was cut to size and taped into place around the flanges to insulate them. The inlet ducting with all insulation can be seen in Figure 33 .

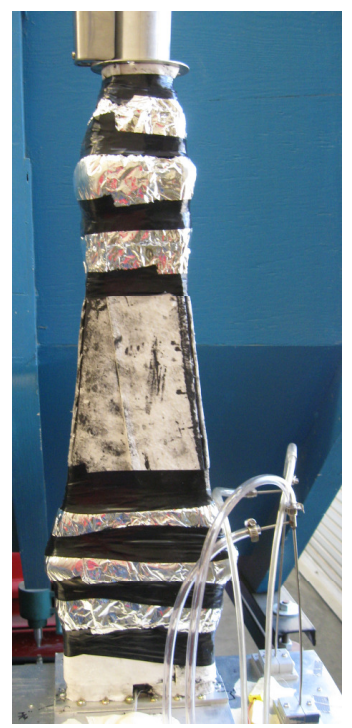

Figure 33 - Insulated hot-flow inlet ducting.

A picture of the final built and assembled test bench can be seen in Figure 34 .

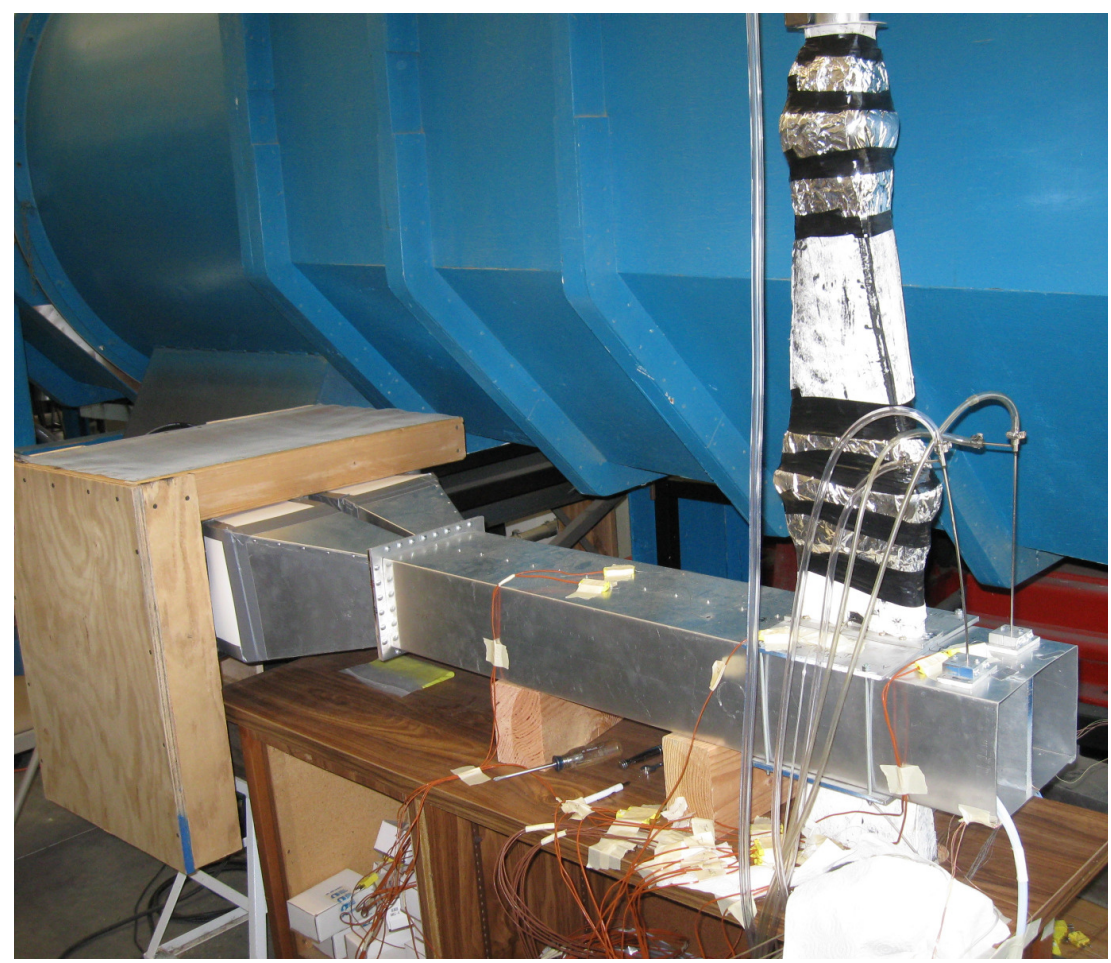

Figure 34 - Final assembled test bench ready for testing. 


\subsection{Instrumentation}

The building compressed air, supplied by a compressor setup with a practical maximum flow rate of 25 SCFM (708 SLPM), was used to supply the hot-flow through the metal foam heat exchanger. The air piping diameter is 2 inches $(5 \mathrm{~cm})$ up to the test room, where it is reduced to 0.75 inches $(1.9 \mathrm{~cm})$. The air was then routed through a Wilkerson liquid separator (model WSA-08), seen in Figure 35, to ensure the rest of the system would receive air without moisture. While the compressor was equipped with a dryer, when the apparatus was originally assembled this dryer was malfunctioning. Because of this and the need to ensure the flow meter received air without moisture, the separator was installed.

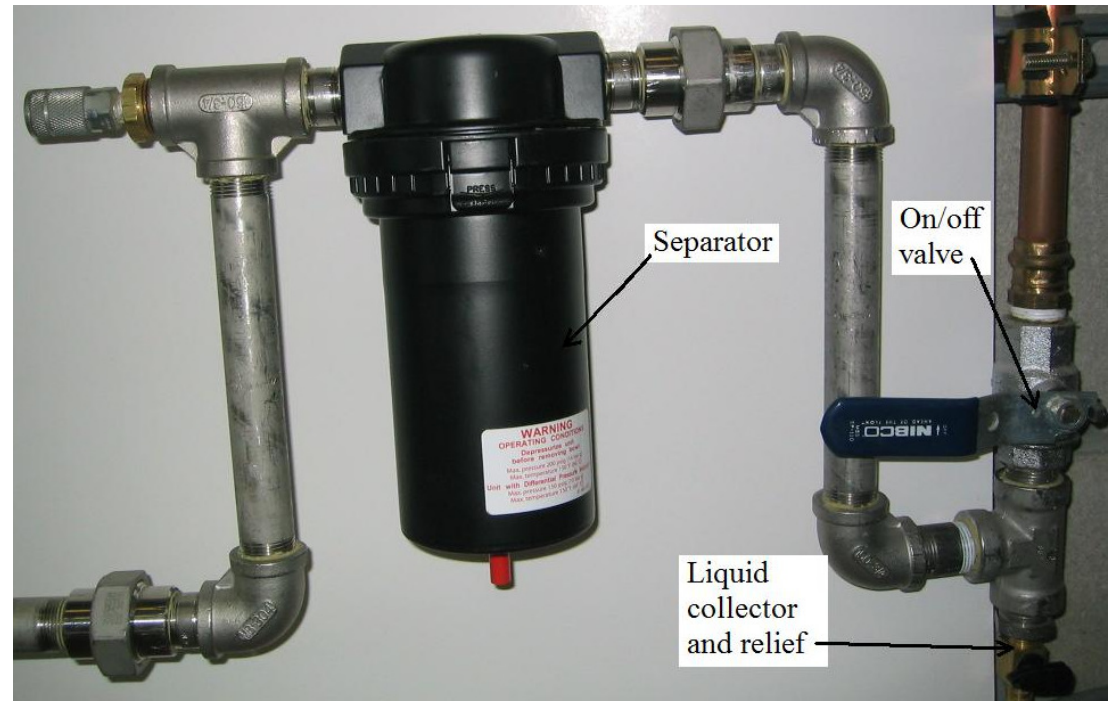

Figure 35 - Wilkerson liquid separator.

\subsection{1. $\quad$ Flow Meter}

From the separator, a 24 inch $(0.61 \mathrm{~m})$ straight section of lead-in pipe connected to an Omega flow meter (model FMA 1845), pictured in Figure 36. This flow meter standardizes the flow rate to $14.7 \mathrm{psia}\left(101.5 \mathrm{kPa}\right.$ absolute) and $70{ }^{\circ} \mathrm{F}(294 \mathrm{~K})$, giving a 
final output of standard liters per minute (SLPM). ${ }^{12}$ This measurement was delivered to a data acquisition box using a 9-pin D-type connector with a 0-5 Volt DC output and converted to SCFM.

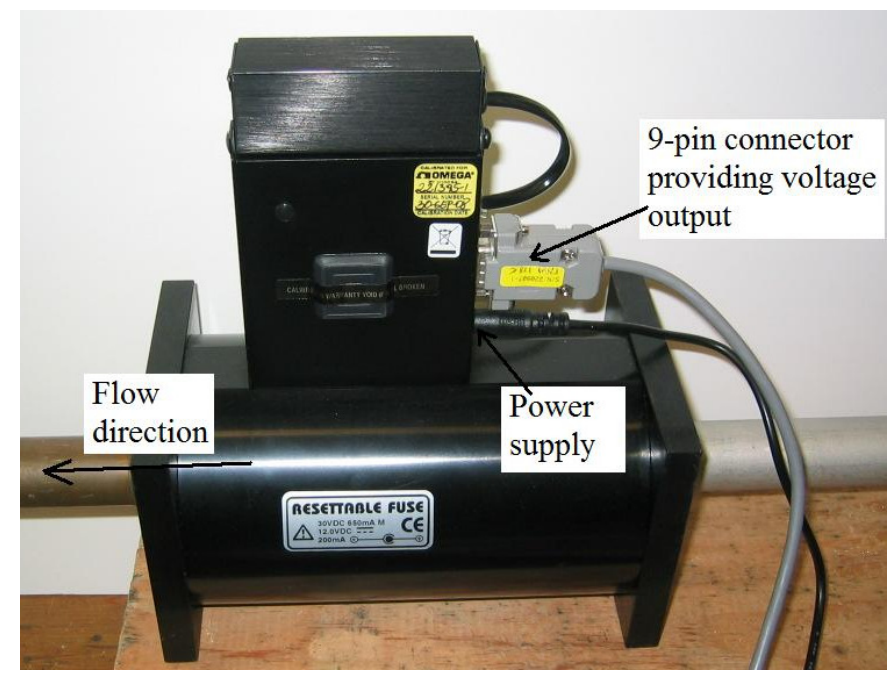

Figure 36 - Omega flow meter.

\subsection{2. $\quad$ Pressure Regulator}

From the flow meter, the air travels through a 3/4 to $1 / 2$ inch (19 to $13 \mathrm{~mm}$ ) reducer, 12 inch $(0.30 \mathrm{~m})$ straight lead-in pipe, and then a Norgren Excelon pressure regulator (model R74G-4AK-RMG), seen in Figure 37. The pressure regulator has $1 / 2$ inch PTF threaded inlet and outlet ports, plus two outlet pressure measurement ports. It has an outlet pressure range of 5 to 150 psig (345 to $1,034 \mathrm{kPa}$ gage) and can utilize up to a 300 psig $(2,070 \mathrm{kPa}$ gage $)$ supply pressure. 


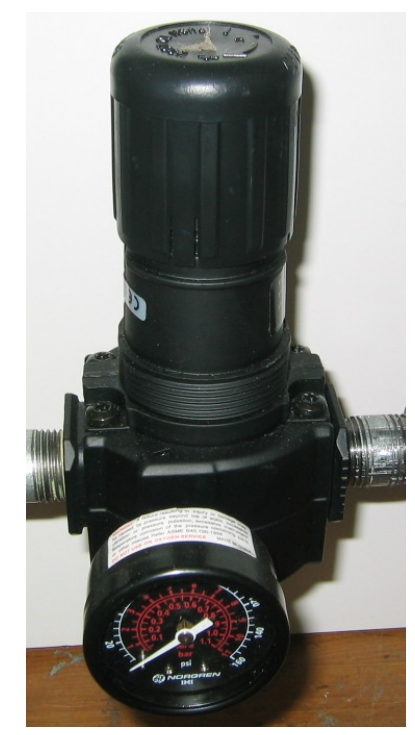

Figure 37 - Norgren pressure regulator and supplied pressure gauge.

Given a supply pressure of 100 psig (690 kPa gage), Figure 38 shows that regardless of outlet pressure, this pressure regulator allows flow rates well above the maximum capability of the compressor and will therefore not restrict the system hot air flow.

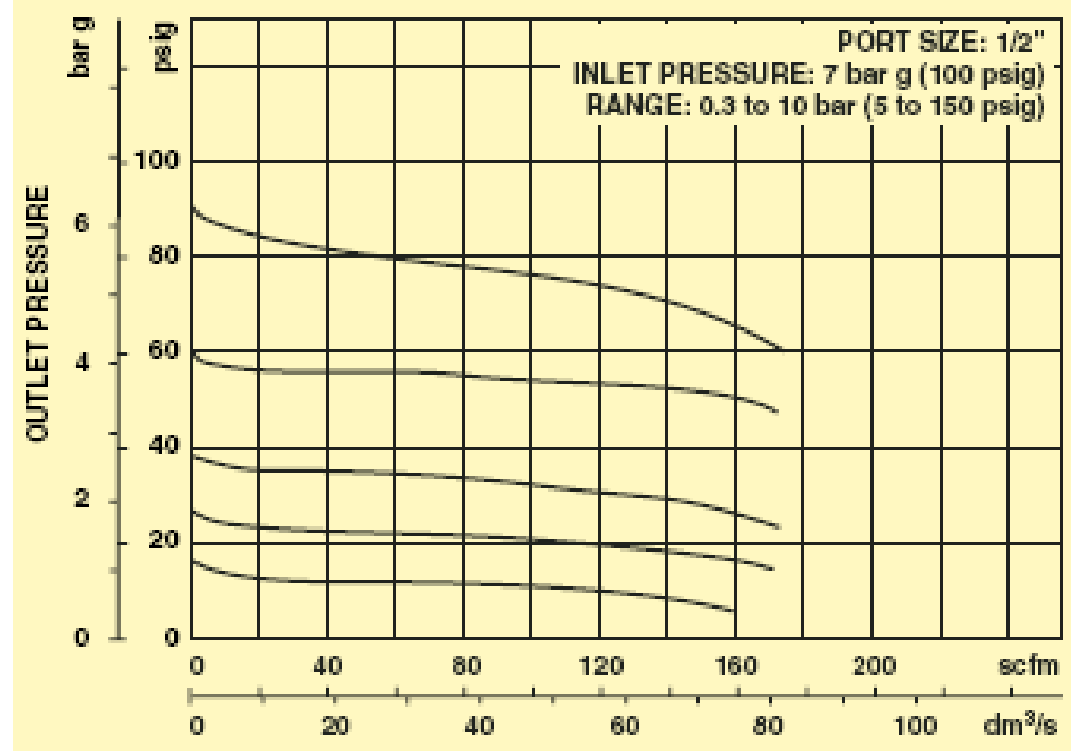

Figure 38 - Pressure regulator flow characteristics. ${ }^{13}$

The main reason for using a pressure regulator was the variation in the air pressure supplied by the compressor. From previous experience, the delivery pressure could vary 
between 95 and 105 psig (655 and $724 \mathrm{kPa}$ gage). However, with a pressure regulator, this variation can be damped out and the system can receive a steady pressure. This particular pressure regulator is designed with a "balanced valve" to "minimize effect of

variation in the inlet pressure on the outlet pressure." ${ }^{\prime 13}$ Since the regulator is a damping device, the outlet pressure was displayed using the pressure gage supplied with the regulator, but was not recorded. As long as the delivery pressure was large enough to overcome system pressure losses, the actual value of this pressure was unimportant for the experiment.

Downstream of the pressure regulator was a gate valve used to control the flow rate. Since the hot-flow eventually exhausts to ambient, as the pressure downstream of the gate valve decreases, so does the flow rate. So, this gate valve was used to create a variable pressure drop while the flow meter was monitored to attain the desired volumetric flow rate.

\subsection{3. $\quad \underline{\text { Heater }}$}

From the gate valve the air traveled through a $1 / 2$ to 2 inch $(1.3$ to $5 \mathrm{~cm})$ bell reducer which was connected directly to 2 inch $(5 \mathrm{~cm})$ inner diameter flexible tubing. This flexible braid reinforced PVC tubing can withstand $75 \mathrm{psi}(517 \mathrm{kPa})$ and up to $150^{\circ} \mathrm{F}$ $(339 \mathrm{~K})$ and was used to transport the air from the delivery system to the test system. It was connected to an insulation piece of similarly sized tubing with a maximum temperature of $500{ }^{\circ} \mathrm{F}(533 \mathrm{~K})$ to ensure the heater temperature would not compromise the tubing. This insulation tubing was then connected to an Omega air heater (model AHF-10120), as pictured in Figure 39. 


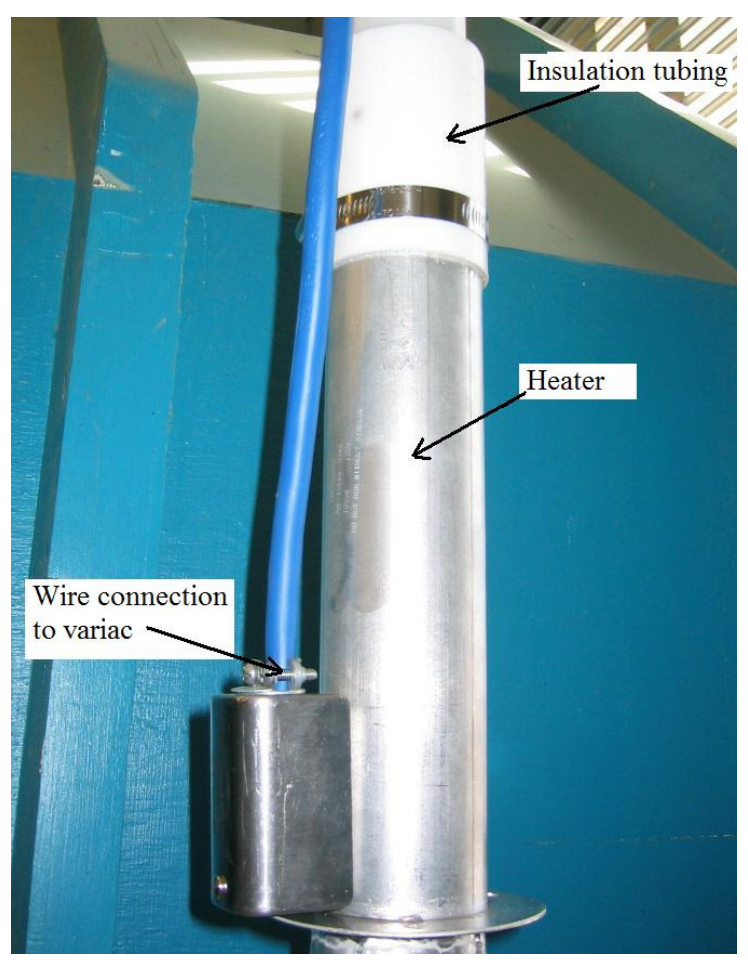

Figure 39 - Omega in-line heater.

This heater has the capacity for up to 200 CFM (5,700 LPM) and can heat to temperatures up to $600{ }^{\circ} \mathrm{F}(589 \mathrm{~K})$. Such a large flow capability was chosen to retain a small flow velocity and minimize the pressure losses caused by the heater. The heater can supply a maximum of one $\mathrm{kW}(3,400 \mathrm{BTU} / \mathrm{hr})$ of heating power to the air. From the heater, the hot air is delivered to the wind tunnel test setup.

To power the heater, a Staco Energy Products variable autotransformer (model 3PN1210B) was purchased from McMaster-Carr. This variac, pictured in Figure 40, can supply $0-120 \mathrm{~V}$ at up to 12 Amps. It was directly connected to the heater and care was taken to ensure the variac did not output more than one $\mathrm{kW}(3,400 \mathrm{BTU} / \mathrm{hr})$, since this would damage the heater. This variable voltage could then be used to control the heat input to the air and consequently the air temperature at the heat exchanger inlet. 


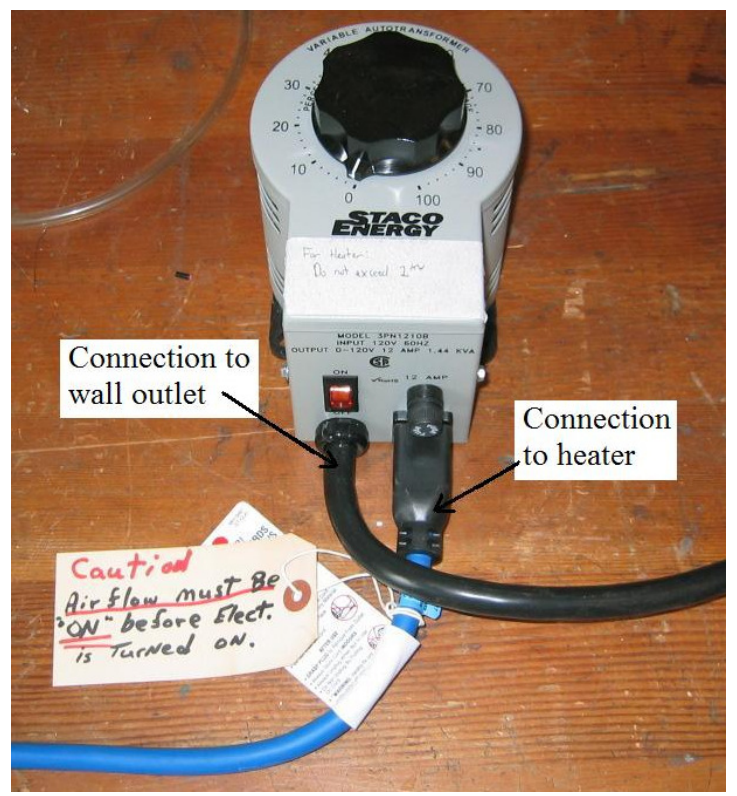

Figure 40 - Variac used to power the heater.

\subsubsection{Blowers, Motors, and Controllers}

Both cold air flows were supplied using a Dayton centrifugal blower, motor, and controller. The belt driven blower (model \# 4TL97) has a double inlet with a 9.5 inch (24 $\mathrm{cm})$ diameter wheel. The motor of choice for this blower was a Dayton $1 / 2 \mathrm{hp}(0.37 \mathrm{~kW})$ motor (model \# 2N103BA) that utilized three phase, 230/460 Volts power. To control the air flow rate in each of the cold flow paths, a Dayton Vector Inverter (model \# 1KBR2) was connected to the motor. This inverter has an output range of $0.01-400 \mathrm{~Hz}$ which will vary the speed at which the motor, and therefore the blower, run. The blowers, motors, and controllers assembled on the test stand can be seen in Figure 41. 


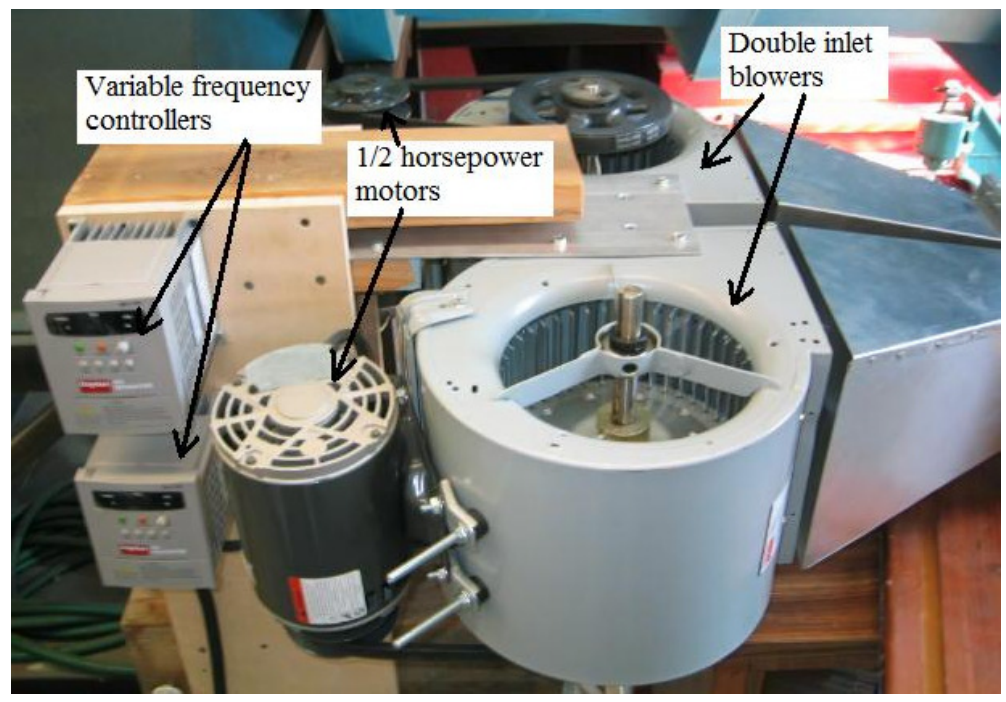

Figure 41 - Cold air flow delivery system.

The air flow rate will be controlled by measuring the flow velocity and changing the blower RPM, through the motor frequency, until the desired flow rate is attained. A wire covering, seen in Figure 42, was built around the blowers to ensure stray objects could not accidentally come in contact with the blowers, motors, or belts.

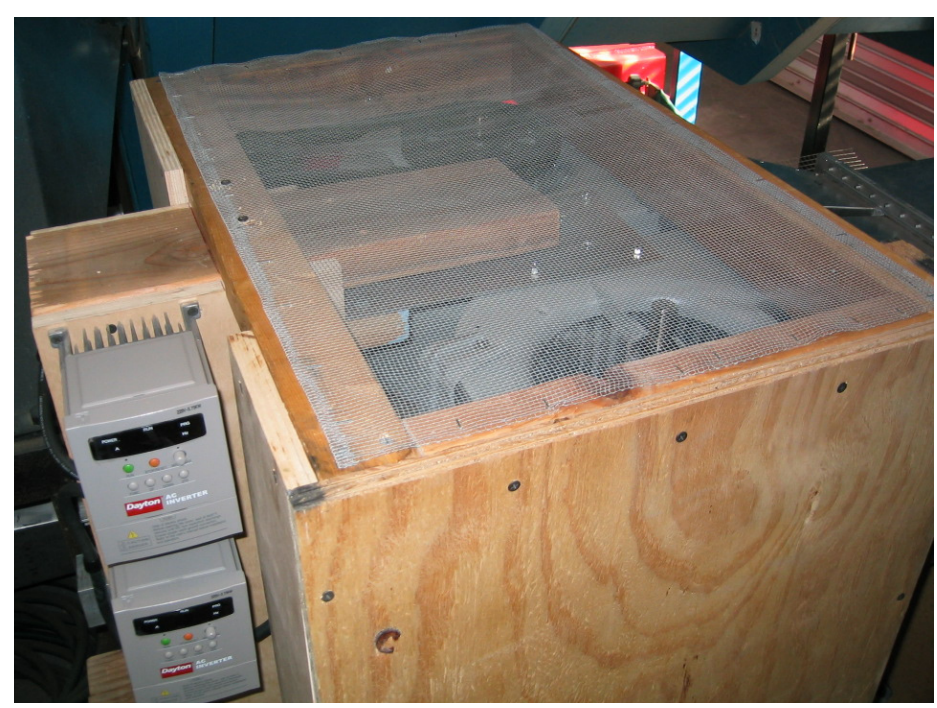

Figure 42 - Blower and motor casing. 


\subsubsection{Pitot Probes and Manometer}

The air velocity at the center of the cold flow ducts will be measured using a 0.125 inch $(3.18 \mathrm{~mm})$ outer diameter Dwyer Pitot tube. To mount the Pitot tube to the cold flow duct, a custom mounting fixture was built and assembled to the exterior of the cold flow duct. Both probes can be seen in Figure 43 mounted to the cold flow ducting.

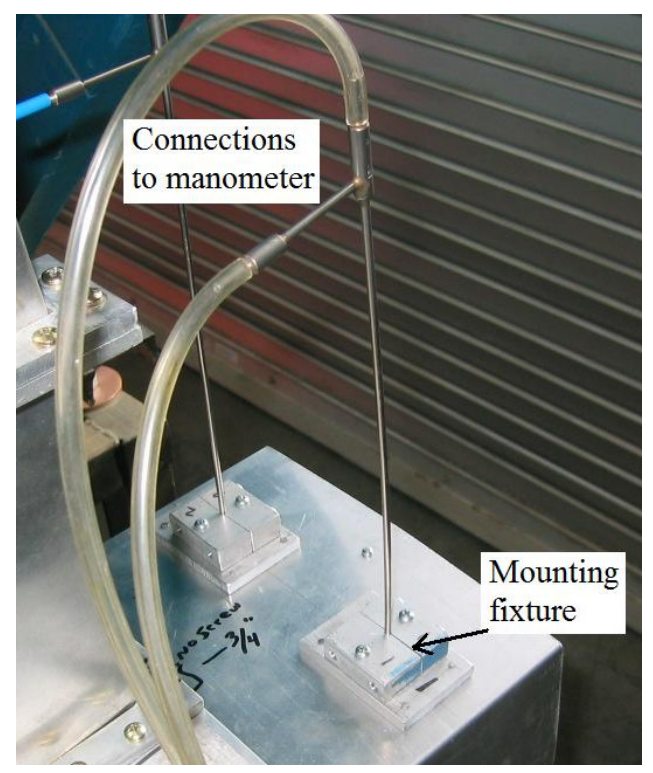

Figure 43 - Pitot tubes mounted externally to the cold flow duct.

The Pitot probe was connected to a Dynatech Frontier incline manometer (model W250-I), seen in Figure 44, to measure the cold flow velocity. Green manometer fluid with a specific gravity of one was used. This manometer was also used as a check for the gauge pressure of the air at the hot-flow inlet which was needed to calculate the inlet air density and hot air mass flow rate. 


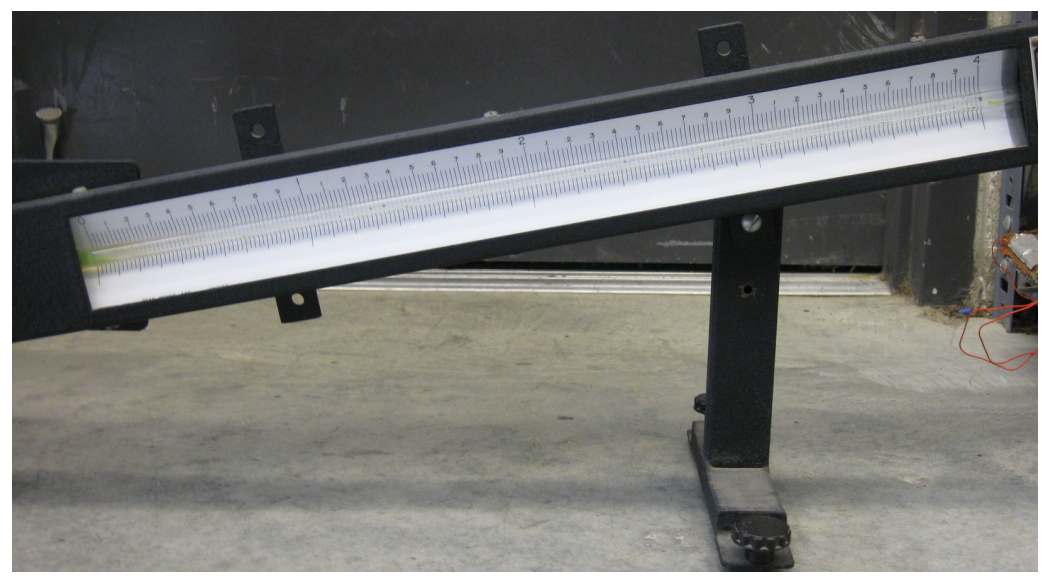

Figure 44 - Manometer used to measure cold flow velocity.

\subsubsection{Thermocouples and Amplifiers}

A combination of quick disconnect and transition joint K-type Omega thermocouples (models KMQSS-010G-36 and TJ120-CASS-010U-36-OSTW-M) were used to measure the internal hot-flow bulk temperature. The probe sheath for both probes is 36 inches $(0.91 \mathrm{~m})$ long, 0.010 inches $(0.254 \mathrm{~mm})$ in diameter, and made of 304 stainless steel. As mentioned earlier, these thermocouples were inserted through the 0.0625 inch $(1.59 \mathrm{~mm})$ diameter steel tubes and carefully arranged to measure the hot-flow bulk temperature. To hold the probes in place and seal the steel tube opening, high temperature silicone sealant was used.

Four more Omega quick disconnect thermocouples (model KMQSS-010G-12) with a sheath length of just 12 inches $(0.305 \mathrm{~m})$ were used to measure the temperature at the center of the duct for the cold flow inlet and outlet. They were inserted through 0.0625 inch $(1.59 \mathrm{~mm})$ holes drilled 5 inches $(12.7 \mathrm{~cm})$ upstream and downstream of the heat exchanger. Again, high temperature silicone sealant was used to both attach the thermocouple and seal the hole. 
Omega surface thermocouples (model SA1-K-120) were used to measure the surface temperature on the external surfaces of the heat exchanger. On the side without measurement ports, a single surface thermocouple was used to measure the surface temperature at the center of the surface. On the side with measurement ports, because of the ports themselves and the Duralco 4525 epoxy used to attach the stainless steel tubes, the surface temperature could not be measured at the center of the surface. Instead, a square of four thermocouples was attached 0.75 inches $(1.91 \mathrm{~cm})$ away from the horizontal and vertical centerlines to obtain an estimate of the surface temperature at the center. These thermocouples utilize a silicone based adhesive to adhere to the heat exchanger surface and fiberglass insulation on the opposite side to ensure the temperature read is the surface temperature and not the cold flow temperature.

The thermocouple connectors were plugged directly into Omega thermocouple-toanalog connector/converters (model \# SMCJ-K). This compact converter takes in a thermocouple reading and outputs an amplified $1 \mathrm{mV}$ per degree $\left({ }^{\circ} \mathrm{F}\right.$ or $\left.{ }^{\circ} \mathrm{C}\right)$ signal. This signal was then routed to the data acquisition box using standard banana plugs. The connector/converter with a miniature quick disconnect thermocouple plugged in can be seen in Figure 45.

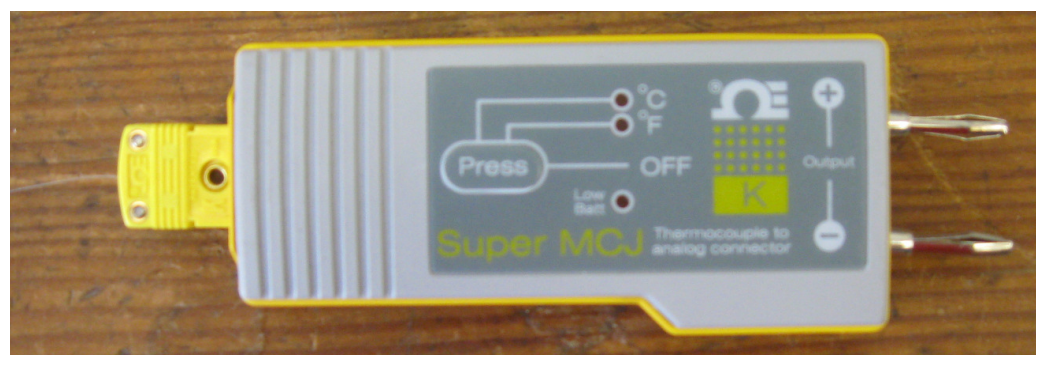

Figure 45 - Thermocouple connected to Omega converter used to amplify the thermocouple signal. 


\subsubsection{Scanivalve and RadLink}

To measure the pressure drop across the metal foam, a Scanivalve system was used. This system is composed of a Scanivalve ZOC33/64Px-X1 pressure scanning module, RAD3200 A/D unit, USB extender, and a RPM1000 power supply. The Scanivalve ZOC33 has 64 differential pressure ports with an accuracy of $\pm 0.20 \%$ full-scale reading. Half the ports have a pressure range of $0.36 \mathrm{psid}$ ( $2.5 \mathrm{kPa}$ differential) while the other half have a range of $1.0 \mathrm{psid}(6.9 \mathrm{kPa}$ differential). The pressures are measured using a single pressure transducer with a solenoid driver that rapidly supplies the transducer with the required pressure channels. The module is equipped with a temperature sensor that compensates for temperature changes in the Scanivalve module and is used to zero the module's output before an experimental run. The RAD3200 A/D unit amplifies, samples, and converts the signal provided by the pressure scanning module. The RPM1000 power supply provides power to the RAD3200 A/D unit, which in turn powers and drives the pressure scanning module. The RAD3200 A/D unit outputs the resulting signal to the Scanivalve USB extender, which is then connected to the test computer. The Scanivalve system schematic and actual unit setup can be seen in Figure 46 and Figure 47. 


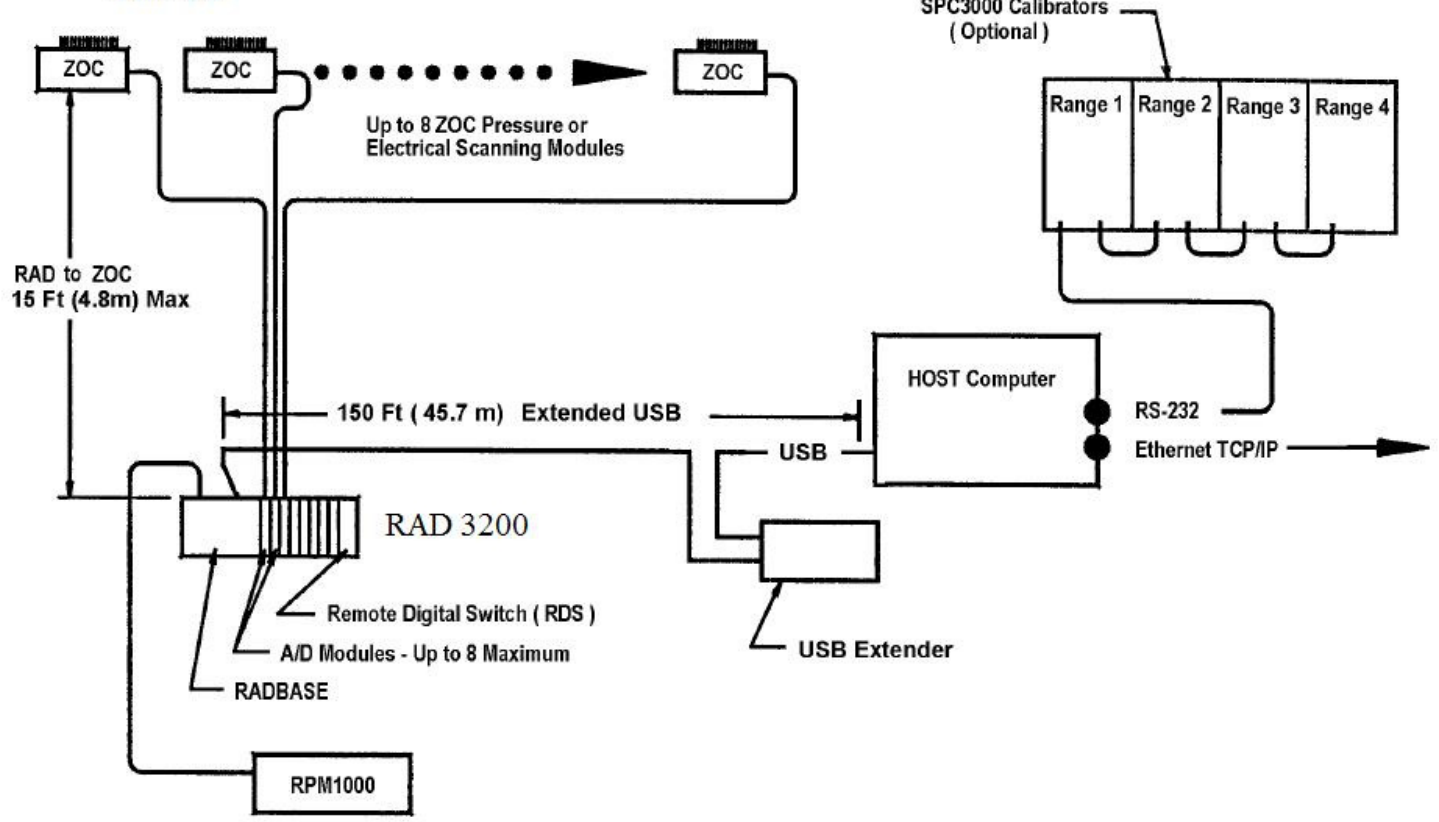

Figure 46 - Scanivalve system configuration.

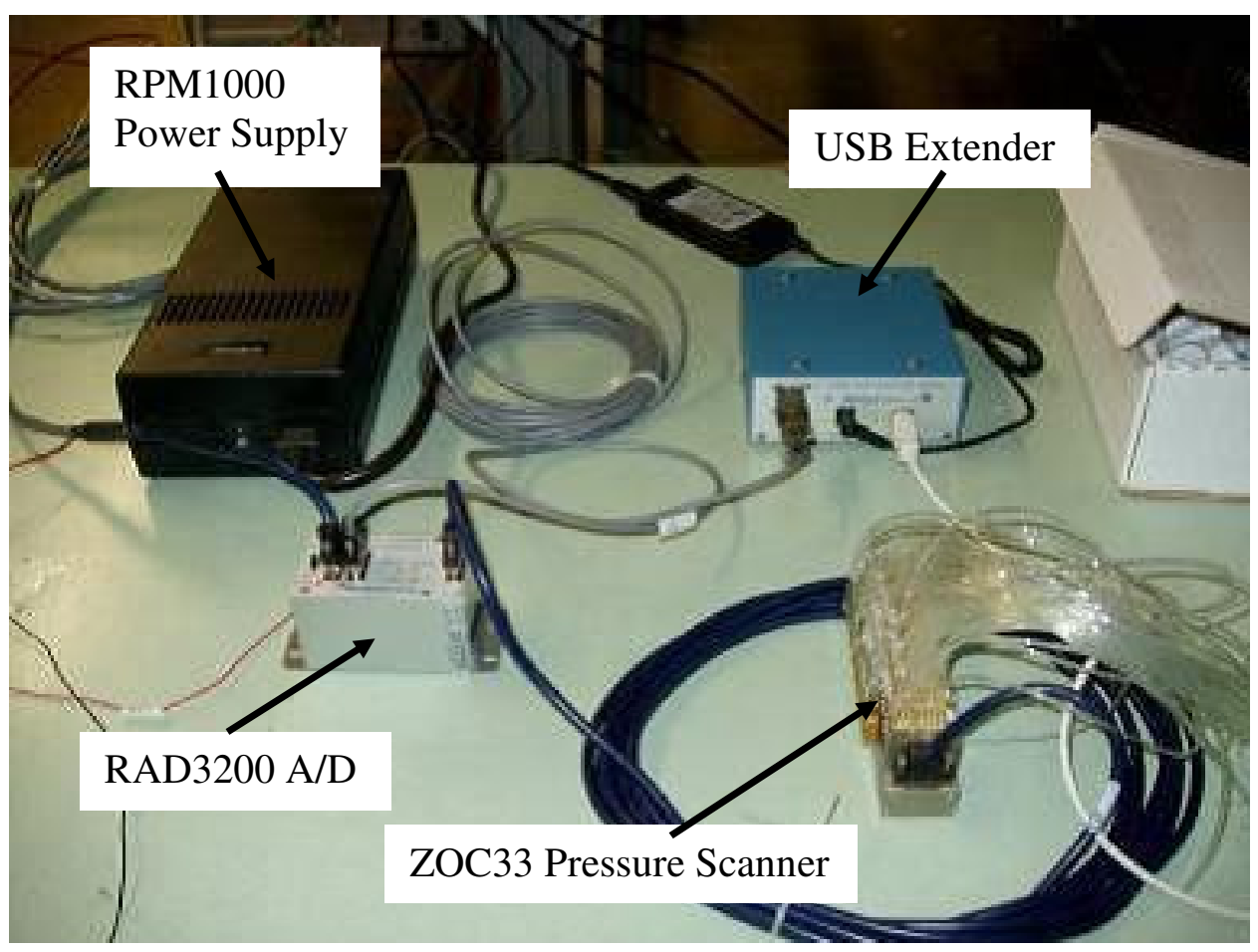

Figure 47 - Physical Scanivalve system. 
The software program RAD is used to connect, start-up, and configure the Scanivalve system with the test computer. Once a connection has been made and calibration coefficients loaded, another software program, RadLink, is used to provide a GUI for operating the RAD3200. The main menu, seen in Figure 48, allows operations ranging from checking calibration coefficients to running a zero calibration to recording pressure readings.

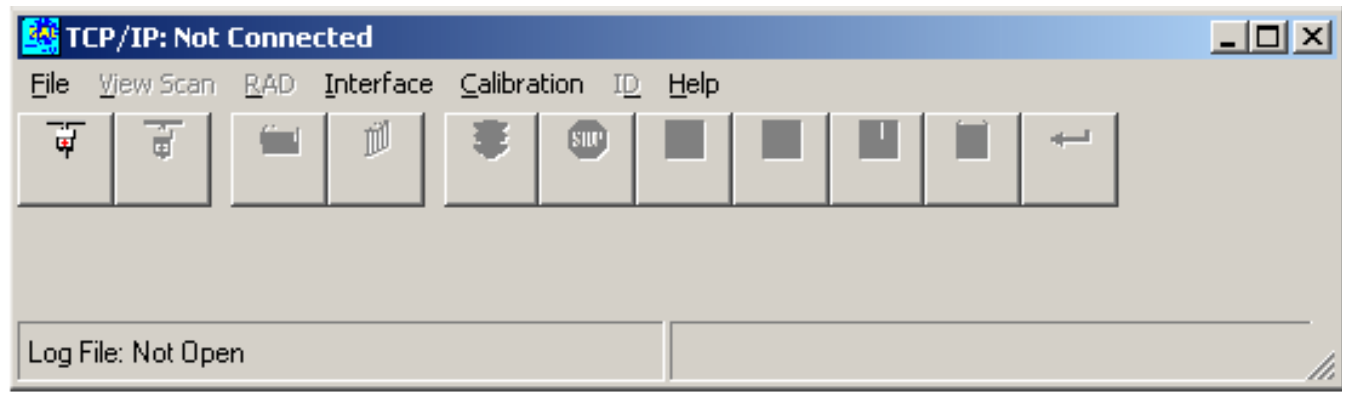

Figure 48 - RadLink GUI used to operate Scanivalve system.

For a given test run, RadLink can configure the Scanivalve system to read any number of the available 64 differential pressure channels for a given number of samples. The Scanivalve system reads pressure using scans, frames, and averages. The number of averages is the number of sequential samples done on a single pressure port. These samples are then averaged for a single pressure reading, with a maximum of 256 samples per port. A compilation of an averaged pressure reading at each pressure port of interest is collectively called a frame. A scan is then one complete run through all pressure ports of interest with pressure value outputs at each given frame. As an example, if 100 averages are taken across 500 frames in one single scan, then the output from RadLink will be 500 pressure values per pressure port of interest, where each one of those values is an average of 100 samples. The final output from RadLink is a dat file containing the frame number, scan number, port number, and averaged pressure reading for all scans, 
frames, and ports. This resulting .dat file was then post-processed using Matlab to obtain mean pressure readings for each measurement port. The Matlab post-processing code can be seen in Appendix B.

\subsubsection{Matlab}

Matlab was used to acquire, condition, and record temperature and flow rate readings as well as post-process the raw data from the Scanivalve. The Data Acquisition Toolbox was used to create data acquisition (DAQ) objects that were capable of interfacing with the DAQ hardware, described below. These DAQ objects could then be manipulated to read test data at varying sampling rates (within hardware and testing limitations) and could be easily reconfigured to match changes in hardware.

Four separate DAQ objects were created in Matlab. An example Matlab code used to create the DAQ objects can be seen in Appendix B. The first object acquired the hot air flow bulk temperature at the inlet, outlet, and the six temperature ports along the flow direction. The second acquired the hot air flow temperature at the six temperature ports in the cross-flow direction and the hot air volumetric flow rate. The third acquired the inlet and outlet cold flow temperatures for both the constant and variable velocity ducts. Finally, the fourth acquired all five surface temperatures, one for the smooth side (variable-fan side) and four for the measurement tube side (constant-fan side) of the heat exchanger.

\subsubsection{Data Acquisition PC Card and Accessories}

A combination of a National Instruments PCI-6259 data acquisition board and a National Instruments SCC-68 data acquisition box were used to acquire and deliver the 
thermocouple and flow meter signals to Matlab. The data acquisition (DAQ) board can accept 32 single ended/16 differential analog inputs at 16-bit resolution and can stream data at 1.25 MS/s. The board, pictured in Figure 49, was installed in the PCI slot of the acquisition computer.

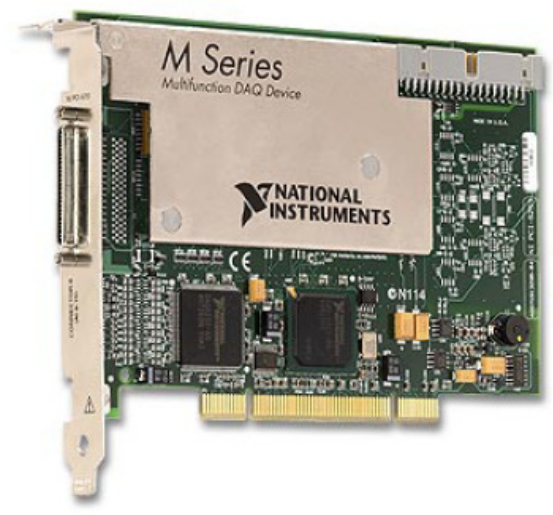

Figure 49 - NI PCI-6259 data acquisition board.

Connected to the acquisition board was a National Instruments SCC-68 DAQ box. This box allowed for easy screw terminal connection for all of the instrumentation. Banana plug connectors were connected to the screw terminals to provide easy connection to a variety of instrumentation. The SCC- 68 box with all banana plug connectors attached can be seen in Figure 50. Note that, while the DAQ card can accept 16 differential analog inputs, each SCC-68 DAQ box can only connect eight differential analog inputs to the PCI-6259. 


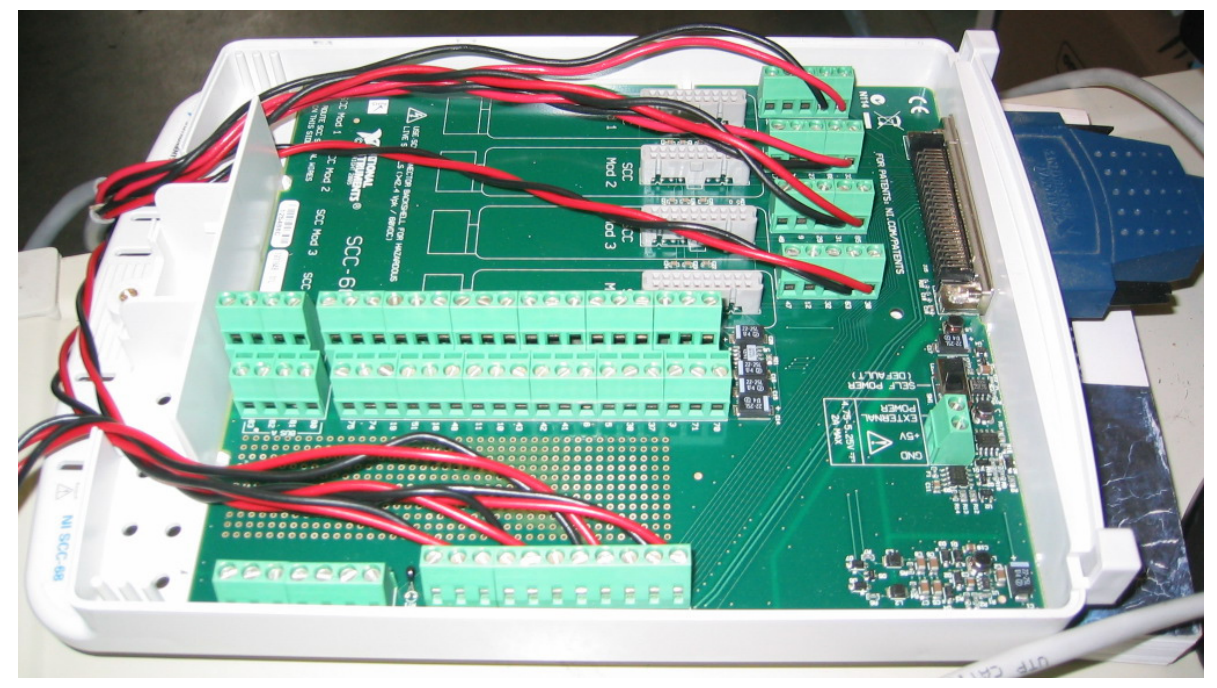

Figure 50 - SCC-68 data acquisition box outfitted to acquire thermocouple and flow rate signals.

A screenshot from the data acquisition computer taken during a test run can be seen in Figure 51. The raw temperature along the hot-flow direction is shown in the upper left corner; the RadLink GUI is in the upper right corner; the currently running pressure scan pressure values are shown on the right hand side; and Matlab can be seen running in the background. 


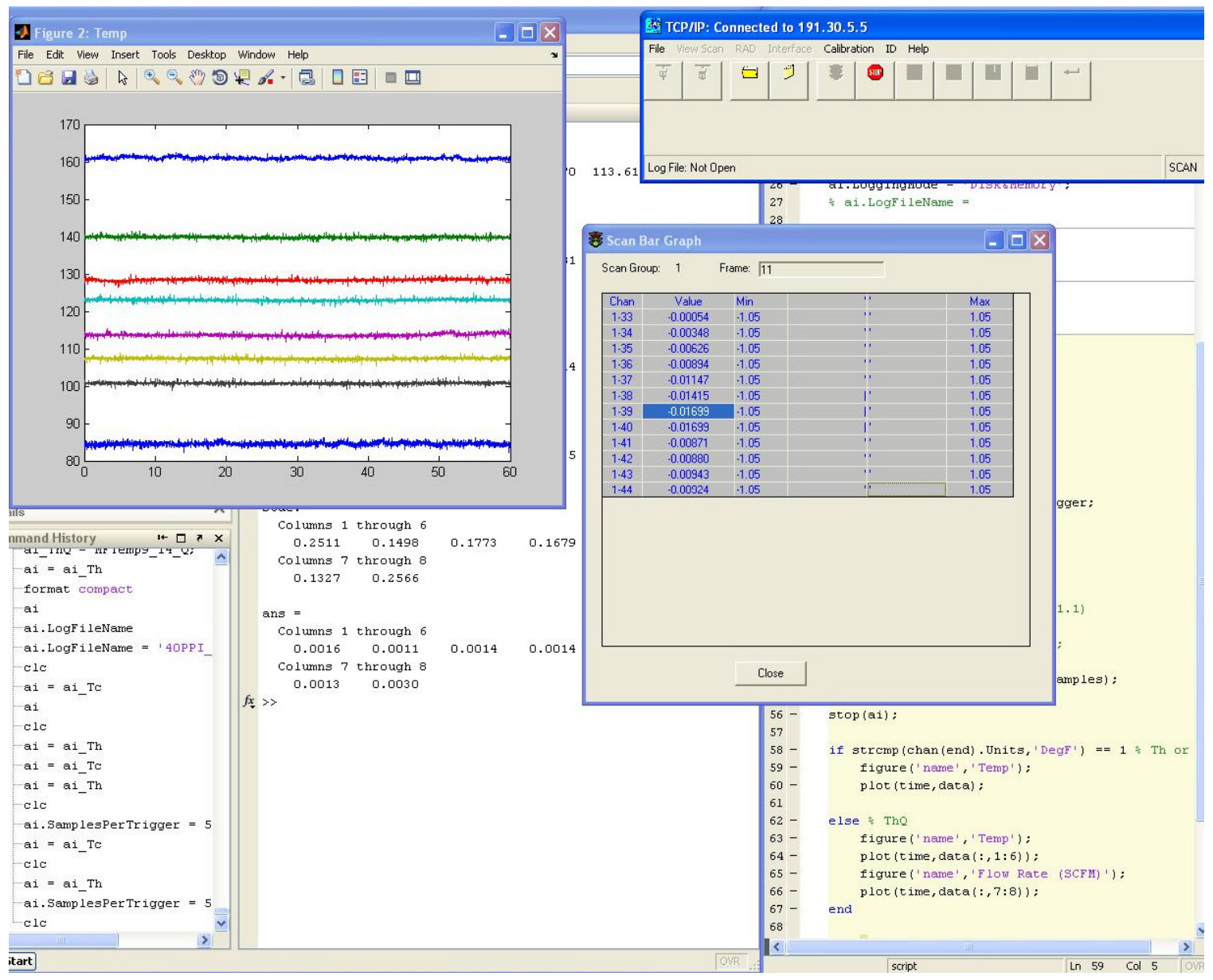

Figure 51 - Screenshot from DAQ computer during a test run. 


\section{EXPERIMENTAL PROCEDURE}

Each metal foam heat exchanger was tested using the same procedure. First, the heat exchanger had to be equipped with tubing and thermocouples to measure pressure and temperature. The tubing was fit over the steel tubes and then a small amount of high temperature silicone sealant was added to ensure a tight seal. The thermocouple leads were carefully inserted to the middle of the metal foam channel and care was taken to ensure the measurement point was not in contact with any metal. The thermocouples were then bent to ensure this insertion depth was maintained and silicone sealant was used to seal the end of the steel tube. This prepared heat exchanger, seen in Figure 52, was then assembled into the cold flow section and the remainder of the cold flow separation plate was assembled downstream.

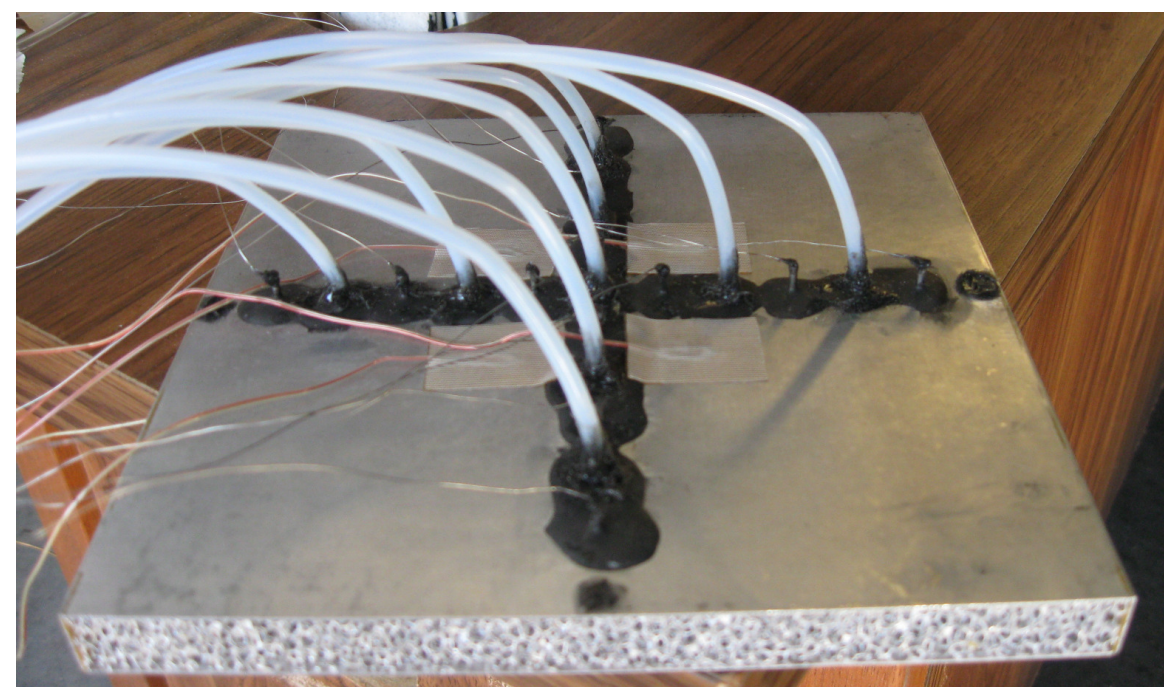

Figure 52 - 20 PPI heat exchanger prepared for testing.

The thermocouples were then connected to the Omega converters while the pressure tubes were connected to the Scanivalve. There were four sets of thermocouple data 
acquired per test point, as discussed above, so only eight of the required temperature and flow rate measurements were connected to the DAQ box at a time, as seen in Figure 53.

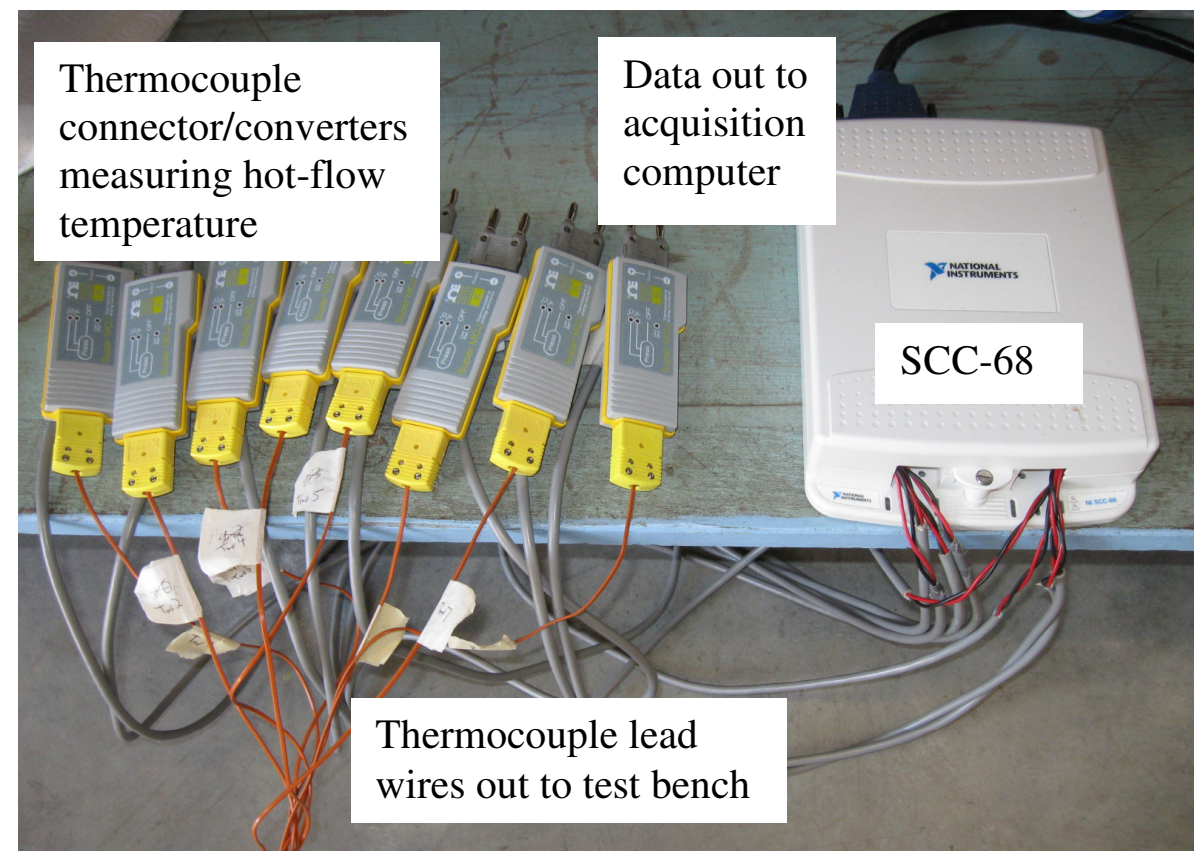

Figure 53 - DAQ box ready to measure flow temperature in the hot-flow direction.

The hot-flow inlet pressure tube from the hot-flow inlet duct was connected to a Tconnector that split to provide the inlet pressure to both the Scanivalve reference pressure port and another T-connector. The second T-connector provided connections to the first Scanivalve measurement port (port 33) and the incline manometer, used as a check to the Scanivalve data. With this setup, port 33 on the Scanivalve will measure the quantity $\left(\mathrm{p}_{\mathrm{mf}, \mathrm{in}}-\mathrm{p}_{\mathrm{mf}, \mathrm{in}}\right)$ which of course should be zero. This measurement was included as a check to ensure there was not a change in the Scanivalve ZOC33 module that would cause the calibrated zero readings to change during testing. The Scanivalve ZOC33 module and all connected pressure tubes can be seen in Figure 54. 


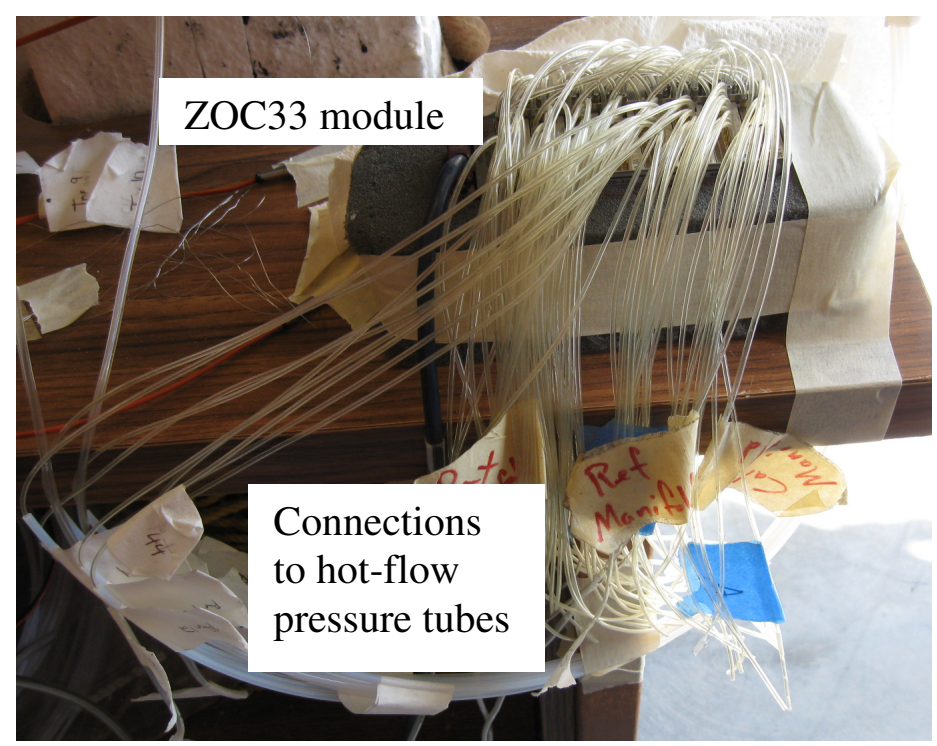

Figure 54 - Scanivalve ZOC33 module with hot-flow pressure tubes connected.

With a hot-flow rate of zero SCFM, a zero calibration was run on the Scanivalve to correct for ambient effects. Then the first flow rate was set to 4 SCFM (113 SLPM) and the variac was turned on to supply power to the heater. The goal inlet temperature for the metal foam was $160{ }^{\circ} \mathrm{F}(344 \mathrm{~K})$, which from trial and error resulted in a variac setting of $46 \%$ (55.2 Volts). While the hot-flow was heating up, the constant-fan velocity was set. This was done by first characterizing the constant and variable cold flow velocities as a function of input motor speeds from the Dayton Vector Inverters, which had been done prior to experimentation on the heat exchanger. This allowed for an estimation of the required input frequency to achieve the desired flow speed. To set the fan velocity for an experimental test run, the constant-fan Dwyer Pitot tube was connected to the incline manometer and the manometer reading was monitored while changing the input frequency.

Once the manometer deflection reached the desired value of 0.26 inches $\mathrm{H}_{2} \mathrm{O}$, indicating a flow speed of about $34 \mathrm{ft} / \mathrm{s}(10.4 \mathrm{~m} / \mathrm{s})$, the input frequency and manometer 
readings were recorded. For the first test run, the variable-fan was left off to test the $0 \%$ variable-fan setting. The inlet and outlet temperatures for both the hot and fan flows were then monitored to ensure steady state had been reached. Reaching steady state from ambient conditions to a hot-flow inlet temperature of $160^{\circ} \mathrm{F}(344 \mathrm{~K})$ took about 75 minutes.

Once steady state had been reached, the Dwyer Pitot probe was disconnected from the manometer and the hot-flow inlet pressure was connected to one end of the manometer while the other was left open to ambient. This reading of the hot-flow inlet gage pressure was recorded as a check to the Scanivalve inlet gage pressure reading. This was done for all hot-flow settings on the 20 PPI model. The 40 PPI model, however, caused a pressure drop larger than the manometer could display at 20 SCFM (566 SLPM) and so the manometer reading was not taken for this test point. The maximum difference between the manometer and Scanivalve readings of the hot-flow inlet pressure was $0.9 \%$ for the 40 PPI model at a hot-flow rate of 16 SCFM (453 SLPM). The average difference was $0.5 \%$.

With the hot-flow and both cold flows set and recorded and the system at steady state, data collection began. The Scanivalve was set to record 200 averages for 20 frames at a rate of 500 samples per second for all 12 pressure readings. As mentioned above, the Scanivalve measures differential pressure and the hot-flow inlet pressure was used as the reference pressure. This implies each reading was $\left(p_{x}-p_{m f, i n}\right)$, where $p_{x}$ is the pressure connected to the Scanivalve measurement port.

The pressure reading took just as long as the temperature and flow rate readings so it was started first. Then the eight thermocouples measuring the temperature along the hot- 
flow direction were connected to the Omega thermocouple-to-analog connector/converters which were in turn connected to the banana plug connectors on the DAQ box. All temperature and flow rate data was taken using Matlab for 60 seconds at 500 samples per second. The data was written to a daq file and recorded to memory to be plotted in Matlab to check the mean values and variation. A sample of the raw temperature data along the hot-flow direction for the 4 SCFM (113 SLPM) hot-flow, $100 \%$ variable-fan velocity test point can be seen in Figure 55.

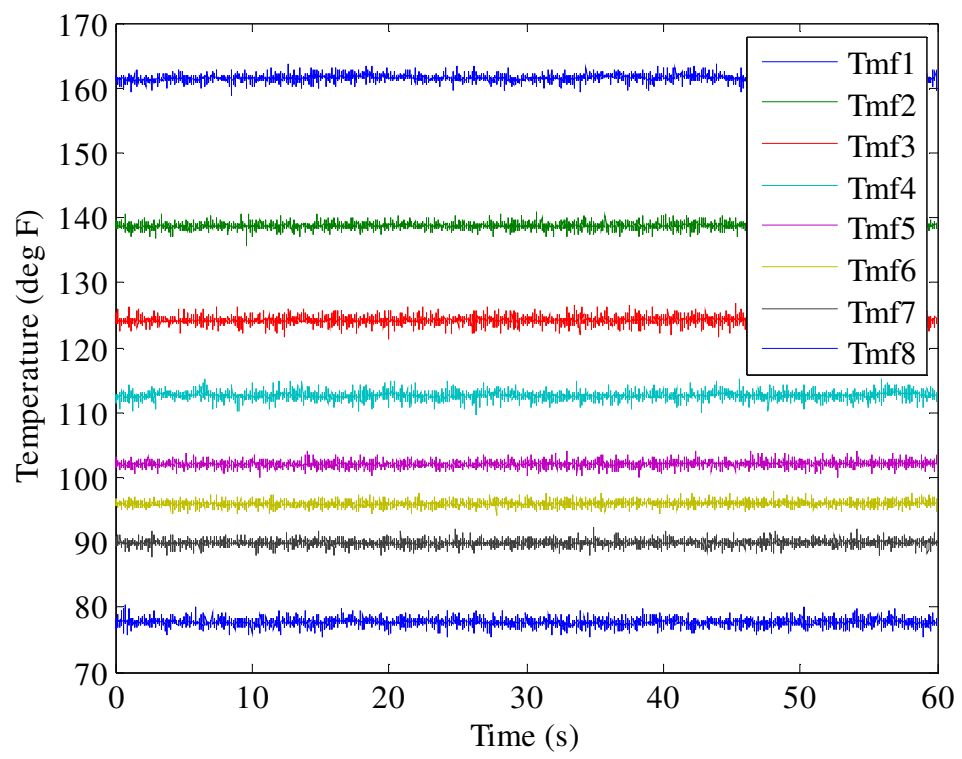

Figure 55 - Hot-flow temperature for $4 \mathrm{SCFM}, \mathrm{VF}=100 \% \mathrm{CF}$ velocity test case.

Once the temperatures along the hot-flow direction had been recorded, those eight thermocouples were disconnected from the connector/converters and the six thermocouples measuring the hot-flow temperature in the cold flow direction were connected to the first six channels of the DAQ box. The thermocouple connector/converters on the last two DAQ box channels were disconnected, the flow meter voltage output was connected, and Matlab was again used to record 60 seconds of data. Next those seven measurements were disconnected and the four cold flow inlet and 
outlet thermocouples were connected to the Omega connector/converters connected to the first four DAQ box channels and 60 seconds of data was recorded. Finally, the cold flow thermocouples were disconnected, the five surface thermocouples were connected, and data was recorded. This concluded the measurement for a single test point.

The next test point was at the same hot-flow rate but with the variable-fan flow speed set to $25 \%$ of the constant-fan flow speed. The hot-flow inlet pressure was disconnected from the manometer and the variable-fan Pitot tube was connected. The same procedure as for setting the constant-fan flow speed was then followed for setting the variable-fan flow speed. About 20 minutes was allowed before taking data to allow the system to reach steady state. With the system again at steady state and the variable-fan flow speed set and recorded, the same procedure as above was followed to record all temperature, pressure, and flow rate data. The variable-fan speed was then set to $50 \%, 75 \%$, and $100 \%$ of the constant-fan speed and all data was recorded.

That concluded all test points for the 4 SCFM (113 SLPM) hot flow rate. The same procedure was conducted for flow rates of 8, 12, 16, and $20 \operatorname{SCFM}(227,340,453,566$ SLPM). As seen in the results, these flow rates resulted in average hot-flow Reynolds numbers of $1,300,2,600,3,900,5,200$, and 6,400. The variac settings for those flow rates were $54 \%, 67 \%, 77 \%$, and $85 \%(64.8,80.4,92.4$, and 102 Volts), respectively. Once all data had been gathered, the heater power was turned off and the hot-flow and both fan flows remained on to help cool the system back to ambient temperature. The hot-flow remained on until the heater was cool to the touch to ensure it would not be damaged by an overheat condition. Then, the 20 PPI heat exchanger was removed from the test bench and the 40 PPI model was inserted. Once again, the same procedure was followed for the 
20 PPI and 40 PPI heat exchangers. The test matrix shown in Table 2 details all required temperature, $\mathrm{T}$, and pressure, $\mathrm{p}$, readings for the experiment.

Table 2 - Test matrix.

\begin{tabular}{|c|c|c|c|c|c|}
\hline \multirow{2}{*}{\begin{tabular}{|c|}
$\begin{array}{c}\text { Variable-fan Flow Speed } \\
\text { (as Percent Constant-fan } \\
\text { Flow Speed) }\end{array}$ \\
\end{tabular}} & \multirow{2}{*}{\begin{tabular}{|r|}
$\begin{array}{c}\text { Flow Rate } \\
\text { Through Metal } \\
\text { Foam (SCFM) }\end{array}$ \\
4 \\
\end{tabular}} & \multicolumn{2}{|c|}{$\begin{array}{l}20 \text { PPI Heat } \\
\text { Exchanger }\end{array}$} & \multicolumn{2}{|c|}{$\begin{array}{l}40 \text { PPI Heat } \\
\text { Exchanger }\end{array}$} \\
\hline & & $\mathrm{T}$ & $\mathrm{P}$ & $\mathrm{T}$ & $p$ \\
\hline \multirow{4}{*}{$0 \%$} & 8 & $\mathrm{~T}$ & $\mathrm{P}$ & $\mathrm{T}$ & $\mathrm{p}$ \\
\hline & 12 & $\mathrm{~T}$ & $\mathrm{P}$ & $\mathrm{T}$ & $\mathrm{p}$ \\
\hline & 16 & $\mathrm{~T}$ & $\mathrm{P}$ & $\mathrm{T}$ & $\mathrm{p}$ \\
\hline & 20 & $\mathrm{~T}$ & $\mathrm{p}$ & $\mathrm{T}$ & $\mathrm{p}$ \\
\hline \multirow{5}{*}{$25 \%$} & 4 & $\mathrm{~T}$ & $\mathrm{p}$ & $\mathrm{T}$ & $\mathrm{p}$ \\
\hline & 8 & $\mathrm{~T}$ & $\mathrm{p}$ & $\mathrm{T}$ & $\mathrm{p}$ \\
\hline & 12 & $\mathrm{~T}$ & $\mathrm{p}$ & $\mathrm{T}$ & $\mathrm{p}$ \\
\hline & 16 & $\mathrm{~T}$ & $\mathrm{p}$ & $\mathrm{T}$ & $\mathrm{p}$ \\
\hline & 20 & $\mathrm{~T}$ & $\mathrm{p}$ & $\mathrm{T}$ & $\mathrm{p}$ \\
\hline \multirow{5}{*}{$50 \%$} & 4 & $\mathrm{~T}$ & $\mathrm{p}$ & $\mathrm{T}$ & $p$ \\
\hline & 8 & $\mathrm{~T}$ & $\mathrm{p}$ & $\mathrm{T}$ & $\mathrm{p}$ \\
\hline & 12 & $\mathrm{~T}$ & $\mathrm{p}$ & $\mathrm{T}$ & $\mathrm{p}$ \\
\hline & 16 & $\mathrm{~T}$ & $\mathrm{p}$ & $\mathrm{T}$ & $\mathrm{p}$ \\
\hline & 20 & $\mathrm{~T}$ & $\mathrm{p}$ & $\mathrm{T}$ & $\mathrm{p}$ \\
\hline \multirow{5}{*}{$75 \%$} & 4 & $\mathrm{~T}$ & $p$ & $\mathrm{~T}$ & $p$ \\
\hline & 8 & $\mathrm{~T}$ & $\mathrm{p}$ & $\mathrm{T}$ & $\mathrm{p}$ \\
\hline & 12 & $\mathrm{~T}$ & $\mathrm{p}$ & $\mathrm{T}$ & $\mathrm{p}$ \\
\hline & 16 & $\mathrm{~T}$ & $\mathrm{p}$ & $\mathrm{T}$ & $\mathrm{p}$ \\
\hline & 20 & $\mathrm{~T}$ & $\mathrm{p}$ & $\mathrm{T}$ & $\mathrm{p}$ \\
\hline \multirow{5}{*}{$100 \%$} & 4 & $\mathrm{~T}$ & $\mathrm{p}$ & $\mathrm{T}$ & $\mathrm{p}$ \\
\hline & 8 & $\mathrm{~T}$ & $\mathrm{p}$ & $\mathrm{T}$ & $\mathrm{p}$ \\
\hline & 12 & $\mathrm{~T}$ & $\mathrm{p}$ & $\mathrm{T}$ & $\mathrm{p}$ \\
\hline & 16 & $\mathrm{~T}$ & $\mathrm{p}$ & $\mathrm{T}$ & $\mathrm{p}$ \\
\hline & 20 & $\mathrm{~T}$ & $\mathrm{p}$ & $\mathrm{T}$ & $\mathrm{p}$ \\
\hline
\end{tabular}




\section{ANALYSIS}

With experimental data to analyze, the following approach was taken to examine the heat exchanger performance. To start, the standardized volumetric flow rate was recorded in SCFM, so to convert this to actual CFM (ACFM), the following relation was used

$$
Q=A C F M=S C F M\left(\frac{p_{s t d}}{p}\right)\left(\frac{T}{T_{s t d}}\right)
$$

where $\mathrm{p}_{\text {std }}$ is the standard pressure, $14.696 \mathrm{psia}\left(101.330 \mathrm{kPa}\right.$ absolute), $\mathrm{T}_{\text {std }}$ is the standard temperature, $527.67^{\circ} \mathrm{R}(293.15 \mathrm{~K})$, and the correction for relative humidity is assumed to be negligible.

From this actual volumetric flow rate, the mean flow velocity can be calculated from

$$
U=\frac{Q}{A}
$$

where $\mathrm{Q}$ is the actual volumetric flow rate and $\mathrm{A}$ is the cross-sectional area. From this, the mass flow rate can be found from

$$
\dot{m}=\rho Q
$$

where $\rho$ is the fluid density.

Next, the hydraulic diameter was calculated from

$$
D_{h}=\frac{4 A}{P}
$$


where $\mathrm{P}$ is the wetted perimeter of the duct for which the hydraulic diameter is being calculated. From this, the hydraulic-diameter-based Reynolds Number can be calculated as

$$
\operatorname{Re}_{D_{h}}=\frac{\rho U D_{h}}{\mu}
$$

where $\mu$ is the fluid dynamic viscosity.

To calculate the cold flow velocity, a Pitot probe was used to measure the difference between the freestream and total pressures at the center of the cold flow duct. The resulting manometer deflection can be used to calculate the flow velocity as

$$
V_{c}=\sqrt{\frac{2}{\rho} \gamma_{H_{2} O} \Delta h}
$$

where $\gamma_{\mathrm{H}_{2} \mathrm{O}}$ is the specific weight of water $\left(62.4 \mathrm{lbf} / \mathrm{ft}^{3}\right)$, since the manometer fluid has a specific gravity of 1.0 , and $\Delta h$ is the manometer deflection.

The Fanning friction factor, $f$, can be calculated using

$$
f=\frac{\Delta p}{4\left(\frac{L}{H}\right)\left(\frac{1}{2} \rho U^{2}\right)}
$$

where $\Delta p$ is the pressure drop across the metal foam, $\mathrm{L}$ is the length of the metal foam, and $\mathrm{H}$ is the height of the metal foam duct.

Next, a curve fit of the length-normalized pressure drop data was created from the governing equation for pressure drop of a fluid passing through a porous media, the Dupuit-Darcy Law 


$$
\frac{\Delta p}{L}=\rho C U^{2}+\frac{\mu}{K} U
$$

and the permeability, $\mathrm{K}$, and form factor, $\mathrm{C}$, were determined.

To evaluate the effectiveness of the heat exchanger's forced convection, the Nusselt number was calculated. The Nusselt number is the ratio of convective heat transfer to conductive heat transfer and is defined as

$$
N u=\frac{h L}{k_{f}}=\frac{q}{A_{c o n} \Delta T} \frac{D_{h}}{k_{f}}
$$

where $\mathrm{h}$ is the convective heat transfer coefficient, $\mathrm{L}$ is the heat transfer characteristic length (here, the hydraulic diameter), $k_{f}$ is the thermal conductivity of the fluid, $\mathrm{q}$ is the heat transfer rate, $\mathrm{A}_{\mathrm{con}}$ is the convective heat transfer surface area, and $\Delta T$ is the temperature difference driving the heat transfer.

Since there are two distinct stages at which conductive heat transfer occurs, namely inside the metal foam and outside in the cold flow ducts, the Nusselt number must be split up. This leads to a distinct Nusselt number for the internal hot-flow and the external cold-flow. The driving temperature difference for the internal flow is

$$
\Delta T_{\text {int }}=T_{m f, a v g}-T_{s, a v g}
$$

where $T_{m f}$ avg is the average hot-flow temperature and $T_{s}$, avg is the average surface temperature on the internal surfaces of the metal foam. Since the aluminum sheet metal casing around the metal foam is only 0.02 inches $(0.51 \mathrm{~mm})$ thick, the internal and external surface temperatures are assumed to be the same. The driving temperature difference for the external convection is 


$$
\Delta T_{e x t}=T_{s, a v g}-T_{c, i n}
$$

where $T_{c, i n}$ is the average cold flow inlet temperature.

While the convection must be separated between internal and external, the actual heat transfer can be quantified with the internal metal foam flow temperature. With the assumption of a perfect gas, the heat transfer rate can be calculated from

$$
q=\dot{m} C_{p}\left(T_{m f, i n}-T_{m f, \text { out }}\right)
$$

where $\mathrm{C}_{\mathrm{p}}$ is the specific heat of the hot air at constant pressure, $T_{m f, \text { in }}$ is the hot-flow inlet temperature, and $T_{m f, \text { out }}$ is the hot-flow outlet temperature.

Substituting Equations 19 and 21 into Equation 18 yields the internal Nusselt number

$$
N u_{i n t}=\frac{\dot{m} C_{p}\left(T_{m f, \text { in }}-T_{m f, \text { out }}\right)}{A_{\text {con }}\left(T_{m f, \text { avg }}-T_{s, \text { avg }}\right)} \frac{D_{h}}{k_{f}}
$$

and then substituting Equations 20 and 21 into Equation 18 yields the external Nusselt number

$$
N u_{e x t}=\frac{\dot{m} C_{p}\left(T_{m f, \text { in }}-T_{m f, \text { out }}\right)}{A_{\text {con }}\left(T_{s, a v g}-T_{c, \text { in }}\right)} \frac{D_{h}}{k_{f}}
$$

Another dimensionless heat exchanger parameter is the Colburn $\mathrm{j}$ factor, defined for the internal flow as

$$
j=\frac{h_{i n t}}{\rho U C_{p}}\left(\frac{C_{p} \mu}{k_{f}}\right)^{2 / 3}
$$


The Colburn $\mathrm{j}$ factor gives a measure of the convective heat transfer performance as compared to the flow rate required for the heat exchanger. ${ }^{14}$

The pumping power required to overcome the pressure drop across the metal foam can be found from

$$
\dot{W}=\Delta p Q
$$

Finally, the internal thermal resistance of the heat exchanger is defined as

$$
R_{t h}=\frac{\Delta T_{i n t}}{q}=\frac{T_{m f, \text { avg }}-T_{s, \text { avg }}}{\dot{m} C_{p}\left(T_{m f, \text { in }}-T_{m f, \text { out }}\right)}
$$

The pumping power and thermal resistance are both good overall indicators of heat exchanger performance. Minimizing both pumping power and thermal resistance, with respect to the required heat exchanger constraints, will provide the optimum heat exchanger design. 


\section{RESULTS AND DISCUSSION}

All of the Matlab .daq and Scanivalve .dat files were distilled from raw data into mean values and put into Microsoft Excel. Each test point was an average of 30,000 samples for the temperature and flow rate measurements and 4,000 samples for the pressure readings.

\subsection{Metal Foam Cross-flow Variation}

The temperature and pressure in the metal foam cross-flow direction (perpendicular to the hot-flow direction and parallel to the cold flow direction) were checked to ensure the variation within the metal foam was as expected. Three representative cases were checked for both heat exchangers: a hot-flow rate of 4 SCFM (113 standard liters per minute, or SLPM) with a variable-fan speed of $0 \%$ the constant-fan speed, 12 SCFM (340 SLPM) with a variable-fan speed of 50\% the constant-fan speed, and 20 SCFM (566 SLPM) with a variable-fan speed of $100 \%$ the constant-fan speed. The pressure variation in the cross-flow direction was expected to be nearly constant, indicating twodimensional flow (except within the side-wall boundary layer) through the metal foam. This was verified for both heat exchangers, as seen in Figure 56 and Figure 57. Note in the legend of Figure 56, the variable-fan flow speed is indicated by "VF $=0 \% \mathrm{CF}$." This notation is shorthand for "variable-fan flow speed equal to $0 \%$ of the constant-fan flow speed." The constant-fan flow speed was nominally $34 \mathrm{ft} / \mathrm{s}(10 \mathrm{~m} / \mathrm{s})$. This convention will be used throughout the report. 


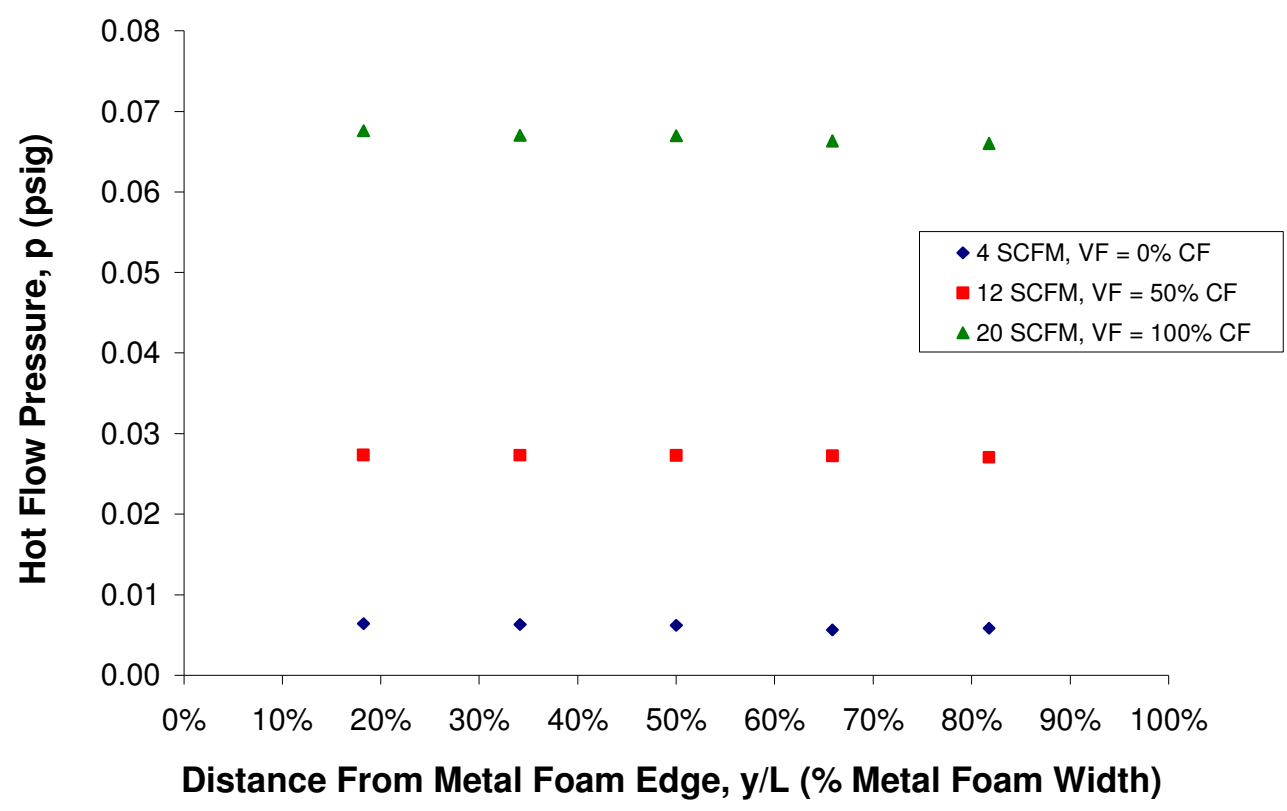

Figure 56 - Pressure check for 2-D flow (20 PPI model).

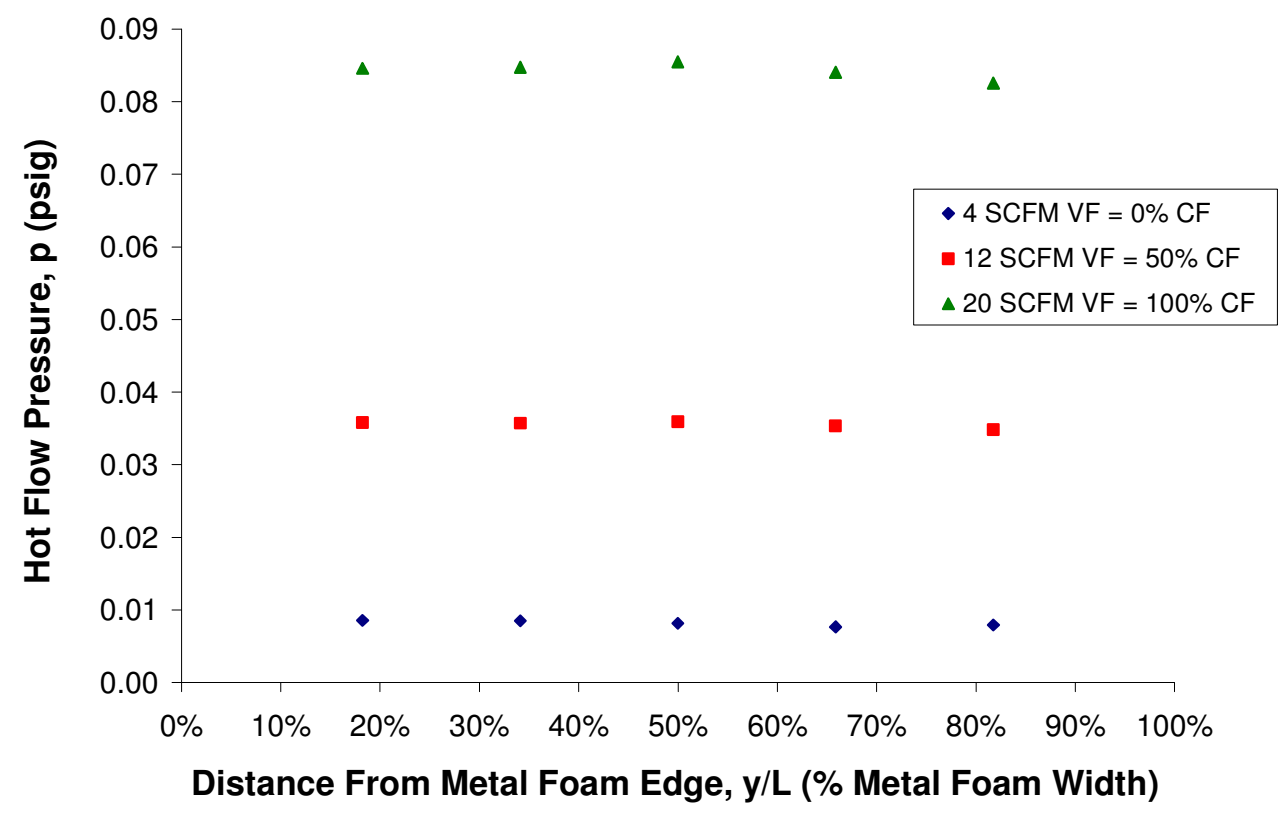

Figure 57 - Pressure check for 2-D flow (40 PPI model).

Unlike the pressure, the temperature was expected to vary in the cross-flow direction. A three-dimensional temperature distribution is expected because the cooling flows on the outside of the heat exchanger are traveling perpendicular to the hot-flow direction. 
Figure 58 and Figure 59 show the temperature distribution in this cross-flow direction for both the 20 PPI and 40 PPI models, respectively. As expected, the temperature does vary in the cross-flow direction, although not to a large extent. For both Figure 58 and Figure $59,0 \%$ is the metal foam location at which the cold flow convection from the heat exchanger surface starts and $100 \%$ is the point at which the cold flow convection ends.

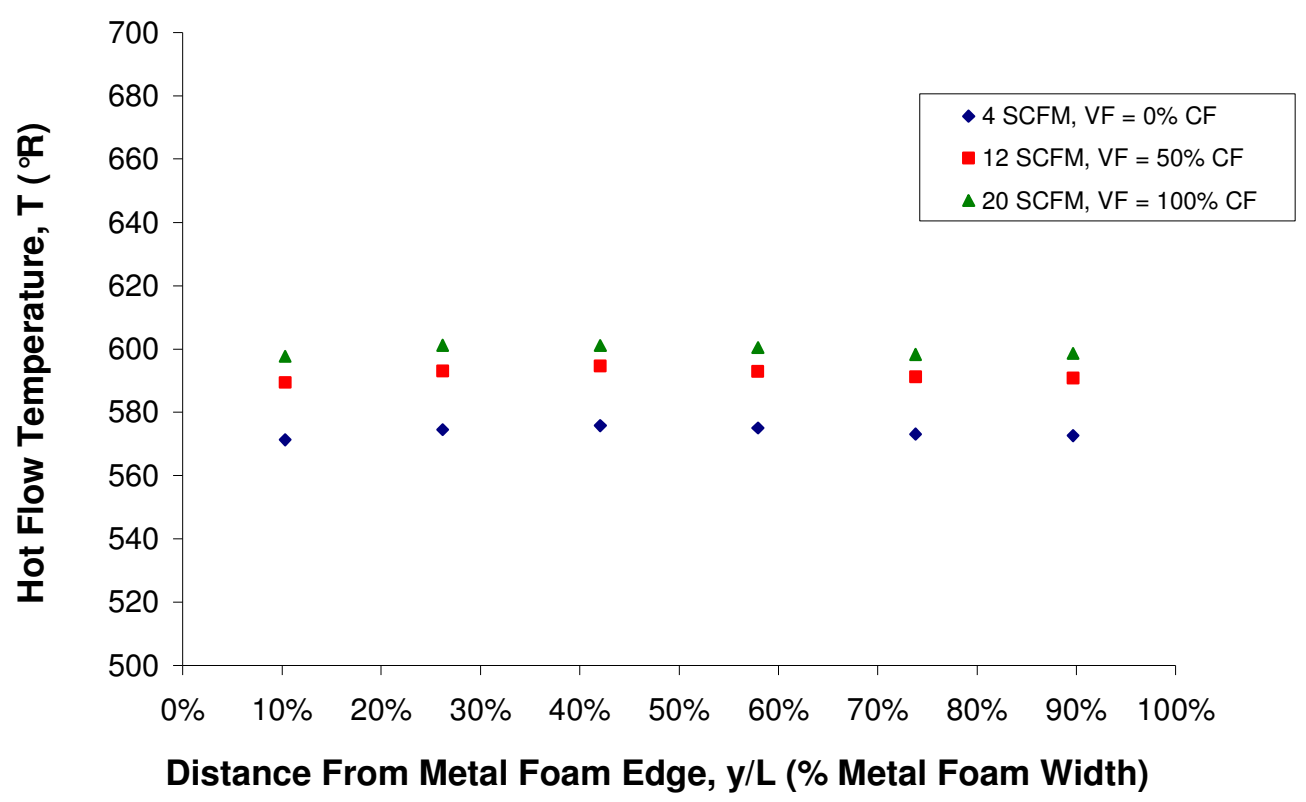

Figure 58 - Temperature check for 2-D flow (20 PPI model). 


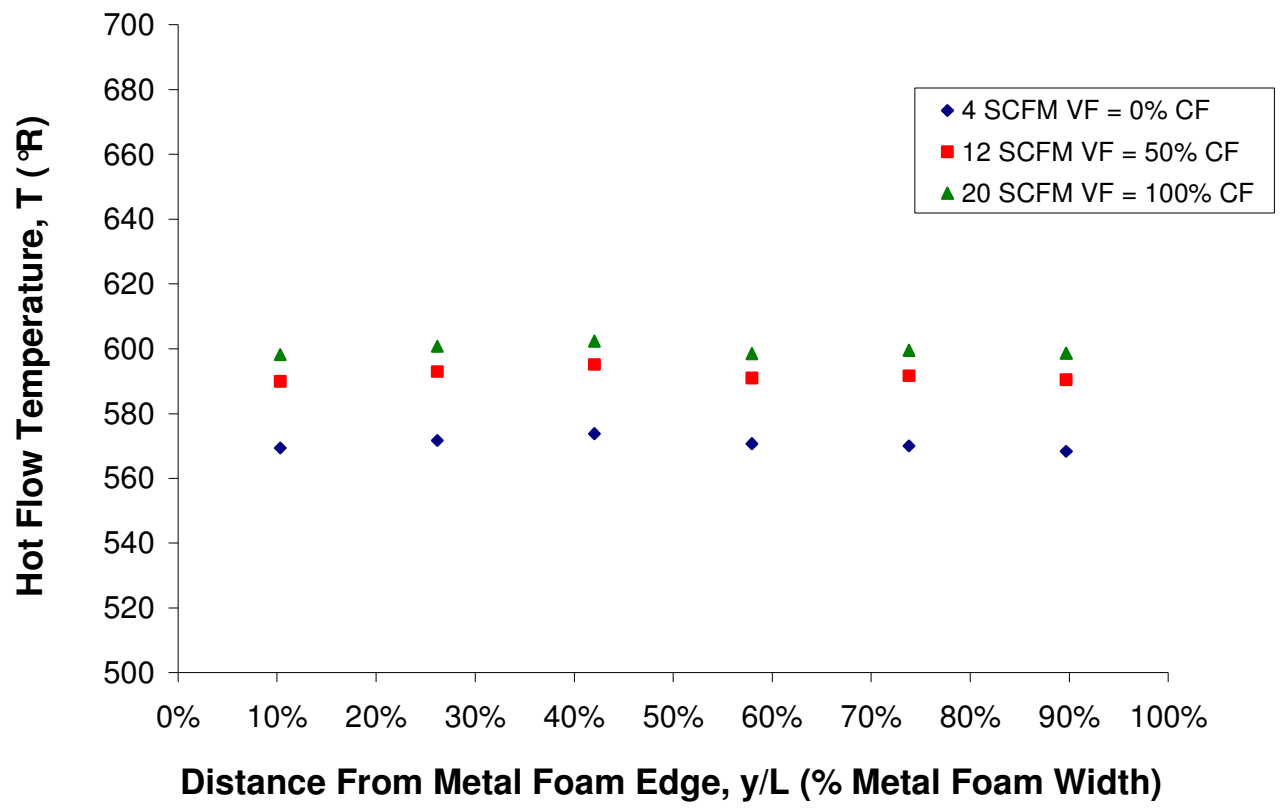

Figure 59 - Temperature check for 2-D flow (40 PPI model).

\subsection{Flow Properties at Metal Foam Inlet and Outlet}

Since the metal foam heat exchanger was placed within the cold flow streams, it was necessary to assemble the heat exchanger into the test section. To assemble it correctly, with an adequate seal, there were multiple flanges on both the inlet and outlet of the metal foam. This made it impossible to directly measure flow properties at the true inlet and outlet to the metal foam. The closest temperature measurement within the metal foam was 0.65 inches $(1.65 \mathrm{~cm})$ and the closest pressure measurement within the metal foam was 1.15 inches $(2.92 \mathrm{~cm})$ away from the inlet and outlet. There were also temperature and pressure measurements taken 1 inch $(2.54 \mathrm{~cm})$ outside the metal foam. Using these experimental test points, a curve fit was created for both the temperature and pressure data so values for the actual metal foam inlet and outlet could be determined.

The raw pressure data, seen in Figure 60 for the 20 PPI, 12 SCFM (566 SLPM) test case, was used to create a linear curve fit. In actuality, the pressures measured within the 
metal foam were used to create the curve while the pressures measured outside the metal foam were used as a check to ensure the curve fit gave reasonable values for the inlet and outlet pressures.

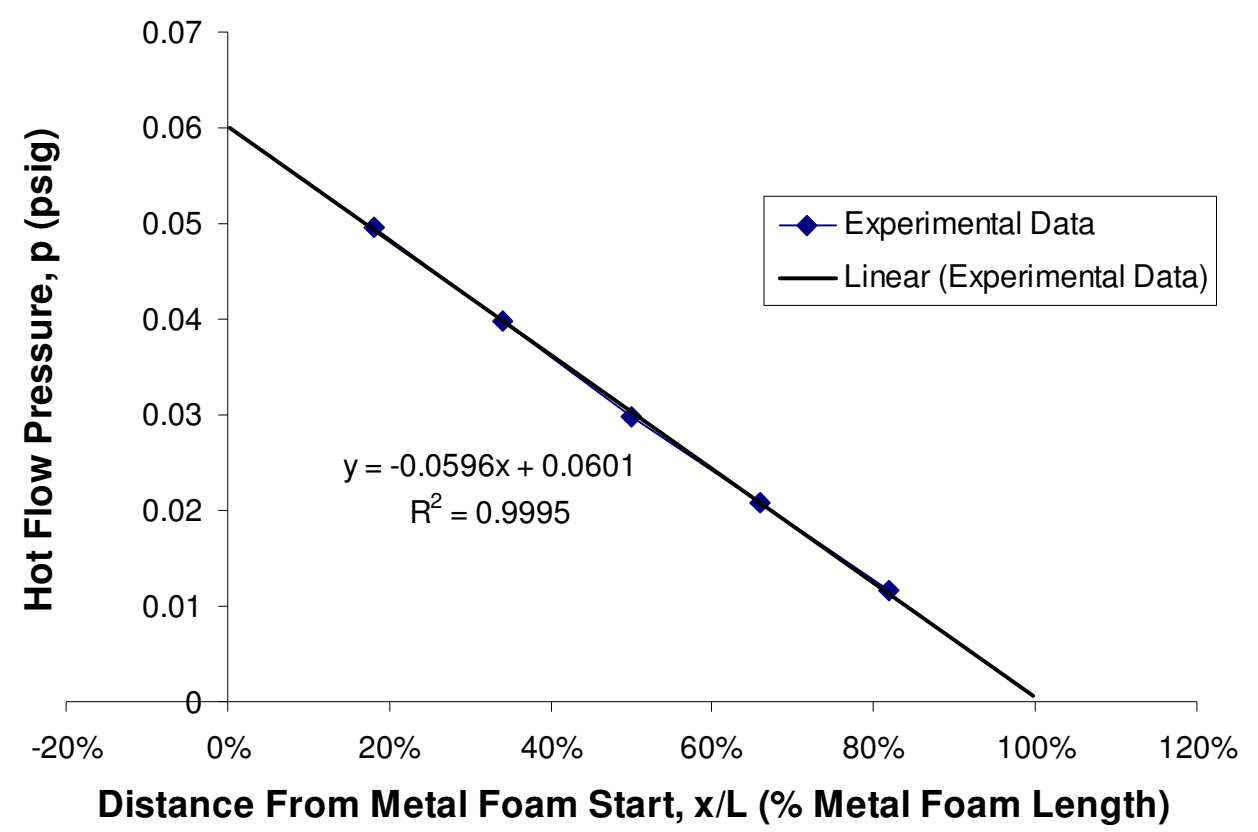

Figure 60 - Example of inlet and outlet pressure determination.

With this method, the data shows a small pressure drop between the measurement ports one inch $(2.54 \mathrm{~cm})$ outside the metal foam and the metal foam inlet and outlet, as expected. In addition, the pressures within the metal foam follow a linear trend very closely ( $\mathrm{R}^{2}$ of 0.9995 in this case). This linear pressure drop is expected due to the constant flow velocity passing through the homogeneous metal foam. This trend can also be seen in Equation 17, where the pressure drop per unit length is only a function of the flow velocity. From this linear curve fit equation, the flow pressure at the inlet and outlet of the metal foam were obtained with extrapolation and used to determine the overall pressure drop. 
A similar process was completed for the temperature data. Just like the pressure data, the temperatures measured within the metal foam were used to fit a curve and determine the temperatures at the inlet and outlet. After examining the hot-flow temperatures, a linear curve fit was chosen, as seen in Figure 61 for the 20 PPI, 12 SCFM (340 SLPM), $\mathrm{VF}=50 \% \mathrm{CF}$ test case. The linear curve fits the data well, as evidenced by an $\mathrm{R}^{2}$ value of 0.996 .

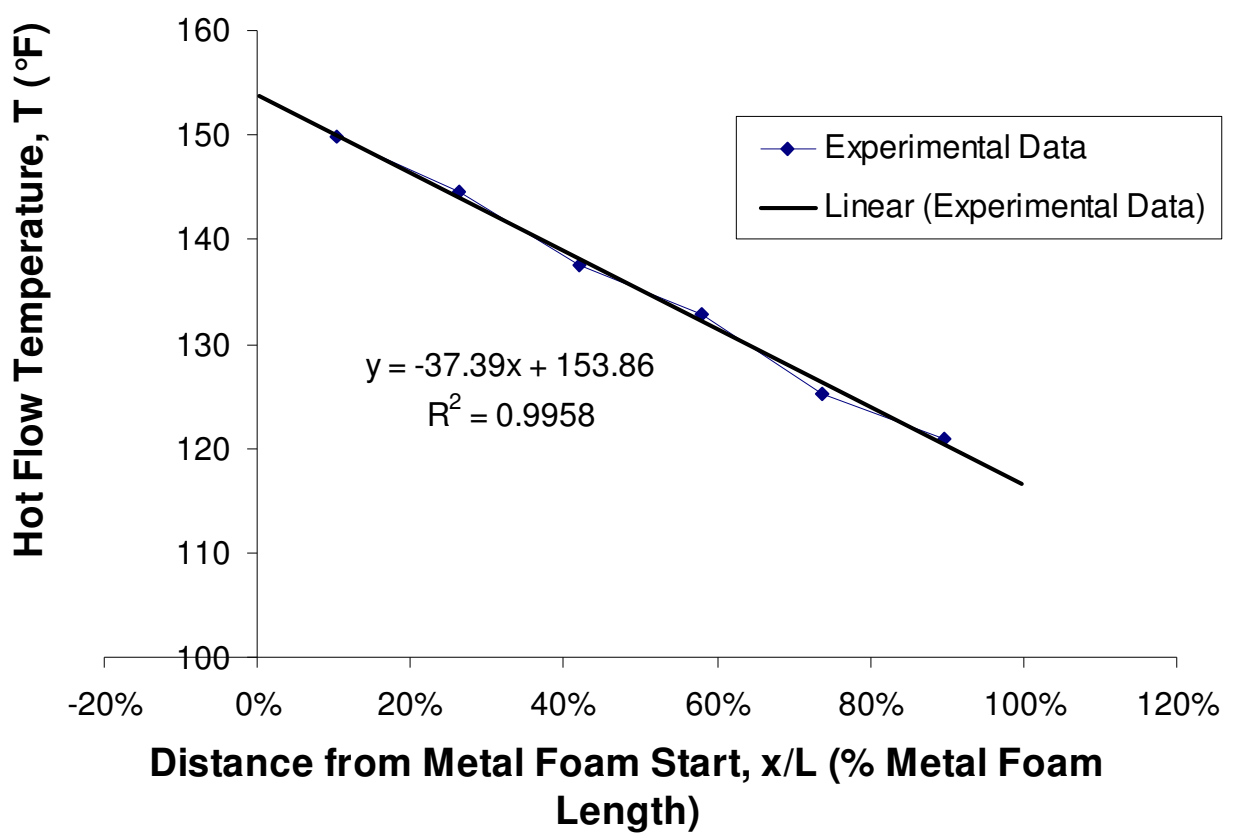

Figure 61 - Example of inlet and outlet temperature determination.

\subsection{Pressure Drop}

The pressure drop across the heat exchanger is an important parameter for sizing the thermal management system in which the heat exchanger will play a part. Recalling the simple system design detailed earlier, the amount of work input required from the motor driven compressor is directly related to the pressure drop across the metal foam heat exchanger. The smaller the pressure drop, the less work input and hopefully smaller this 
compressor can be. In aerospace applications especially, smaller, lighter components allow for a more efficient, better performing vehicle. However, this pressure drop must be balanced with heat transfer performance, which will be discussed later.

The length normalized pressure drop was calculated using the pressure drop across the metal foam, determined using the curve fit detailed above, and the heat exchanger length. This pressure drop can be seen in Figure 62 for the 20 and 40 PPI heat exchangers, both of which were 6.3 inches $(16 \mathrm{~cm})$ long.

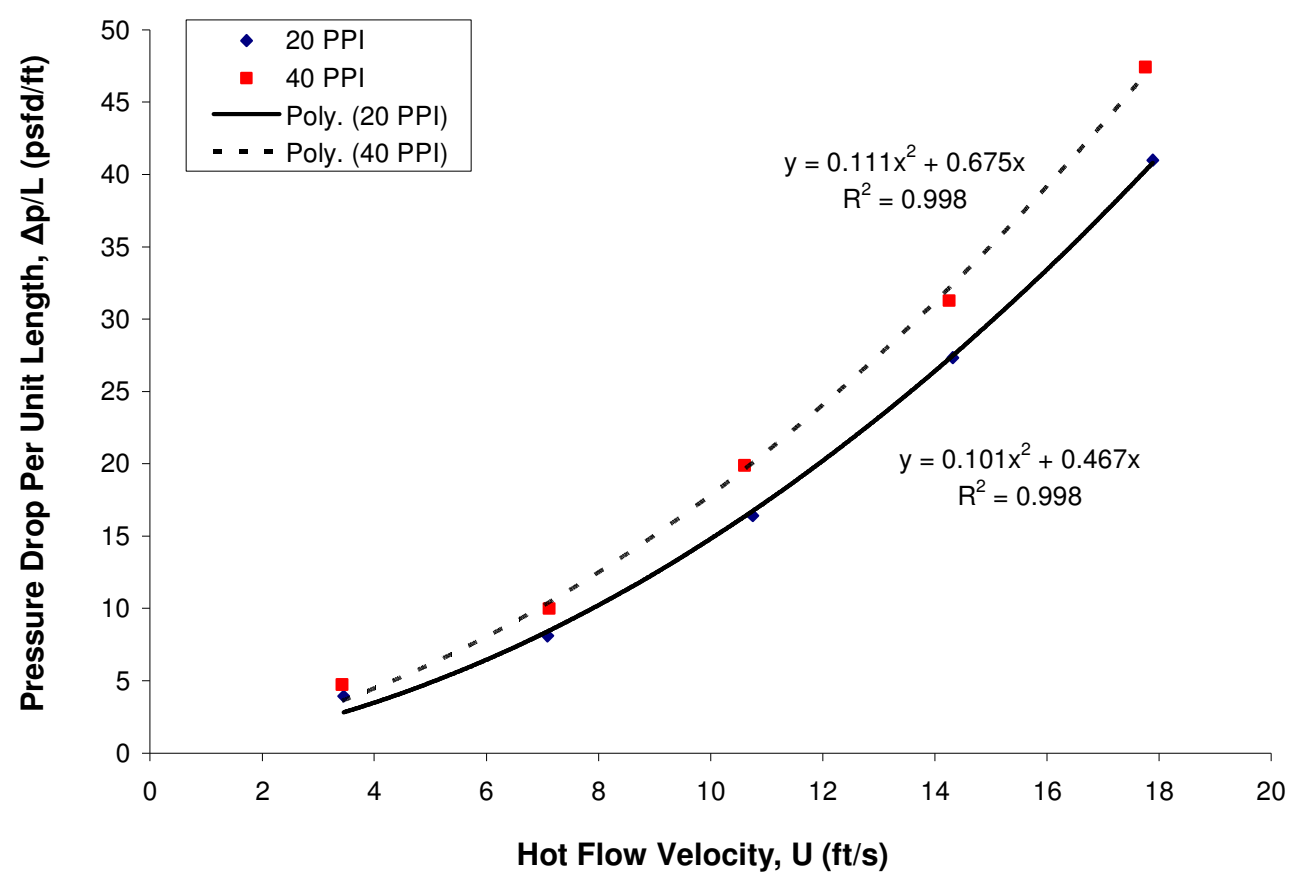

Figure 62 - Pressure drop per unit length for both 20 and 40 PPI models.

As can be seen, both heat exchangers show a parabolic trend for this length normalized pressure drop, which increases with increasing hot-flow velocity. This parabolic trend is predicted by Equation 17, the governing equation for pressure drop of a fluid passing through a porous media (metal foam). As expected, the 40 PPI heat exchanger has a larger pressure drop than the 20 PPI heat exchanger. This follows the 
trend of the metal foam model used earlier, as was seen in Figure 8. It also makes physical sense because the 40 PPI heat exchanger has more ligament surface area than the 20 PPI model. Also of note is that as the velocity increases, so does the difference in pressure drop between the 40 and 20 PPI models.

A parabolic curve fit for the length normalized pressure drop was created for each of the heat exchangers, as seen in Figure 62. These curve fits were then compared to the Dupuit-Darcy Law, Equation 17, to determine the permeability, K, and form factor, C, for each model. Table 3 summarizes the results.

Table 3 - Permeability and form factor results.

\begin{tabular}{|r|c|r|r|}
\hline Metal Foam PPI & Curve Fit Equation & Permeability, $\mathrm{K}\left(\mathrm{ft}^{2}\right)$ & Form Factor, $\mathrm{C}\left(\mathrm{ft}^{-1}\right)$ \\
\hline Theory & $\frac{\Delta p}{L}=\rho C U^{2}+\frac{\mu}{K} U$ & - & - \\
\hline 20 & $\mathrm{y}=0.101 \mathrm{x}^{2}+0.467 \mathrm{x}$ & $9.11 \mathrm{E}-07$ & 50.4 \\
\hline 40 & $\mathrm{y}=0.111 \mathrm{x}^{2}+0.675 \mathrm{x}$ & $6.32 \mathrm{E}-07$ & 54.8 \\
\hline
\end{tabular}

From these results, it can be seen that the 40 PPI model has a larger form factor and smaller permeability than the 20 PPI model, which is to be expected from the pressure drop results. Recalling Equation 17, the pressure drop is proportional to the form factor and inversely proportional to the permeability. So the 40 PPI model, with the larger pressure drop, is expected to have a smaller permeability and larger form factor than the 20 PPI model, as it does. The larger form factor is due to the increase in exposed ligament surface area of the 40 PPI model, which leads to larger drag. While both heat exchangers utilize the same metal foam porosity, the increased flow resistance of the 40 PPI model causes it to have the smaller permeability. These permeability and form factor trends agree with both Sheridan ${ }^{11}$ and Boomsma and Poulikakos. ${ }^{15}$ 
Another important pressure drop term is the Fanning friction factor. The Fanning friction factor provides a non-dimensional look at the fluid resistance caused by the metal foam. The Fanning friction factor can be seen plotted against the hot-flow Reynolds number in Figure 63. Recall the hot-flow Reynolds number is based on the hydraulic diameter of the metal foam duct and the fluid properties at the inlet to the heat exchanger.

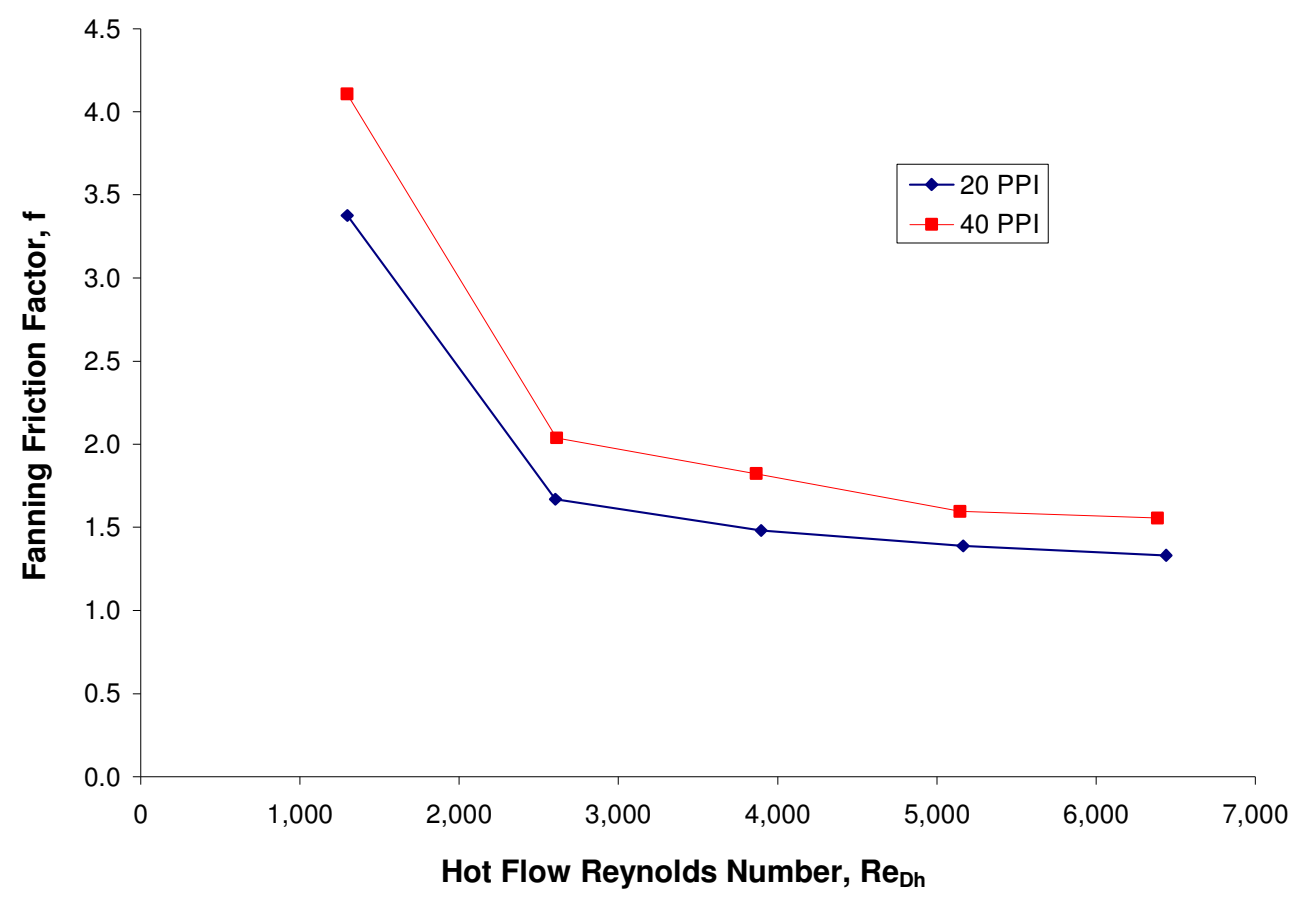

Figure 63 - Fanning friction factor for both 20 and 40 PPI models.

As seen in the figure, the Fanning friction factor initially drops steeply and then begins to slowly decrease and possibly reach a relatively constant value for both heat exchangers. This relatively constant value is a result of the length normalized pressure drop being dominated by the form factor term seen in Equation 17. Since the Fanning friction factor is inversely proportional to the velocity squared, as seen in Equation 16, this gives rise to a relatively constant value. This trend also agrees with results from Boomsma et. al. ${ }^{14}$ Since the Fanning friction factor is directly related to the pressure 
drop, the larger friction factors found for the 40 PPI model are expected due to its larger pressure drop. The 40 PPI model has, on average, a 16\% greater Fanning friction factor than the 20 PPI model.

\subsection{Heat Transfer Performance}

To analyze the heat transfer performance of the heat exchangers, the first step was to examine the hot-flow temperature distribution within the metal foam. As seen earlier, this distribution was roughly linear with the hot-flow temperature decreasing as it flowed through the metal foam. Both the 20 and 40 PPI models exhibited this reasonable temperature data; however, when comparing the two, a problem arose with the 40 PPI heat transfer.

\subsection{1. $\quad$ Forty PPI Heat Exchanger Anomaly}

From the metal foam model and previous test data, it was expected the 40 PPI heat exchanger would have better thermal characteristics than the 20 PPI heat exchanger. This is expected because the 40 PPI model has a larger ligament surface area which should increase the convective heat transfer from the hot-flow to the metal foam ligaments. Previous experiments, such as those by Salas and Waas ${ }^{6}$ as well as Calmidi and Mahajan, ${ }^{16}$ have shown this trend, albeit for a slightly different configuration. For these past experiments, the flow of heat was from the external surface of the heat exchanger, through the metal foam ligaments, and then to a cooling flow within the metal foam. A constant heat flux was applied to the outer surface of these heat exchangers, whereas in the present study two cooling flows are used to cool the heat exchanger surfaces which are heated by the internal hot-flow. Despite these differences, the 40 PPI heat exchanger 
was still expected to exhibit increased thermal performance as compared to the 20 PPI heat exchanger. In short, the 40 PPI heat exchanger is expected to provide a smaller outlet temperature than the 20 PPI heat exchanger, all other things being equal.

While non-dimensional heat transfer coefficients, such as the Nusselt number, show the unexpected trend of the 40 PPI model, the raw temperature data can lead to the root of the problem. Figure 64 shows the bulk temperatures of the hot-flows for both 20 and 40 PPI models for the 20 SCFM, VF $=100 \% \mathrm{CF}$ velocity test case. Note that for this test case, both the variable and constant-fan flows are expected to have similar heat transfer rates because they have the same flow velocities and similar temperatures. For given hotflow inlet and cold-flow properties, one would expect the 40 PPI model outlet temperature to be less than the 20 PPI model's. This would indicate the increased ligament surface area of the 40 PPI model does in fact increase the heat transfer from the hot-flow to the metal foam ligaments and therefore provides a lower outlet temperature. However, as Figure 64 clearly shows, the 20 and 40 PPI heat exchangers have nearly identical hot-flow bulk temperatures. These similar temperature trends lead to comparable inlet and outlet temperatures, which from Equation 21, lead to comparable heat loss from the hot-flow. 


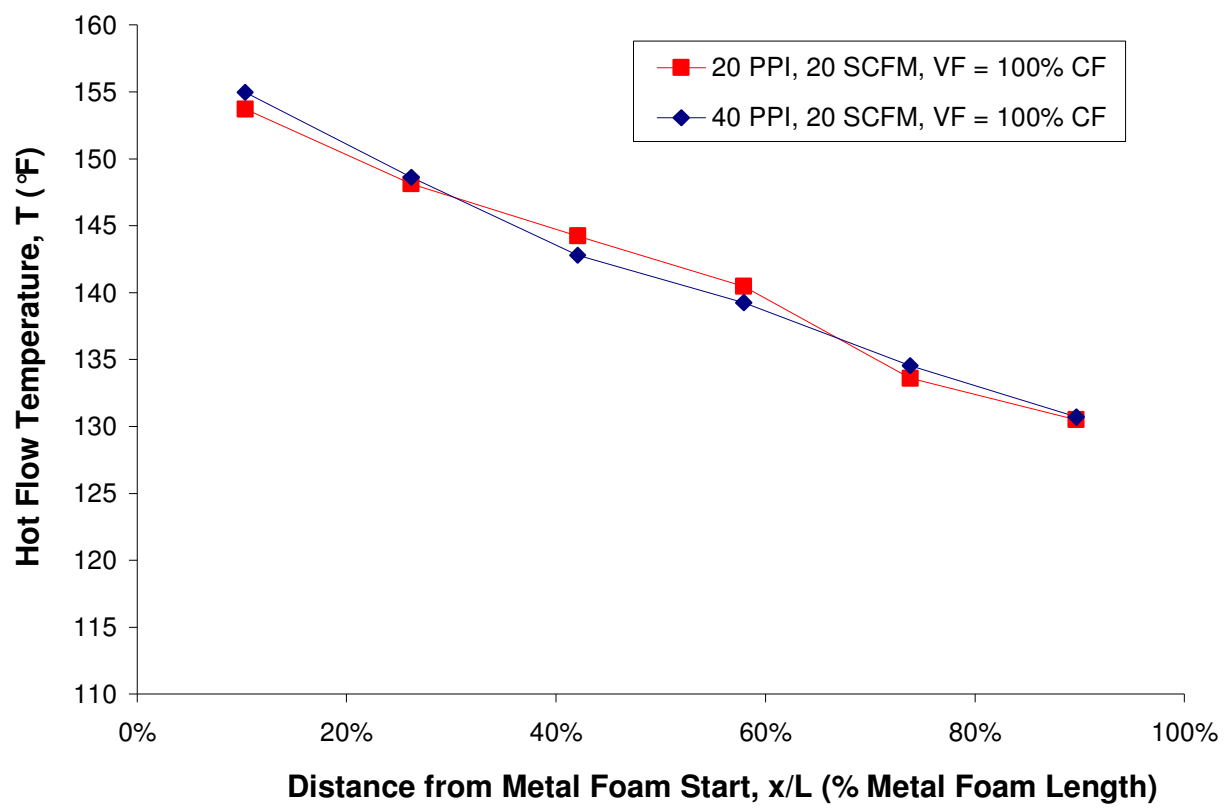

Figure 64 - Flow temperatures within metal foam for 20 SCFM, VF $=100 \%$ CF test case.

Because this trend went against what was expected of the different PPI heat exchangers, extensive testing was conducted to ensure this trend was not a result of measurement error. An independent check of representative thermocouples for the 20 and 40 PPI models was conducted using an ice bath and heated water. A thermometer with an LSR of $0.5^{\circ} \mathrm{F}$ was used as a check to the thermocouple measurements, which were conducted using the same equipment as during the test to see if possibly the DAQ setup was causing errors. When checking the thermocouples in an ice bath, the maximum difference between the thermometer reading and any thermocouple reading was $0.6^{\circ} \mathrm{F}$. When checking in heated water, the maximum difference was $0.7^{\circ} \mathrm{F}$. This verified the measured hot-flow temperatures for both heat exchangers were in fact valid.

In addition to the measured bulk flow temperatures, the measured surface temperatures showed the 40 PPI model to have equal or diminished heat transfer properties as the 20 PPI model. For the $100 \%$ variable-fan velocity test case seen in 
Figure 64, the constant and variable cold flows are expected to have close heat transfer characteristics. Because the cooling flow is simple convection, the heat transfer on one side of the heat exchanger is estimated by

$$
q_{\text {cold }}=A_{c o n} h\left(T_{s, a v g}-T_{c, \text { in }}\right)
$$

where $\mathrm{A}_{\text {con }}$ is the convective surface area, $\mathrm{h}$ is the convective heat transfer coefficient, $\mathrm{T}_{\mathrm{s}, \text { avg }}$ is the average surface temperature on the external surface of the heat exchanger, and $\mathrm{T}_{\mathrm{c}, \text { in }}$ is the cold flow inlet temperature.

Neglecting heat loss, the internal heat transfer given by Equation 21 is equal to the sum of the two cooling flow heat transfers, given individually by Equation 27 . The convective surface area, $\mathrm{A}_{\mathrm{con}}$, is the same for the constant and variable-fan sides. In addition, for the test points with the same flow velocity for the constant and variable-fans, the convective heat transfer coefficient is expected to be comparable. With the same flow velocity, the only significant difference between the two cold flow convective heat transfer coefficients should arise from the Duralco 4525, measurement tubes, and thermocouple wires contained within the cold flow duct. However, this was checked by switching the role of the two fans: the constant-fan was set for the smooth side of the heat exchanger while the variable-fan was set for the side with Duralco 4525 epoxy and measurement tubes. The measured differences in terms such as the Nusselt number for these cases were within experimental uncertainty, so the epoxy and measurement tubes do not have a significant effect.

From this, it can be deduced for the test cases with the variable-fan velocity equal to the constant-fan velocity that the heat transfer from the hot-flow to the metal foam is equal to the sum of the two cold flow convective heat transfers and the temperature 
difference between the heat exchanger surface and the cold flow should be comparable between both sides of the heat exchanger. In terms of the heat transfer, the heat exchanger will be symmetric. This case is illustrated in Figure 65, which shows a crosssection of the metal foam heat exchanger contained within the cold flow ducts. Note the cold flows are directed out of the page in this figure.

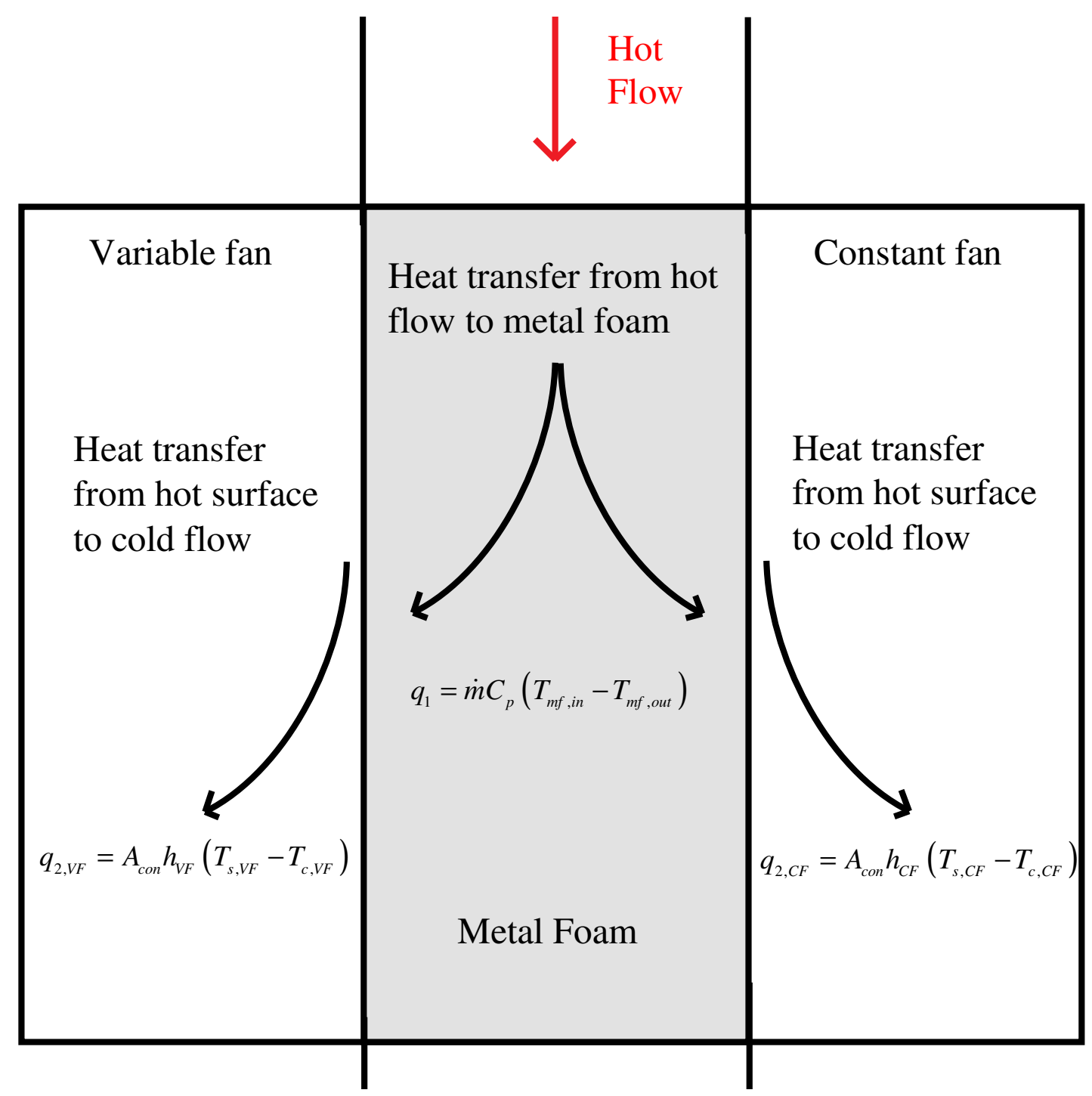

Figure 65 - Heat transfer modes from the hot-flow to the cold flow.

As Figure 65 shows, the convective cooling can be split between the two sides of the heat exchanger. Since $A_{c o n}$ and $h$ are the same and $T_{c}$ is roughly equal for both sides, the 
heat transfer should be symmetric. Recall the temperature difference between the heat exchanger surface and the cold flow is the driving temperature difference for the external convection. Examining this driving temperature difference for the constant and variablefan sides, the expected trend is the two temperature differences will be roughly equal. This is confirmed for the 20 PPI model since the driving temperature difference for the constant and variable-fan sides are within $0.8^{\circ} \mathrm{F}$ of each other. However, for the 40 PPI model, there is a significant discrepancy between the temperature differences that drive the external convection. The temperature difference $\left(\mathrm{T}_{\mathrm{s}, \mathrm{avg}}-\mathrm{T}_{\mathrm{c}, \mathrm{in}}\right)$ on the constant-fan side was consistently less than on the variable-fan side, with a separation of at least $9.3^{\circ} \mathrm{F}$. This means, even in the best case scenario for the 40 PPI model, the external convection on the constant-fan side produces a temperature difference $9.3^{\circ} \mathrm{F}$ less in magnitude than the external convection on the variable-fan side. Still assuming the two sides have the same convective heat transfer coefficient, this results in a $24 \%$ reduction in heat transfer on the constant-fan side as compared to the variable-fan side, for the 4 SCFM (113 SLPM) hot-flow rate.

This implies the constant-fan side, with the Duralco 4525 epoxy and measurement tubes, of the 40 PPI heat exchanger consistently exhibits worse heat transfer performance than the variable-fan side, with a smooth surface. Because the internal heat transfer is equal to the external convection, less heat is removed from the internal hot-flow. This is the same result as reached above using the hot-flow bulk temperature measurements. Therefore, this anomaly was not only examined through checking the validity of instrumentation, but was also reached using a second, independent measurement method. 
As far as why the constant-fan side of the 40 PPI heat exchanger performed worse than expected, there are two main suspicions. The first is the Duralco 4525 epoxy and measurement tubes reduced the cold flow heat transfer performance on the constant-fan flow side. However, the 20 PPI model had similar epoxy and measurement tubes but did not show reduced performance. Unfortunately, to see if the bonding method has a significant impact, a new method of bonding the measurement tubes would need to be fully explored and a new heat exchanger would have to be acquired. Because of time and budget constraints, this was not feasible.

The second possible reason for the poor performance of the 40 PPI heat exchanger's constant-fan side is a defect with the heat exchanger itself. It is unlikely the metal foam has significant defects because a problem with the metal foam structure would have appeared in the pressure data of the 40 PPI model, which was free of anomalies. The brazed connection between the metal foam and the sheet metal housing, however, could have had a problem. If the brazing were defective, it could cause a restriction in the heat flow from the metal foam ligaments to the outer surface which would reduce the surface temperature on the constant-fan side as well as the overall heat transfer from the hotflow. However, to correct this problem a new 40 PPI heat exchanger would be required, which again was not feasible. As a result of the 40 PPI heat exchanger's poor thermal performance, only the 20 PPI heat transfer results will be presented here. Figures showing the 40 PPI heat exchanger's thermal performance can be seen in Appendix C.

In summary, the expected outcome of the temperature measurements was a lower outlet temperature from the 40 PPI model as compared to the 20 PPI model with comparable test conditions. This was not shown by the test data. From surface 
temperature measurements, it appears the root of the problem lies with the constant-fan side of the 40 PPI heat exchanger. However, fixing the problem would require a new heat exchanger be purchased and prepared, which is beyond the scope of the current study.

\subsubsection{Heat Transfer Performance of 20 PPI Heat Exchanger}

To analyze the heat transfer performance of the 20 PPI heat exchanger, the average internal Nusselt number was calculated from Equation 22 using the average hot-flow temperature to evaluate the fluid properties. The results can be seen plotted against the hot-flow Reynolds number in Figure 66.

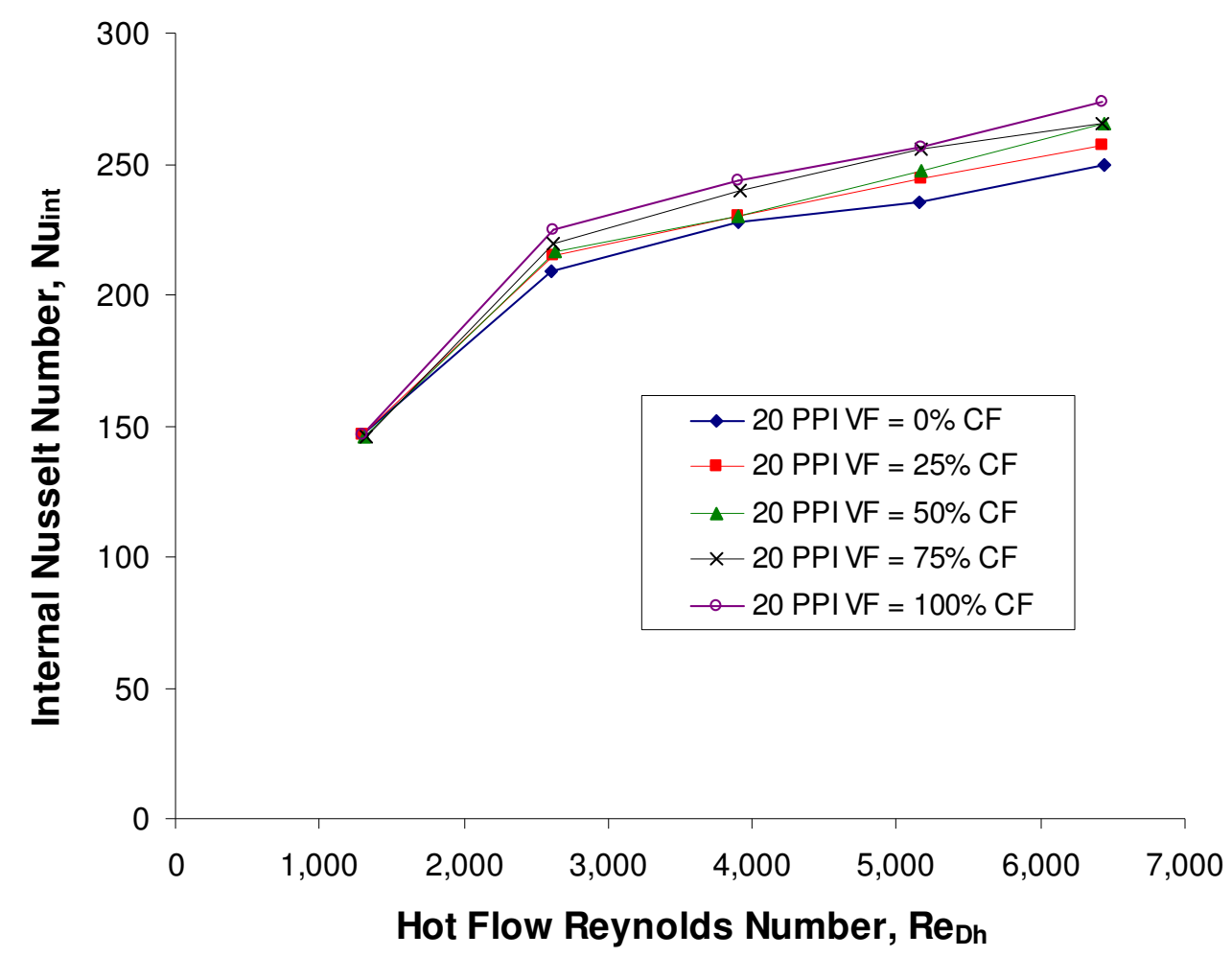

Figure 66 - Internal Nusselt number for the 20 PPI heat exchanger.

As seen in Figure 66, as the hot-flow Reynolds number increases, so does the internal Nusselt number. The increasing Reynolds number reflects the increasing flow speed through the metal foam. This increasing flow speed increases the turbulence intensity 
which enhances the convective heat transfer from the hot-flow to the metal foam ligaments. As a result, the Nusselt number is increased and the heat transfer performance internal to the metal foam is increased. There is a large jump between Reynolds numbers of 1,300 and 2,600. While the metal foam ligaments form a complex shape that can cause internal flow to become turbulent, the cases with a Reynolds number 1,300 may still be below the critical Reynolds number for the inlet duct and so the hot-flow may start out laminar. Since laminar flow provides less scrubbing of the metal foam ligaments, one would expect laminar flow to have less heat transfer than turbulent flow. While it may not be true for the entirety of the hot-flow, at this small Reynolds number there may be a portion of the flow that is laminar and therefore is less capable of transferring heat. So, when the flow does transition from laminar to turbulent completely, there is a large jump in the Nusselt number, as seen between the two smallest Reynolds numbers. After this large jump, the increase in the Nusselt number is relatively constant.

For the smallest hot-flow Reynolds number, there is virtually no difference in the Nusselt number for a change in the variable-fan flow velocity. But, for the other hot-flow Reynolds numbers, it appears the internal Nusselt number is increased from the zero variable-flow velocity to full speed. While the differences are small, all hot-flow Reynolds numbers show the $100 \%$ variable-fan speed has a larger internal Nusselt number than the $0 \%$ variable-fan speed. This is apparently due to the increase in the variable-fan cooling flow convection, which will increase the heat transfer from the heat exchanger surface to the cold flow on the variable-fan side. If the cooling flow has a larger heat transfer, it is implied the internal flow must also transfer more heat, which then increases the internal Nusselt number. 
It is interesting to see for the hot-flow Reynolds number of 1,300, the variable-fan flow speed makes little difference. This may indicate, despite the fact an increase in the variable-fan velocity allows for an increase in heat transfer, the hot-flow is unable to transfer more heat. If the hot-flow is transferring heat at its maximum rate, then an increase in the ability of the cooling flow to transfer heat will do nothing because the hotflow heat transfer to the metal foam is the limiting factor. However, for the larger hotflow Reynolds numbers, there is an increase in the internal Nusselt number with an increase in the variable-fan flow speed. For these cases, the external cooling flow may be the limiting factor. So, as the cooling flow heat transfer capability is increased, the internal flow heat transfer correspondingly increases because it was no longer at its maximum value. This result leads to a practical implication of using an external cooling flow to cool surfaces that are heated by metal foam: the heat transfer performance may not be limited by the metal foam. This information may help determine if a certain metal foam configuration will be used in a design such as this.

The average external Nusselt number was also analyzed, the results of which can be seen in Figure 67. The external Nusselt number shows similar trends as the internal Nusselt number, which is expected because the internal and external heat transfers are dependent on each other. 


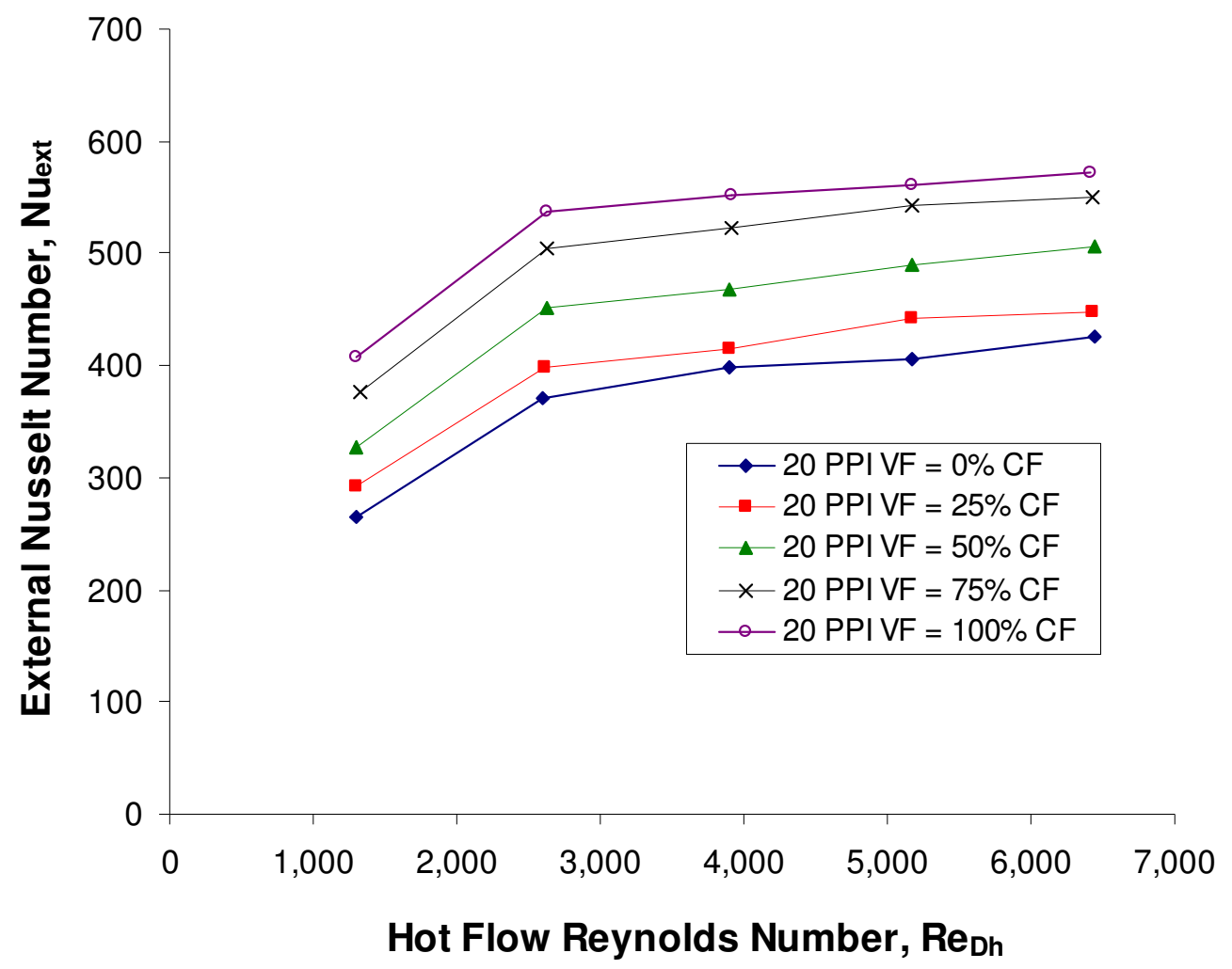

Figure 67 - External Nusselt number for the 20 PPI heat exchanger.

There is a sharp increase in the external Nusselt number between hot-flow Reynolds numbers of 1,300 and 2,600. This is a result of the increased heat transfer from the internal flow due to a possible laminar to turbulent transition. With a sharp increase in the internal heat transfer, the external heat transfer must also increase, resulting in the sharp external Nusselt number increase. For the larger hot-flow Reynolds numbers, the external Nusselt number shows a much slower increase as the hot-flow Reynolds number increases. As mentioned above, this implies that an increase in the internal heat transfer performance is having little effect on the external heat transfer, which may imply the external heat transfer is limiting the overall heat exchanger's heat transfer.

As seen in Figure 67, an increase in the variable-fan flow speed provides a corresponding increase in the external Nusselt number, as expected. In actually, the $0 \%$ 
variable-fan velocity case results in natural convection on one side of the heat exchanger, so it is not truly comparable with the other cases of forced convection. However, for the rest of the variable-fan flow speeds, there is a relatively uniform increase in external Nusselt number for a given increase in cold flow speed.

The Colburn $\mathrm{j}$ factor, defined by Equation 24, is another important heat transfer quantity. Again, the average hot-flow temperature was used to evaluate the fluid properties for this quantity, the result of which can be seen in Figure 68.

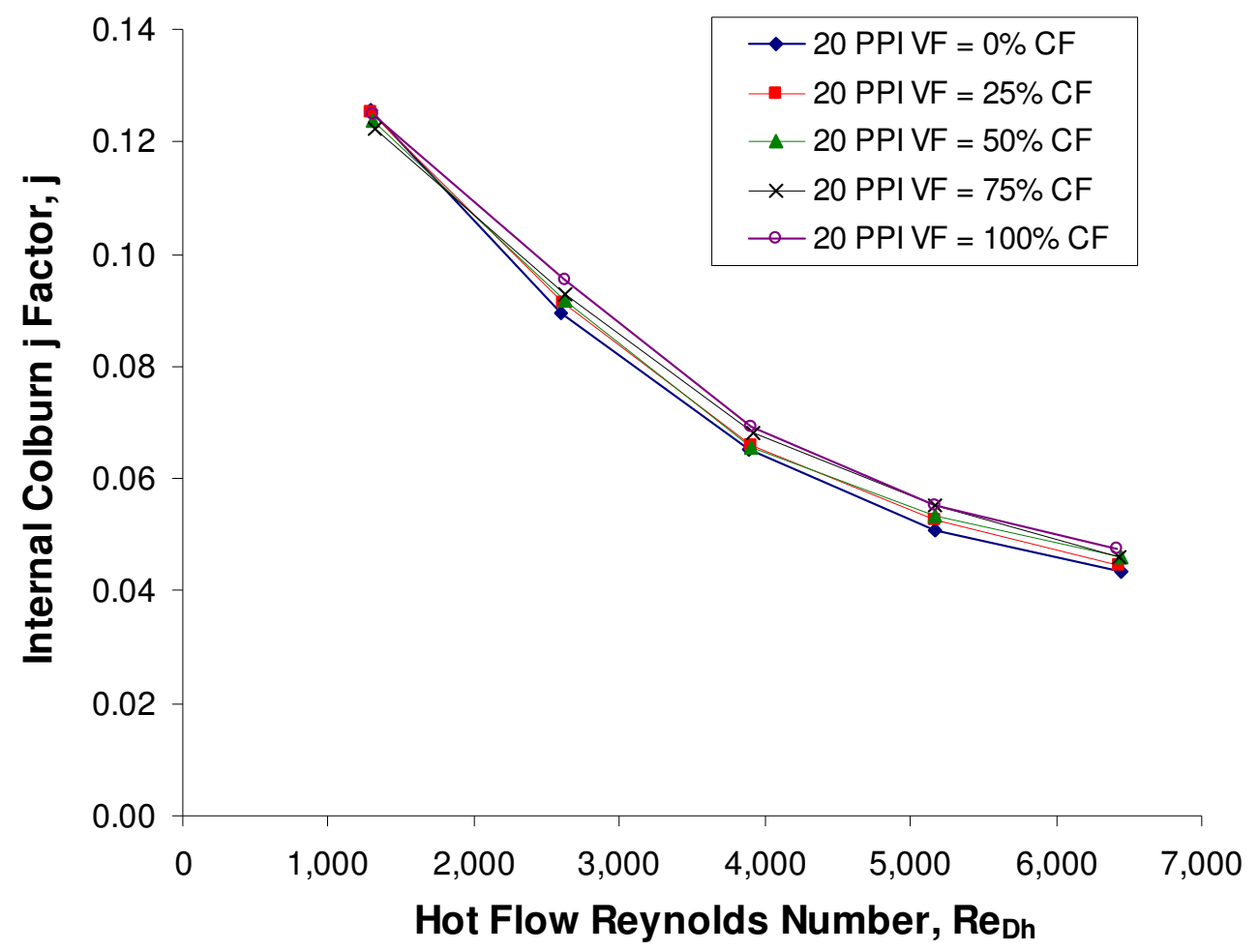

Figure 68 - Colburn j factor for the 20 PPI internal flow.

As the hot-flow Reynolds number increases, the Colburn $\mathrm{j}$ factor decreases. This implies as the flow rate through the metal foam is increased, the corresponding increase in the internal convective heat transfer coefficient is smaller. So, as more flow is pumped through the heat exchanger, there is a diminishing return in the convective heat transfer 
capability of the hot-flow. This range of hot-flow Reynolds numbers begins to show this diminishing return as evidenced by the gradual slope decrease in Figure 68 as the hotflow Reynolds number is increased. This gradual decrease in slope is in agreement with data presented by Boomsma et. al. ${ }^{14}$

The internal Colburn $\mathrm{j}$ factor shows a similar trend as the internal Nusselt number with respect to the variable-fan velocity. The $100 \%$ variable-fan velocity provides larger $\mathrm{j}$ factors than the $0 \%$ velocity, although the difference is small. This occurs because, as mentioned above, an increase in variable-fan velocity increases the external convection of the cooling flow, which in turn increases the overall heat transfer from the hot-flow. This increase in heat transfer, with a corresponding decrease in flow temperature, results in larger Colburn j factor values.

While most metal foam studies to date have concentrated on heat exchangers with a constant heat flux on the external surface, the heat exchanger in the present study relies on convection from two external cross-flows to pull heat from the internal hot-flow. Because of this difference, the trends of the internal Nusselt number can be compared to other studies, but the magnitudes may be vastly different. To explore this possible difference, internal Nusslet number data from the present study was compared to data published by Salas and Waas. ${ }^{6}$ The main focus of their study was the metal foam thickness effect on heat transfer. All of their heat exchangers were 20 PPI, $8 \%$ relative density, and built from aluminum 6101-T6, just like the present study. One side of their heat exchanger was supplied with a constant $730 \mathrm{~W} / \mathrm{m}^{2}$ heat flux while the other side was insulated. Figure 69 shows the data from Salas and Waas for their 0.5 inch $(12.7 \mathrm{~mm})$ thickness test case as compared to the 20 PPI, $100 \%$ variable-fan velocity test case from 
the present study. Note Salas and Waas used the metal foam thickness as the characteristic length for both the Nusselt number and Reynolds number, which was repeated for Figure 69. While the internal Nusselt number is obviously not the same between the two experiments, the values are comparable in magnitude. This means while the heat exchanger configuration in this study is different, the metal foam still provides superior heat transfer.

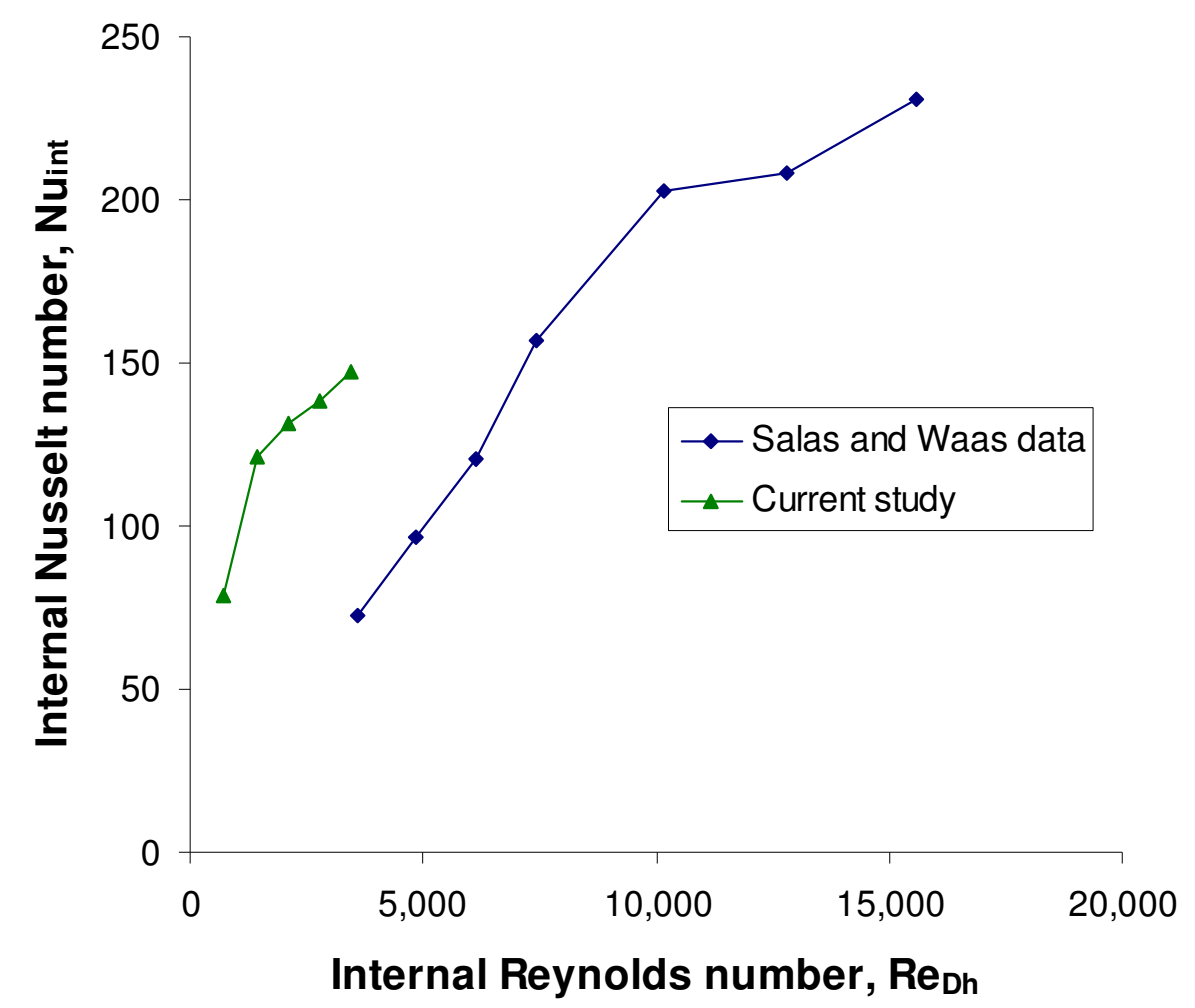

Figure 69 - Comparison of $100 \%$ variable fan velocity test case to data from Salas and Waas. ${ }^{6}$

\subsection{Overall Heat Exchanger Performance}

With the pressure drop and heat transfer characteristics determined, the two must be combined to examine the heat exchanger as a whole. The two key parameters to examine are the pumping power required to push flow through the heat exchanger and the thermal 
resistance of the heat exchanger. The 20 PPI heat exchanger performance parameters can be seen in Figure 70.

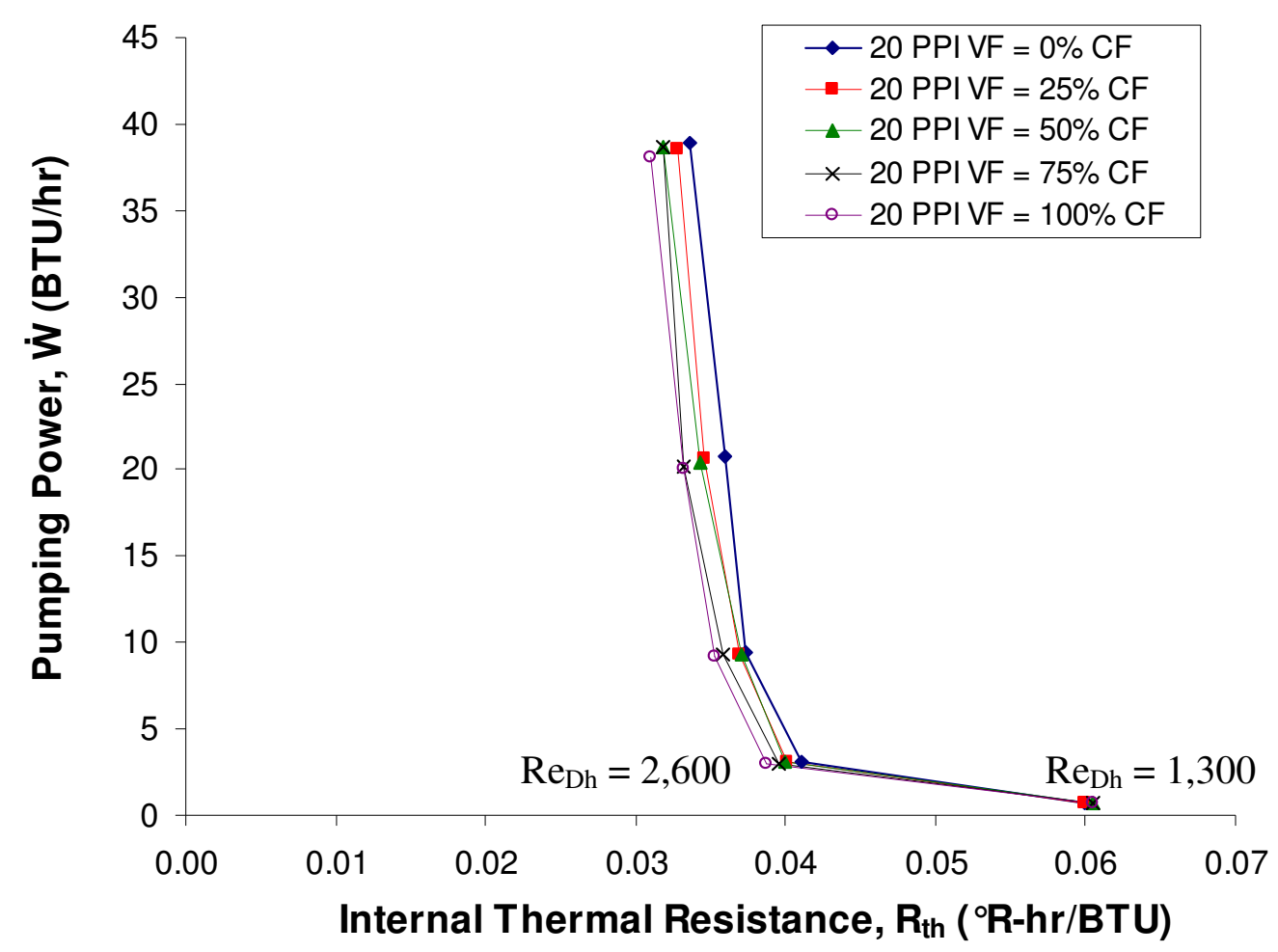

Figure 70 - Pumping power and internal thermal resistance for the 20 PPI heat exchanger.

As shown in Figure 70, the price of decreasing the thermal resistance is an increase in the required pumping power. Examining Equation 26, the internal thermal resistance is basically the inverse of the internal Nusselt number, Equation 22, with the exception of a few constants. So, it is no surprise there is a sharp decrease in the thermal resistance for the first two hot-flow velocities, corresponding to hot-flow Reynolds numbers of 1,300 and 2,600, respectively. However, the pumping power does not show a sharp increase for these two Reynolds numbers. This implies there is a desirable minimum Reynolds number through the heat exchanger to achieve this large decrease in thermal resistance without a corresponding large increase in pumping power. As with the internal Nusselt number, there is a slight difference in the thermal resistance for a given change in 
variable-fan velocity. Namely, the $100 \%$ variable-fan velocity cases provide slightly smaller thermal resistances than the $0 \%$ variable-fan velocity cases.

While Figure 70 provides an insight into the overall performance of the 20 PPI heat exchanger, the real power of this figure lies in its ability to simultaneously compare the thermal and hydraulic performance of the heat exchanger. However, to properly compare the two parameters, they must be reduced to the same scale. To do this, each parameter was normalized by its respective maximum value to produce the results in Figure 71. While Figure 71 shows the same general trends as Figure 70, if the 40 PPI model had produced reasonable thermal performance results then normalized values would be the correct way to compare the two heat exchangers. In addition, if any optimization were to occur for the overall heat exchanger performance, the normalized parameters would need to be used. Otherwise, the scale of each parameter would add artificial weighting to the parameters in an objective function, which is the function to be minimized during the optimization. 


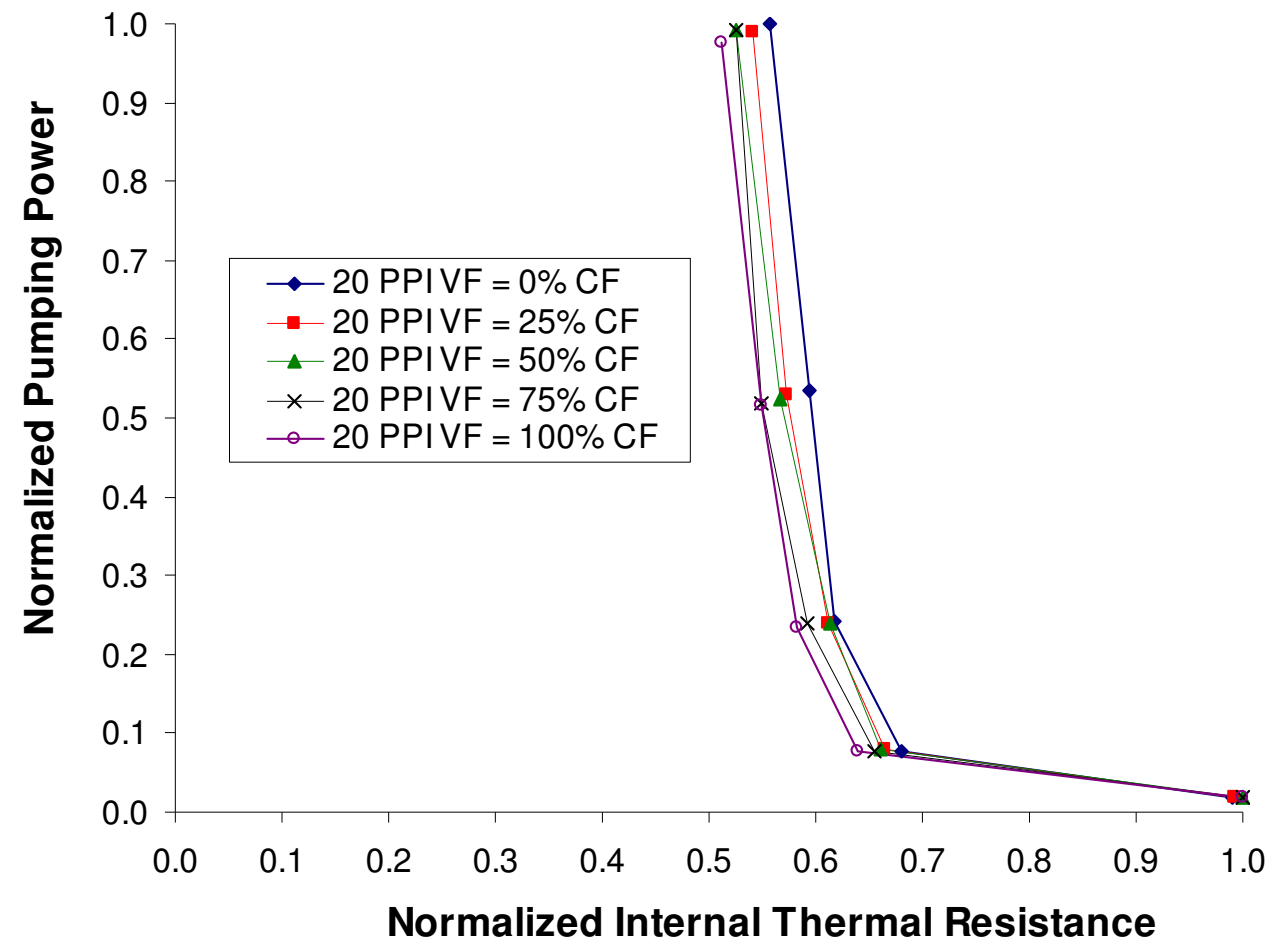

Figure 71 - Normalized pumping power and thermal resistance for the 20 PPI heat exchanger.

As an example of the possible optimization opportunities this comparison provides, consider just the $100 \%$ variable-fan velocity case. As mentioned above, the test points with hot-flow Reynolds numbers of 1,300 and 2,600 showed a sharp increase in thermal performance without a correspondingly large increase in pumping power. Therefore, the first test point with the largest thermal resistance will be ignored for this examination. Taking the remaining four points and fitting a curve to the normalized parameters, as seen in Figure 72, yields a method of estimating the normalized parameters for untested conditions. This curve fit can then be used to build up an objective function that would provide an estimate to the optimal configuration for the 20 PPI heat exchanger. 


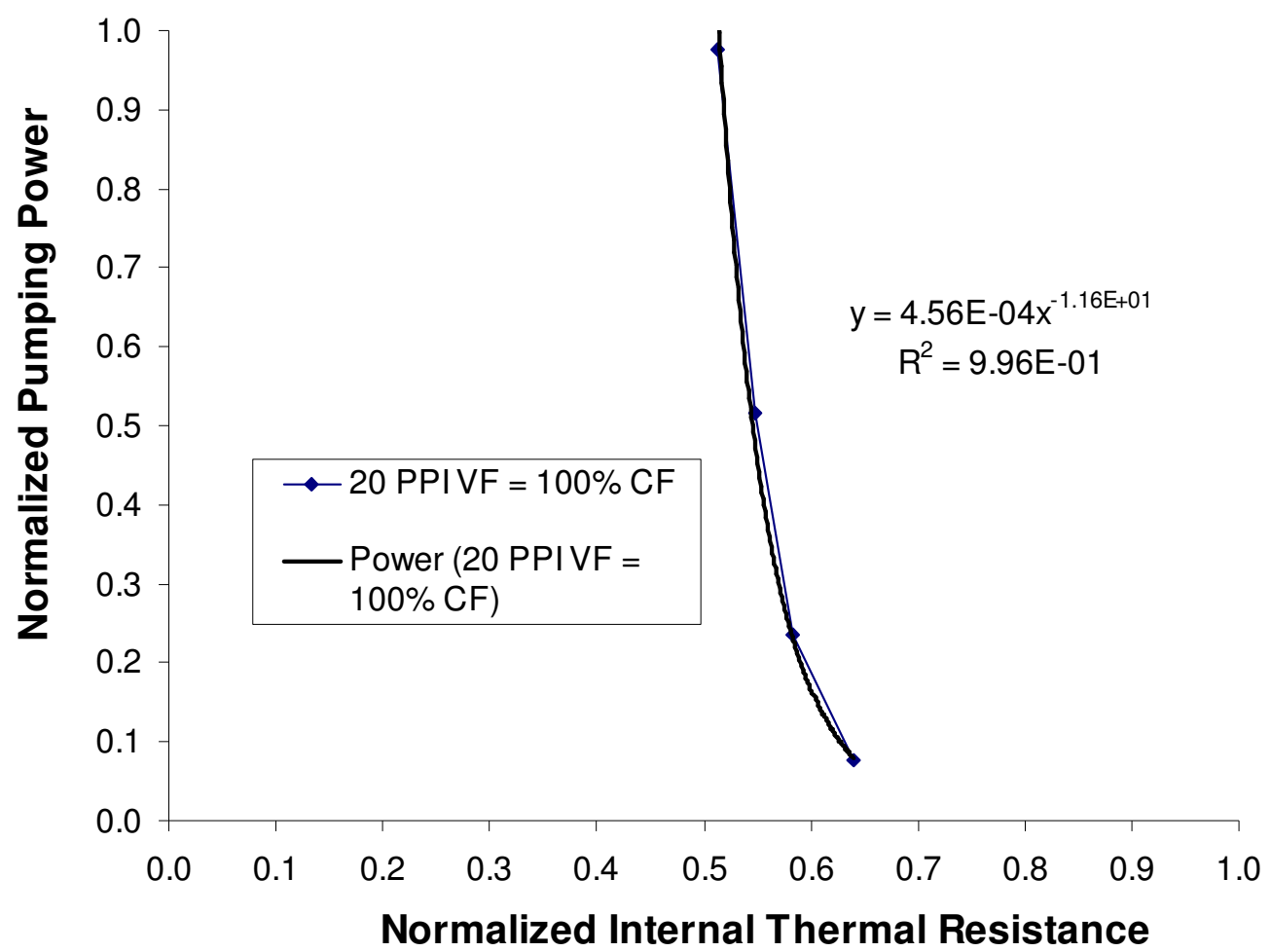

Figure 72 - 20 PPI heat exchanger performance model used for optimization.

Assuming the objective function is to have equal weighting for the pumping power and thermal resistance and there are no constraints to satisfy, it is appropriate to minimize both normalized parameters simultaneously. This corresponds to finding the point closest to the origin in Figure 72. This is easily done using the curve fit from above as a model for the 20 PPI heat exchanger's performance. The result is an optimum point with a normalized pumping power of 0.17 and a normalized thermal resistance of 0.6 . This corresponds to an actual pumping power of $6.7 \mathrm{BTU} / \mathrm{hr}$ and thermal resistance of 0.036 $\frac{{ }^{\circ} R}{B T U / h r}$. Now that the pumping power is known, it can be used to estimate the best hotflow rate for the 20 PPI heat exchanger. Using the parabolic curve fit for the length normalized pressure drop of the 20 PPI heat exchanger seen in Figure 62, the pressure 
drop can be estimated using just the hot-flow velocity. In addition, the flow rate through the heat exchanger is a known function of the hot-flow velocity. So, the pumping power can be estimated by a function of the hot-flow velocity alone. Since the desired pumping power is known, this function can be solved for the hot-flow velocity and then the hotflow rate can be calculated. The result is a hot-flow rate of 10.5 SCFM (297 SLPM). This flow rate yields the predicted optimum 20 PPI heat exchanger performance with the variable-fan velocity at $100 \%$ the constant-fan velocity.

With this information, a test case with a hot-flow rate of 10.5 SCFM (297 SLPM) and the variable-fan velocity set to $100 \%$ of the constant-fan speed was run. The result was a pumping power of $6.5 \mathrm{BTU} / \mathrm{hr}$, a $3.0 \%$ decrease from the prediction, and a thermal resistance of $0.034 \frac{{ }^{\circ} R}{B T U / h r}$, a $5.6 \%$ decrease from the prediction. Given the uncertainties associated with not only the measurements but also the curve fit approximations used for the optimization, these results verify the optimization method and give confidence to this approach for determining the best heat exchanger configuration.

\subsection{Error Estimation}

As detailed in Appendix A, estimations of the error in all measured quantities were determined using data for the 20 PPI model with a 12 SCFM (340 SLPM) hot-flow rate and a variable-fan flow speed set to $50 \%$ of the constant-fan flow speed. This representative case was analyzed using the standard deviation of the mean as the most probable uncertainty in a single measurement. The error estimation methods presented by 
Taylor $^{17}$ were used for all error quantities. The resulting error estimations can be seen in Table 4.

Table 4 - Most probable error estimation in significant results.

\begin{tabular}{|l|l|}
\hline \multicolumn{1}{|c|}{ Quantity } & Percent Uncertainty \\
\hline Pressure drop per length, $\frac{\Delta p}{L}=\rho C U^{2}+\frac{\mu}{K} U$ & $0.93 \%$ \\
\hline Hot-flow rate, Q & $0.10 \%$ \\
\hline Pumping power, $\dot{W}=\Delta p Q$ & $0.94 \%$ \\
\hline Fanning friction factor, $f=\frac{\Delta p}{4\left(\frac{L}{H}\right)\left(\frac{1}{2} \rho U^{2}\right)}$ & $0.95 \%$ \\
\hline Internal Nusselt number, $N u_{i n t}=\frac{\dot{m} C_{p}\left(T_{m f, \text { in }}-T_{m f, \text { out }}\right)}{A_{c o n}\left(T_{m f, a v g}-T_{s, a v g}\right)} \frac{D_{h}}{k_{f}}$ & $3.37 \%$ \\
\hline External Nusselt number, $N u_{e x t}=\frac{\dot{m} C_{p}\left(T_{m f, \text { in }}-T_{m f, \text { out }}\right)}{A_{c o n}\left(T_{s, a v g}-T_{c, \text { in }}\right)} \frac{D_{h}}{k_{f}}$ & $3.29 \%$ \\
\hline Internal thermal resistance, $R_{t h}=\frac{T_{m f, a v g}-T_{s, a v g}}{\dot{m} C_{p}\left(T_{m f, \text { in }}-T_{m f, \text { out }}\right)}$ & $3.37 \%$ \\
\hline Colburn j factor, $j=\frac{h_{i n t}}{\rho U C_{p}}\left(\frac{C_{p} \mu}{k_{f}}\right)^{2 / 3}$ & $3.37 \%$ \\
\hline
\end{tabular}




\section{CONCLUSIONS}

To examine the feasibility of metal foam heat exchangers integrated into the ducting of a variable cycle engine for use in a thermal management system, a test bench was manufactured to test two representative heat exchangers. Both heat exchangers had internal dimensions of 6.3 inch width by 6.3 inch length by 0.5 inch height (16 by 16 by $1.3 \mathrm{~cm}$ ) and contained Duocel open-celled aluminum foam with a nominal relative density of $8 \%$. The two heat exchangers, constructed from 20 and 40 PPI metal foam, were subjected to forced convection with a hot-flow pumped through the metal foam and two independent and controllable cold flows ducted over the exterior surfaces of the heat exchangers. One of the cold flows delivered a constant air flow with an average velocity of $34 \mathrm{ft} / \mathrm{s}(10.4 \mathrm{~m} / \mathrm{s})$ while the other flow speed was varied between $0 \%$ and $100 \%$ of the constant cold flow speed, in $25 \%$ increments. In addition, hot-flow rates of $4,8,12,16$, and $20 \operatorname{SCFM}(113,227,340,453$, and 566 SLPM) were tested. The temperature and pressure of the flow internal to the metal foam heat exchanger were measured, as well as temperatures on the surfaces of the heat exchangers and within the cold flow. The test results allowed hydraulic and thermal comparisons to be made for varying hot and cold flow speeds. The internal hot flow Reynolds number ranged from 1,300 to 6,400, while the variable-fan flow Reynolds number ranged from zero to 81,000.

Due to a defect on one side of the 40 PPI heat exchanger, its thermal results had to be neglected. The key conclusions based on the 20 PPI heat exchanger are summarized below: 
- The temperature and pressure data internal to the metal foam were nearly linear and provided a trustworthy method of determining the temperature and pressure at the metal foam inlet and outlet, where it could not be measured.

- The external cooling flow provided a different method of external heat transfer than most studies, which examine a constant heat flux on the metal foam heat exchanger external surface. However, the internal Nusselt numbers of this present study are comparable to those of other studies, such as Salas and Waas. ${ }^{6}$ This lends credit to the metal foam as a superior heat exchanger in an integrated thermal management system on a variable cycle engine. In addition, the pumping power requirements are within reasonable levels and will allow the thermal management system to be realized without an unreasonable amount of energy input. Therefore, the idea of integrating a metal foam heat exchanger into the ducting between the constant and variable-fans of a variable cycle engine and subjecting it to a cooling cross-flow is feasible.

- A sharp decrease in the internal thermal resistance was seen between hot flow Reynolds numbers of 1,300 and 2,600. This beneficial decrease in thermal resistance was not accompanied by a large increase in pumping power.

- The measured pumping power and thermal resistance were normalized to create a model for use in determining the optimum flow rate for the 20 PPI heat exchanger. Assuming no constraints and equal weighting on the pumping power and thermal resistance, this resulted in an estimated best flow rate of 10.5 SCFM 
(297 SLPM) through the heat exchanger with a predicted pumping power and thermal resistance of $6.7 \mathrm{BTU} / \mathrm{hr}$ and $0.036 \frac{{ }^{\circ} R}{\mathrm{BTU} / \mathrm{hr}}$, respectively.

Work was done to improve the measurement tube bonding method for the 40 PPI heat exchanger. This work will be incorporated in any follow-on studies and should decrease the likelihood that one side of the heat exchanger shows a heat transfer anomaly.

Recommended future work includes the examination of a wider range of metal foams. Variations in the type of metal used to make the foam, relative density, and a larger range of PPIs would further the knowledge of metal foams for this application. For the case of using metal foams inside the fan ducting on a variable cycle engine to be fully argued, the structural properties of the metal foam within the ducting must also be tested. Finally, the convection between the cooling fan flows and the exterior surfaces of the heat exchanger could be characterized in more depth and methods could be tested to enhance this heat transfer without deteriorating the fan flow. 


\section{APPENDIX A: ERROR CALCULATIONS}

All error calculations are performed using data for the 20 PPI heat exchanger at a hot air flow rate of 12 SCFM (340 SLPM) and variable-fan setting of 50\% the constant-fan velocity. The standard deviation of the mean is used as an estimate for the error in individual measurements. The standard deviation of the mean was calculated using 30 readings of 5,000 samples each for all temperature and flow rate data and 40 readings of 200 samples each for the pressure data.

\section{Static Pressure Drop}

$$
\begin{aligned}
& \frac{\Delta p}{L}=\frac{p_{m f, \text { in }}-p_{m f, \text { out }}}{L} \\
& \frac{\delta(\Delta p / L)}{|\Delta p / L|}=\sqrt{\left(\frac{\delta \Delta p}{\Delta p}\right)^{2}+\left(\frac{\delta L}{L}\right)^{2}}
\end{aligned}
$$

Assuming the error involved with the length measurement is negligible, this becomes

$$
\frac{\delta(\Delta p / L)}{|\Delta p / L|}=\frac{\delta \Delta p}{\Delta p}=\frac{\delta\left(p_{m f, \text { in }}-p_{m f, \text { out }}\right)}{\left|p_{m f, \text { in }}-p_{m f, \text { out }}\right|}
$$

The Scanivalve was used to measure the differential pressure as compared to the metal foam inlet pressure. These pressure measurements were then used to create a best fit curve for the gage pressure of the hot-flow within the metal foam. From this best fit equation, the pressure at the metal foam inlet and outlet were determined. As a result, the error in the inlet and outlet pressures can be estimated by the standard deviation of the predicted pressure value, given by ${ }^{17}$ 
$\sigma_{p}=\sqrt{\frac{1}{N-2} \sum_{i=1}^{N}\left(p_{i}-A-B x_{i}\right)^{2}}$

where $\mathrm{N}$ is the number of samples used to create the best fit curve, $\mathrm{p}_{\mathrm{i}}$ is the measured pressure value, $\mathrm{A}$ and $\mathrm{B}$ are the linear curve fit constants, and $\mathrm{x}_{\mathrm{i}}$ is the position along the length of the metal foam. From the best fit equation and the pressure data used to create the curve fit, this becomes

$\sigma_{p}=3.923 \mathrm{e}-4$ psid

Since this is the error estimation for the individual error estimates, this becomes

$\delta\left(p_{m f, \text { in }}-p_{m f, \text { out }}\right)=\sqrt{\sigma_{p_{m f, \text { in }}}^{2}+\sigma_{p_{m f, \text { out }}}^{2}}=5.547 \mathrm{e}-4$ psid

The error in the pressure drop is then

$$
\frac{\delta(\Delta p / L)}{|\Delta p / L|}=\frac{\delta\left(p_{m f, \text { in }}-p_{m f, \text { out }}\right)}{\left|p_{m f, \text { in }}-p_{m f, \text { out }}\right|}=\frac{5.547 \mathrm{e}-4 \text { psid }}{0.0596 \text { psid }}=0.93 \%
$$

\section{Volumetric Flow Rate}

$\sigma_{\bar{Q}}=0.0115 \mathrm{SCFM}$

$$
Q=12.08 \mathrm{SCFM}
$$

$$
\frac{\delta Q}{|Q|}=\frac{\sigma_{\bar{Q}}}{|Q|}=\frac{0.0115 \mathrm{SCFM}}{12.08 \mathrm{SCFM}}=0.10 \%
$$

Assuming there is negligible error in the hot air inlet density and metal foam ducting cross-sectional area measurements, this error also corresponds to the error in the mass flow rate and velocity measurements, since $\dot{m}=\rho Q=\rho(A U)$ 


\section{Pumping Power}

$$
\begin{aligned}
& \dot{W}=\Delta p Q \\
& \frac{\delta \dot{W}}{|\dot{W}|}=\sqrt{\left(\frac{\delta \Delta p}{\Delta p}\right)^{2}+\left(\frac{\delta Q}{Q}\right)^{2}} \\
& \frac{\delta \dot{W}}{|\dot{W}|}=\sqrt{(0.0093)^{2}+(0.0010)^{2}}=0.94 \%
\end{aligned}
$$

\section{Fanning Friction Factor}

$$
\begin{aligned}
& f=\frac{\Delta p}{4\left(\frac{L}{H}\right)\left(\frac{1}{2} \rho U^{2}\right)} \\
& \frac{\delta f}{|f|}=\sqrt{\left(\frac{\delta \Delta p}{\Delta p}\right)^{2}+\left(\frac{\delta L}{L}\right)^{2}+\left(\frac{\delta H}{H}\right)^{2}+\left(\frac{\delta \rho}{\rho}\right)^{2}+\left(2 \frac{\delta U}{U}\right)^{2}}
\end{aligned}
$$

Assuming the errors in $\mathrm{L}, \mathrm{H}$, and $\rho$ are negligible, and recalling that the error in the velocity measurement is equal to the error in the flow rate measurement, the error in the Fanning Friction Factor becomes

$$
\begin{aligned}
& \frac{\delta f}{|f|}=\sqrt{\left(\frac{\delta \Delta p}{\Delta p}\right)^{2}+\left(2 * \frac{\delta Q}{Q}\right)^{2}}=\sqrt{(0.0093)^{2}+(2 * 0.0010)^{2}} \\
& \frac{\delta f}{|f|}=0.95 \%
\end{aligned}
$$

\section{Internal Nusselt Number}

$$
N u_{\text {internal }}=\frac{\dot{m} C_{p}\left(T_{m f, \text { in }}-T_{m f, \text { out }}\right)}{A_{\text {con }}\left(T_{m f, \text { avg }}-T_{s, \text { avg }}\right)} \frac{D_{h}}{k_{f}}
$$




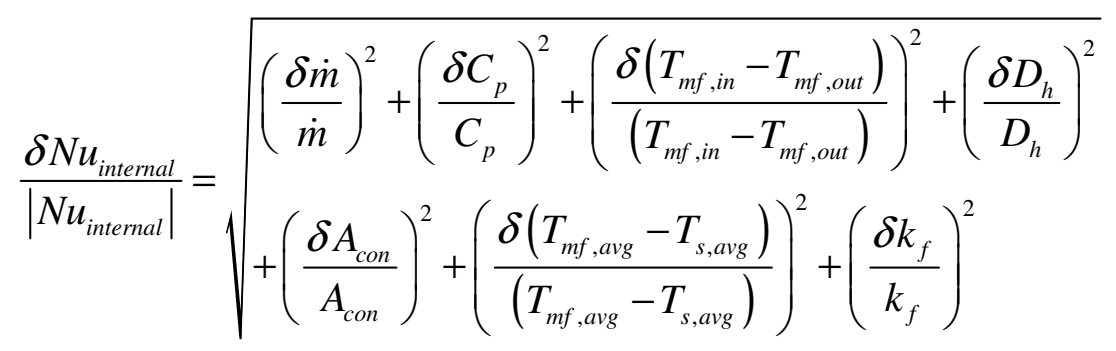

Assuming negligible error in $\mathrm{C}_{\mathrm{p}}, \mathrm{D}_{\mathrm{h}}, \mathrm{A}_{\mathrm{con}}$, and $k_{f}$, this becomes

$$
\frac{\delta N u}{|N u|}=\sqrt{\left(\frac{\delta Q}{Q}\right)^{2}+\left(\frac{\delta\left(T_{m f, \text { in }}-T_{m f, \text { out }}\right)}{\left(T_{m f, \text { in }}-T_{m f, \text { out }}\right)}\right)^{2}+\left(\frac{\delta\left(T_{m f, \text { avg }}-T_{s, \text { avg }}\right)}{\left(T_{m f, \text { avg }}-T_{s, \text { avg }}\right)}\right)^{2}}
$$

To evaluate the error in the temperature difference measurements, the error in each individual temperature term must be evaluated. The inlet and outlet temperatures are determined from a best fit linear equation derived from the six temperatures measured within the metal foam, so there error can be evaluated using ${ }^{17}$

$$
\sigma_{T}=\sqrt{\frac{1}{N-2} \sum_{i=1}^{N}\left(T_{i}-A-B x_{i}\right)^{2}}
$$

where again $\mathrm{N}$ is the number of samples used to create the best fit curve, $\mathrm{T}_{\mathrm{i}}$ is the measured temperature value (in ${ }^{\circ} \mathrm{R}$ ), $\mathrm{A}$ and $\mathrm{B}$ are the linear curve fit constants, and $\mathrm{x}_{\mathrm{i}}$ is the position along the length of the metal foam. From the best fit equation and the temperature data used to create the curve fit, this becomes $\sigma_{T}=0.847^{\circ} R$

So the error in the first temperature difference becomes $\delta\left(T_{m f, \text { in }}-T_{m f, \text { out }}\right)=\sqrt{\left(\delta T_{m f, \text { in }}\right)^{2}+\left(\delta T_{m f, \text { out }}\right)^{2}}=1.20^{\circ} R$

Both the average hot-flow temperature and surface temperature were based on more than one directly measured quantity, so the error associated with those measurements becomes 


$$
\begin{aligned}
& \delta\left(T_{m f, a v g}-T_{s, a v g}\right)=\sqrt{\left(\delta T_{m f, a v g}\right)^{2}+\left(\delta T_{s, a v g}\right)^{2}} \\
& \delta T_{m f, a v g}=\frac{1}{8} \sqrt{\begin{array}{l}
\left(\delta \bar{T}_{m f, i n}\right)^{2}+\left(\sigma_{\bar{T}_{m f, 2}}\right)^{2}+\left(\sigma_{\bar{T}_{m f, 3}}\right)^{2}+\left(\sigma_{\bar{T}_{m f, 4}}\right)^{2} \\
+\left(\sigma_{\bar{T}_{m f, 5}}\right)^{2}+\left(\sigma_{\bar{T}_{m f, 6}}\right)^{2}+\left(\sigma_{\bar{T}_{m f, 7}}\right)^{2}+\left(\delta \bar{T}_{m f, o u t}\right)^{2}
\end{array}} \\
& \delta T_{m f, a v g}=\frac{1}{8} \sqrt{\begin{array}{l}
(0.847)^{2}+(0.145)^{2}+(0.0831)^{2}+(0.109)^{2} \\
+(0.0972)^{2}+(0.117)^{2}+(0.0713)^{2}+(0.847)^{2}
\end{array}}{ }^{\circ} R \\
& \delta T_{m f, a v g}=0.153^{\circ} R \\
& \delta T_{s, a v g}=\frac{1}{5} \sqrt{\left(\sigma_{\bar{T}_{s, Y F}}\right)^{2}+\left(\sigma_{\bar{T}_{s, C F 1}}\right)^{2}+\left(\sigma_{\bar{T}_{s, C F 2}}\right)^{2}+\left(\sigma_{\bar{T}_{s, C F 3}}\right)^{2}+\left(\sigma_{\bar{T}_{s, C F 4}}\right)^{2}} \\
& \delta T_{s, a v g}=\frac{1}{5} \sqrt{(0.170)^{2}+(0.144)^{2}+(0.158)^{2}+(0.187)^{2}+(0.156)^{2}}{ }^{\circ} R \\
& \delta T_{s, a v g}=0.0732^{\circ} R \\
& \delta\left(T_{m f, a v g}-T_{s, a v g}\right)=\sqrt{(0.153)^{2}+(0.0732)^{2}}{ }^{\circ} R \\
& \delta\left(T_{m f, a v g}-T_{s, a v g}\right)=0.170^{\circ} R
\end{aligned}
$$

So the internal Nusselt Number error can be calculated as

$$
\begin{aligned}
& \frac{\delta N u_{\text {internal }}}{\left|N u_{\text {internal }}\right|}=\sqrt{\left(\frac{\delta Q}{Q}\right)^{2}+\left(\frac{\delta\left(T_{m f, \text { in }}-T_{m f, \text { out }}\right)}{\left(T_{m f, \text { in }}-T_{m f, \text { out }}\right)}\right)^{2}+\left(\frac{\delta\left(T_{m f, \text { avg }}-T_{s, \text { avg }}\right)}{\left(T_{m f, a v g}-T_{s, \text { avg }}\right)}\right)^{2}} \\
& \frac{\delta N u_{\text {internal }}}{\left|N u_{\text {internal }}\right|}=\sqrt{(0.0010)^{2}+\left(\frac{1.20^{\circ} R}{37.1^{\circ} R}\right)^{2}+\left(\frac{0.170^{\circ} R}{18.0^{\circ} R}\right)^{2}} \\
& \frac{\delta N u_{\text {internal }}}{\left|N u_{\text {internal }}\right|}=3.37 \%
\end{aligned}
$$

The same $3.37 \%$ error is present in the internal thermal resistance measurement because it has the same sources of error as the internal Nusselt Number. 


\section{External Nusselt Number}

$N u_{\text {external }}=\frac{\dot{m} C_{p}\left(T_{m f, \text { in }}-T_{m f, \text { out }}\right)}{A_{\text {con }}\left(T_{s, \text { avg }}-T_{c, \text { in }}\right)} \frac{D_{h}}{k_{f}}$

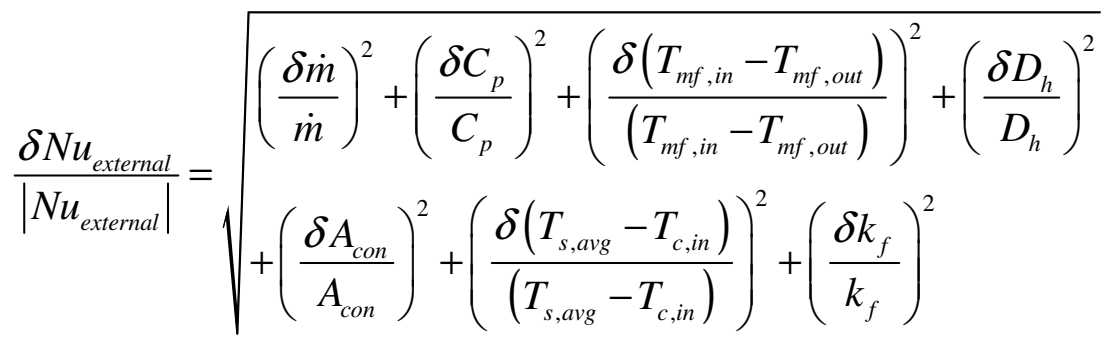

Again neglecting the error in $\mathrm{C}_{\mathrm{p}}, \mathrm{D}_{\mathrm{h}}, \mathrm{A}_{\text {con }}$, and $k_{f}$, the error becomes

$\frac{\delta N u_{\text {external }}}{\left|N u_{\text {external }}\right|}=\sqrt{\left(\frac{\delta Q}{Q}\right)^{2}+\left(\frac{\delta\left(T_{m f, \text { in }}-T_{m f, \text { out }}\right)}{\left(T_{m f, \text { in }}-T_{m f, \text { out }}\right)}\right)^{2}+\left(\frac{\delta\left(T_{s, \text { avg }}-T_{c, \text { in }}\right)}{\left(T_{s, \text { avg }}-T_{c, \text { in }}\right)}\right)^{2}}$

Evaluation of the temperature measurements occurs as before

$\delta\left(T_{s, a v g}-T_{c, \text { in }}\right)=\sqrt{\left(\delta T_{s, a v g}\right)^{2}+\left(\delta T_{c, \text { in }}\right)^{2}}$

where $\mathrm{T}_{\mathrm{c}, \text { in }}$ was an average of two measurements. So, its error becomes

$\delta T_{c, \text { in }}=\frac{1}{2} \sqrt{\left(\sigma_{\bar{T}_{c, i n, C F}}\right)^{2}+\left(\sigma_{\bar{T}_{c, i n . V F}}\right)^{2}}=\frac{1}{2} \sqrt{(0.440)^{2}+(0.467)^{2}}{ }^{\circ} R$

$\delta T_{c, \text { in }}=0.321^{\circ} R$

$\delta\left(T_{s, \text { avg }}-T_{c, \text { in }}\right)=\sqrt{(0.0732)^{2}+(0.321)^{2}}$

$\delta\left(T_{s, a v g}-T_{c, \text { in }}\right)=0.329^{\circ} R$

So the external Nusselt number error can be calculated as 


$$
\begin{aligned}
& \frac{\delta N u_{\text {external }} \mid}{\left|N u_{\text {external }}\right|}=\sqrt{\left(\frac{\delta Q}{Q}\right)^{2}+\left(\frac{\delta\left(T_{m f, \text { in }}-T_{m f, \text { out }}\right)}{\left(T_{m f, \text { in }}-T_{m f, \text { out }}\right)}\right)^{2}+\left(\frac{\delta\left(T_{s, a v g}-T_{c, i n}\right)}{\left(T_{s, \text { avg }}-T_{c, \text { in }}\right)}\right)^{2}} \\
& \frac{\delta N u_{\text {external }}}{\left|N u_{\text {external }}\right|}=\sqrt{(0.0010)^{2}+\left(\frac{1.20^{\circ} R}{37.1^{\circ} R}\right)^{2}+\left(\frac{0.329^{\circ} R}{53.3}\right)^{2}} \\
& \frac{\delta N u_{\text {external }}}{\left|N u_{\text {external }}\right|}=3.29 \%
\end{aligned}
$$

\section{Colburn j Factor}

$$
\begin{aligned}
& j=\frac{h_{\text {internal }}}{\rho U C_{p}}\left(\frac{C_{p} \mu}{k_{f}}\right)^{2 / 3}=\frac{(\rho A U) C_{p}\left(T_{m f, \text { in }}-T_{m f, \text { out }}\right)}{A_{c o n}\left(T_{m f, \text { avg }}-T_{s, a v g}\right)} \frac{1}{\rho U C_{p}}\left(\frac{C_{p} \mu}{k_{f}}\right)^{2 / 3} \\
& j=\frac{A\left(T_{m f, \text { in }}-T_{m f, \text { out }}\right)}{A_{\text {con }}\left(T_{m f, \text { avg }}-T_{s, a v g}\right)}\left(\frac{C_{p} \mu}{k_{f}}\right)^{2 / 3}
\end{aligned}
$$

Again assuming negligible error in the air properties, $\mathrm{C}_{\mathrm{p}}, \mu, k_{f}, \mathrm{~A}$, and $\mathrm{A}_{\text {con }}$, the error in the $\mathrm{j}$ factor becomes

$$
\begin{aligned}
& \frac{\delta j}{|j|}=\sqrt{\left(\frac{\delta\left(T_{m f, \text { in }}-T_{m f, \text { out }}\right)}{\left(T_{m f, \text { in }}-T_{m f, \text { out }}\right)}\right)^{2}+\left(\frac{\delta\left(T_{m f, a v g}-T_{s, \text { avg }}\right)}{\left(T_{m f, a v g}-T_{s, a v g}\right)}\right)^{2}} \\
& \frac{\delta j}{|j|}=\sqrt{\left(\frac{1.20^{\circ} R}{37.1^{\circ} R}\right)^{2}+\left(\frac{0.170^{\circ} R}{18.0^{\circ} R}\right)^{2}}=3.37 \%
\end{aligned}
$$




\section{APPENDIX B: MATLAB CODE}

\section{Create analog input object to measure temperature along the hot-flow direction}

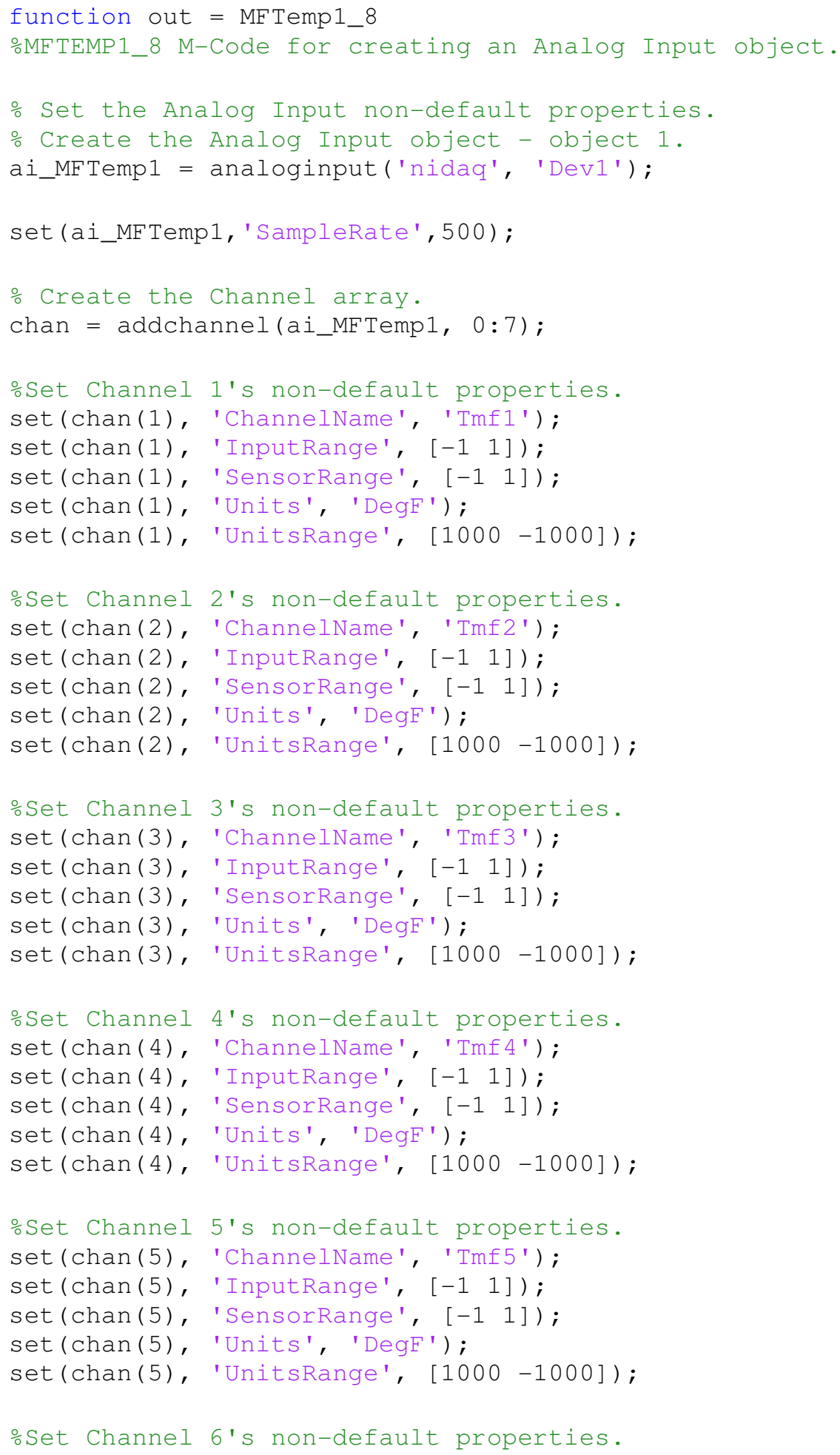




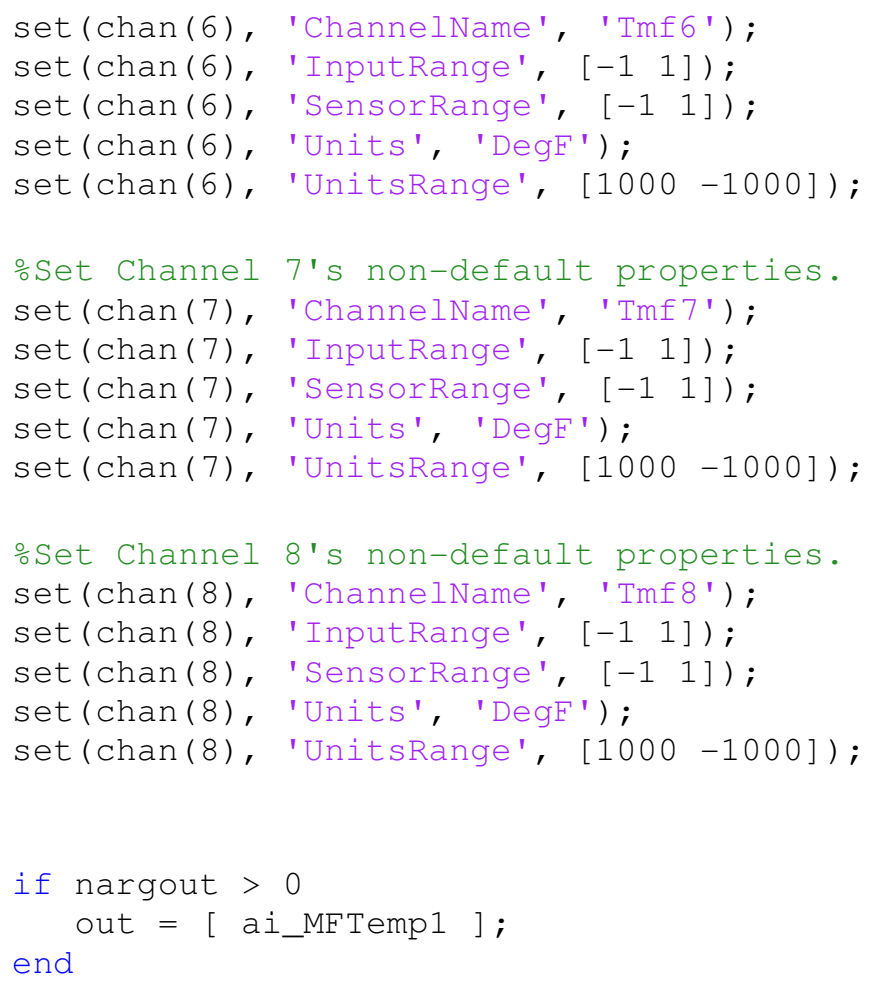

\section{Use analog input object to take data and display results}

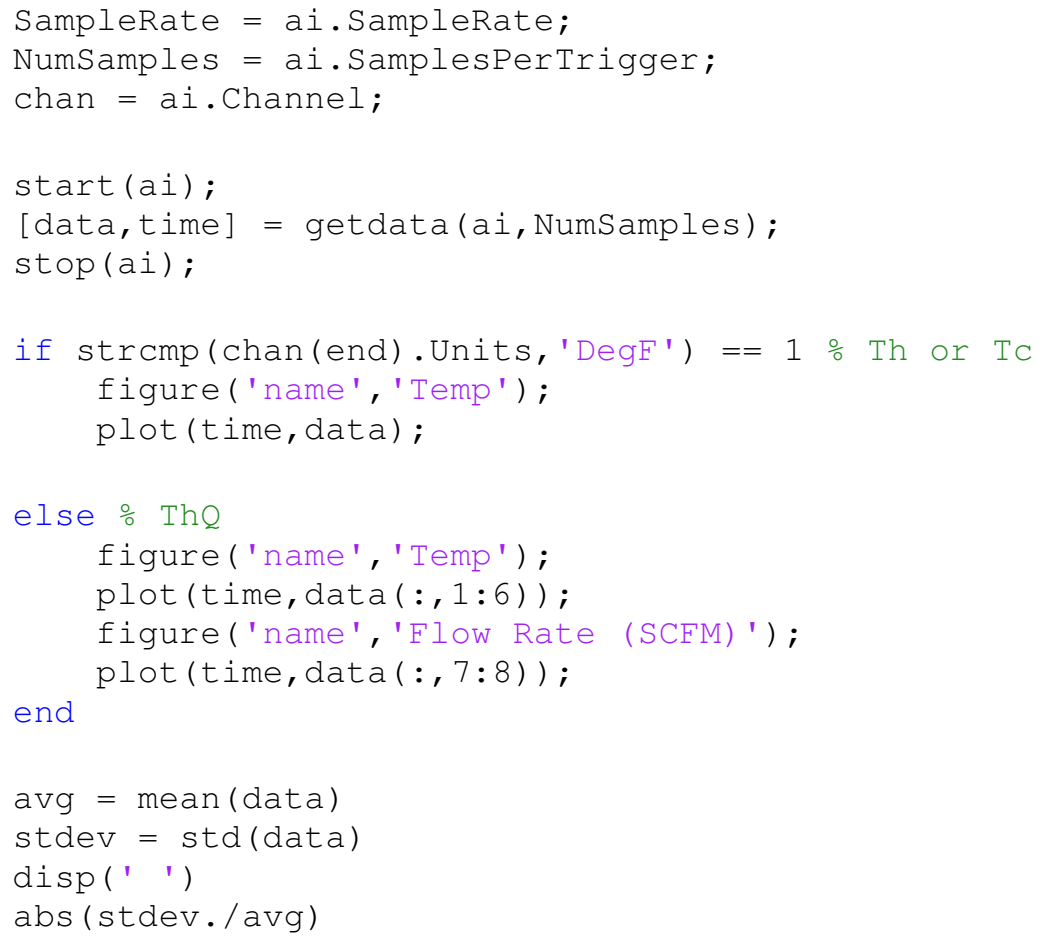




\section{Transfer recorded .daq files to excel, plot raw data, and display averages}

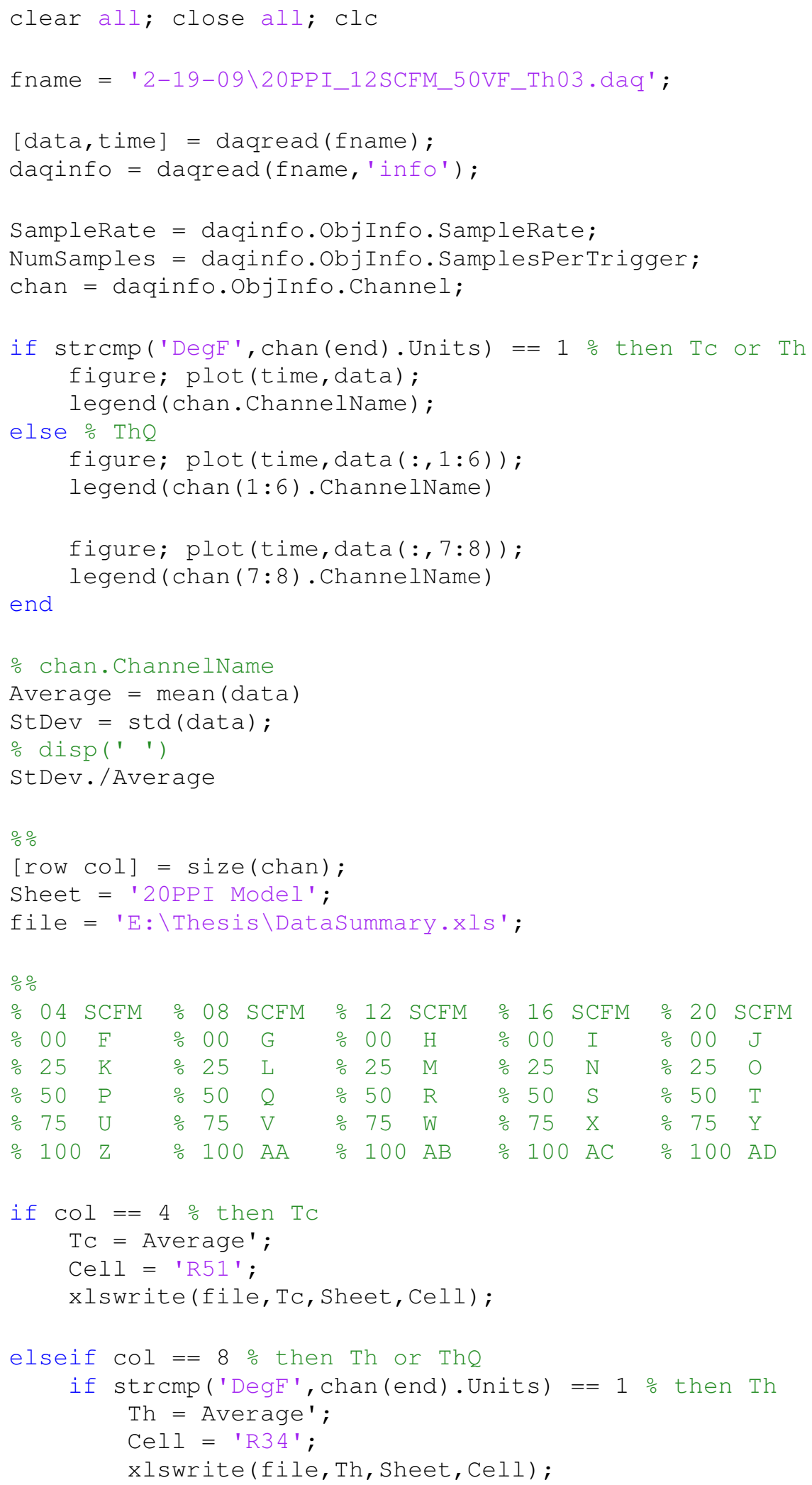




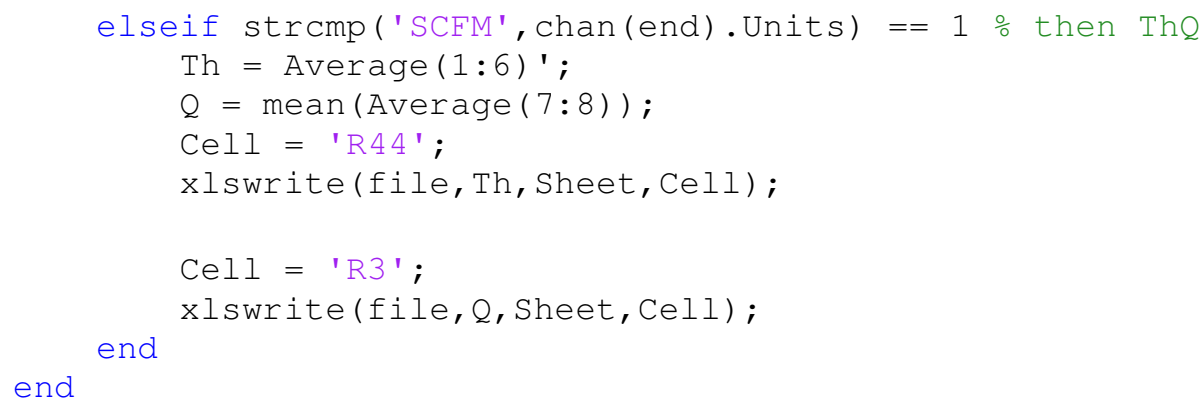

\section{Write Scanivalve .dat file to Excel}

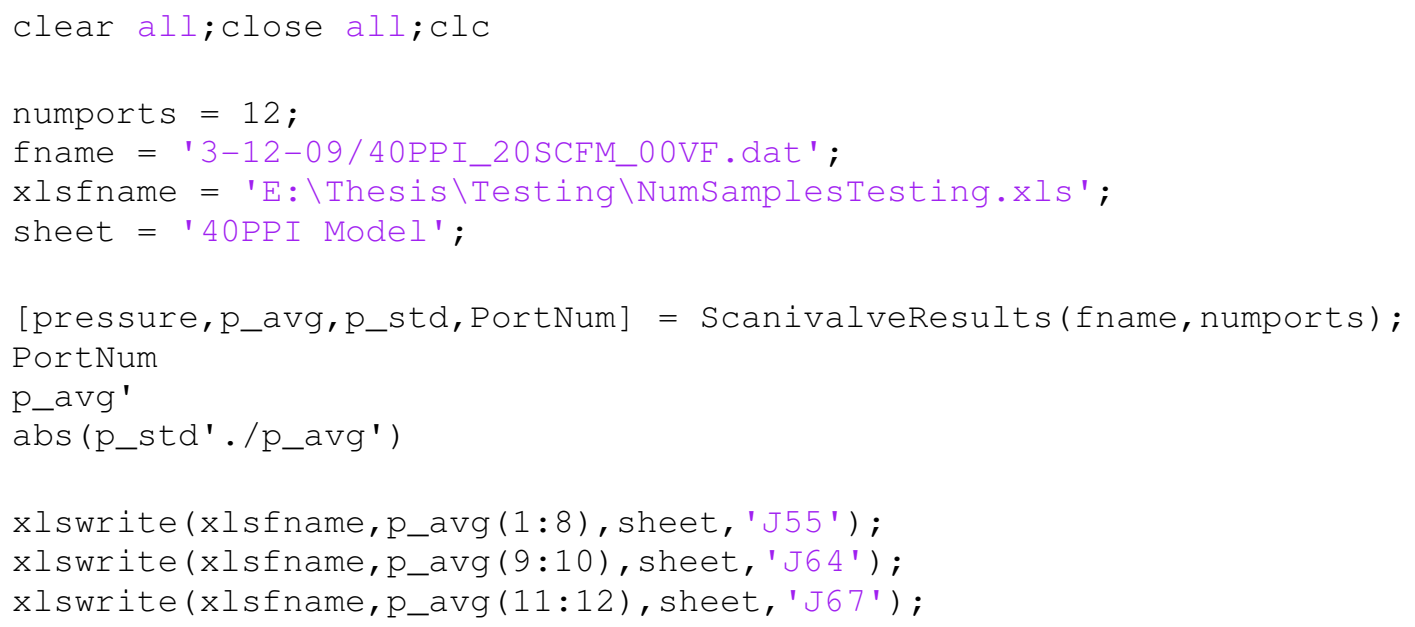

\section{Reduce Scanivalve .dat file to pertinent information (port numbers, means, and}

standard deviations)

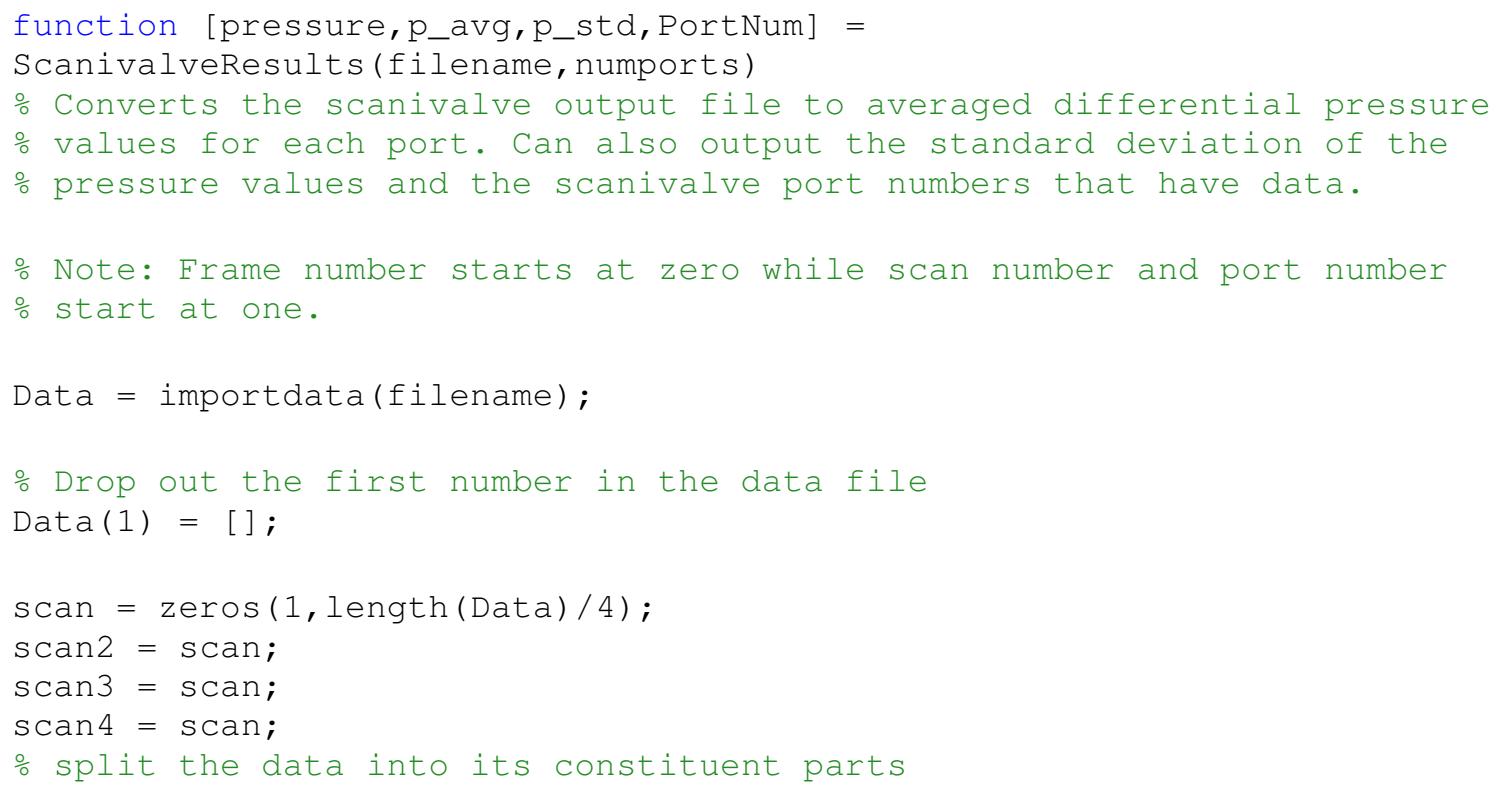




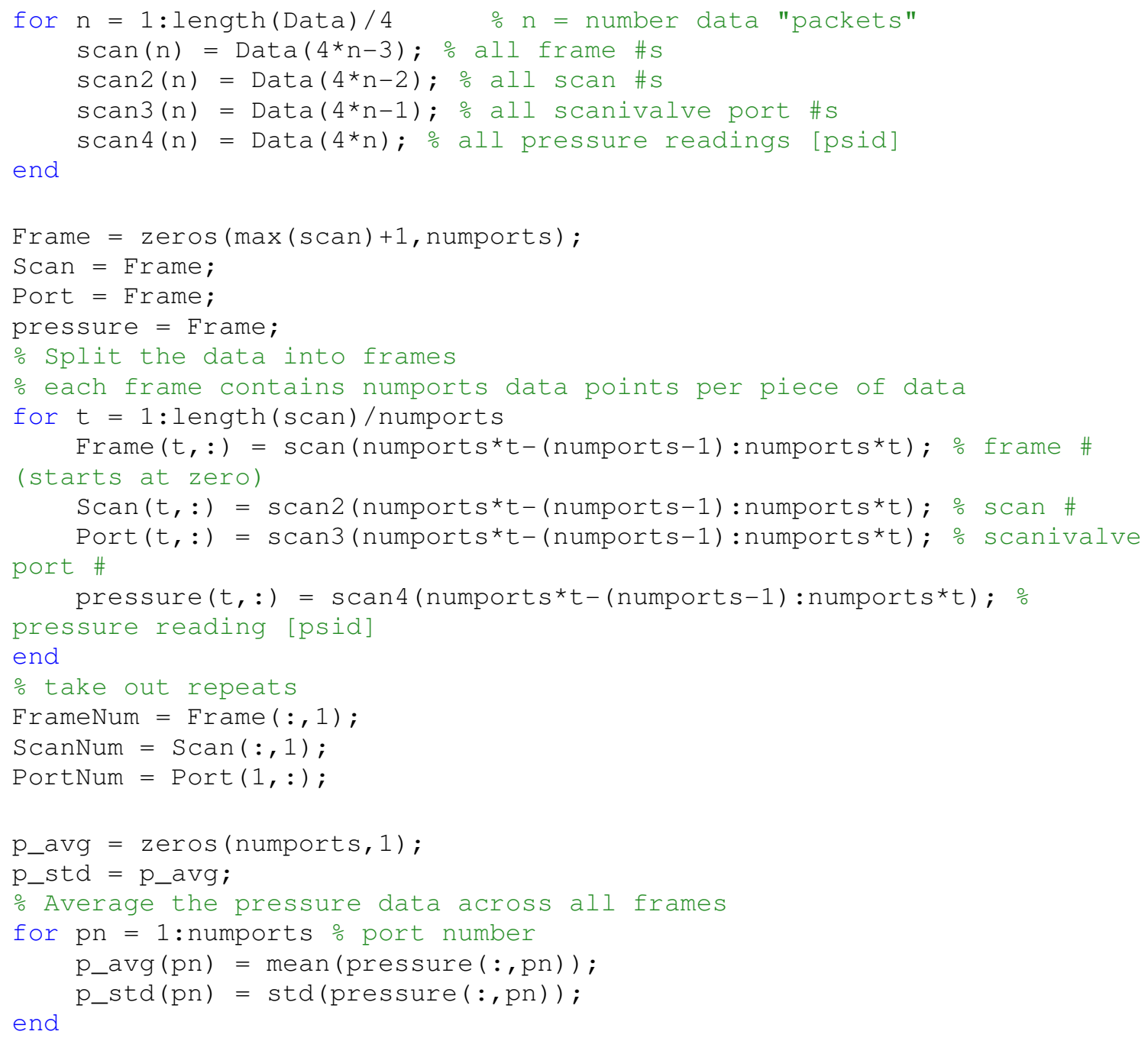




\section{APPENDIX C: 40 PPI HEAT EXCHANGER RESULTS}

\section{Internal Nusselt number}

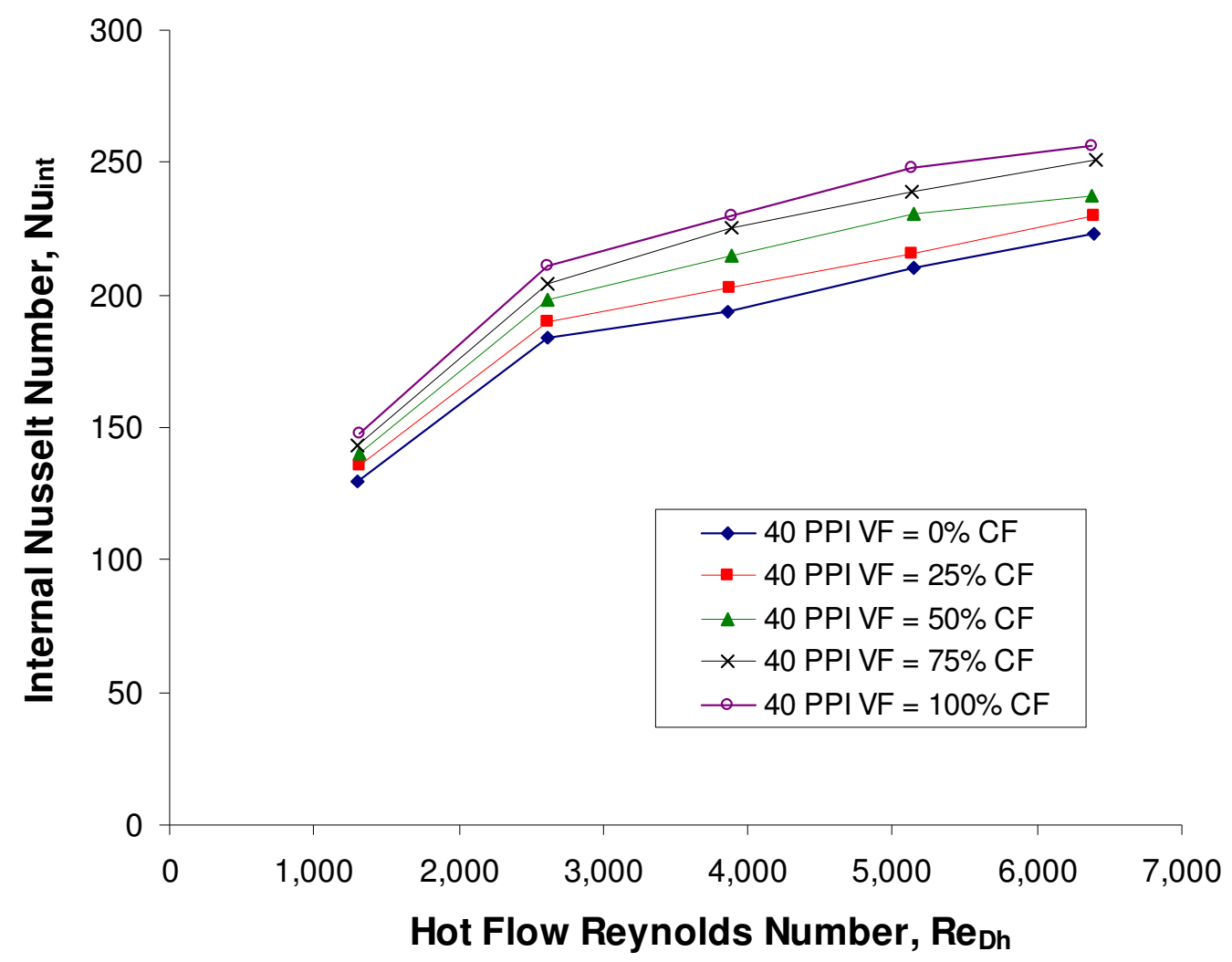

The same trends exist for the internal Nusselt number of the 40 PPI model as was seen above for the 20 PPI model. The only large difference is for the 4 SCFM hot-flow rate case. For the 20 PPI model, this flow rate setting resulted in a minimal change in internal Nusselt number for a given change in the variable-fan flow velocity. However, for the 40 PPI model, which has deteriorated heat transfer on the constant-fan side, there is an increase in the Nusselt number with a given increase in the variable-fan velocity. This is most likely due to the variable-fan side carrying away more heat than the constant-fan side; so, if the variable-fan side cooling flow has an increase in cooling 
effectiveness, it will be reflected because the variable-fan is carrying away more heat than the constant-fan side.

\section{External Nusselt number}

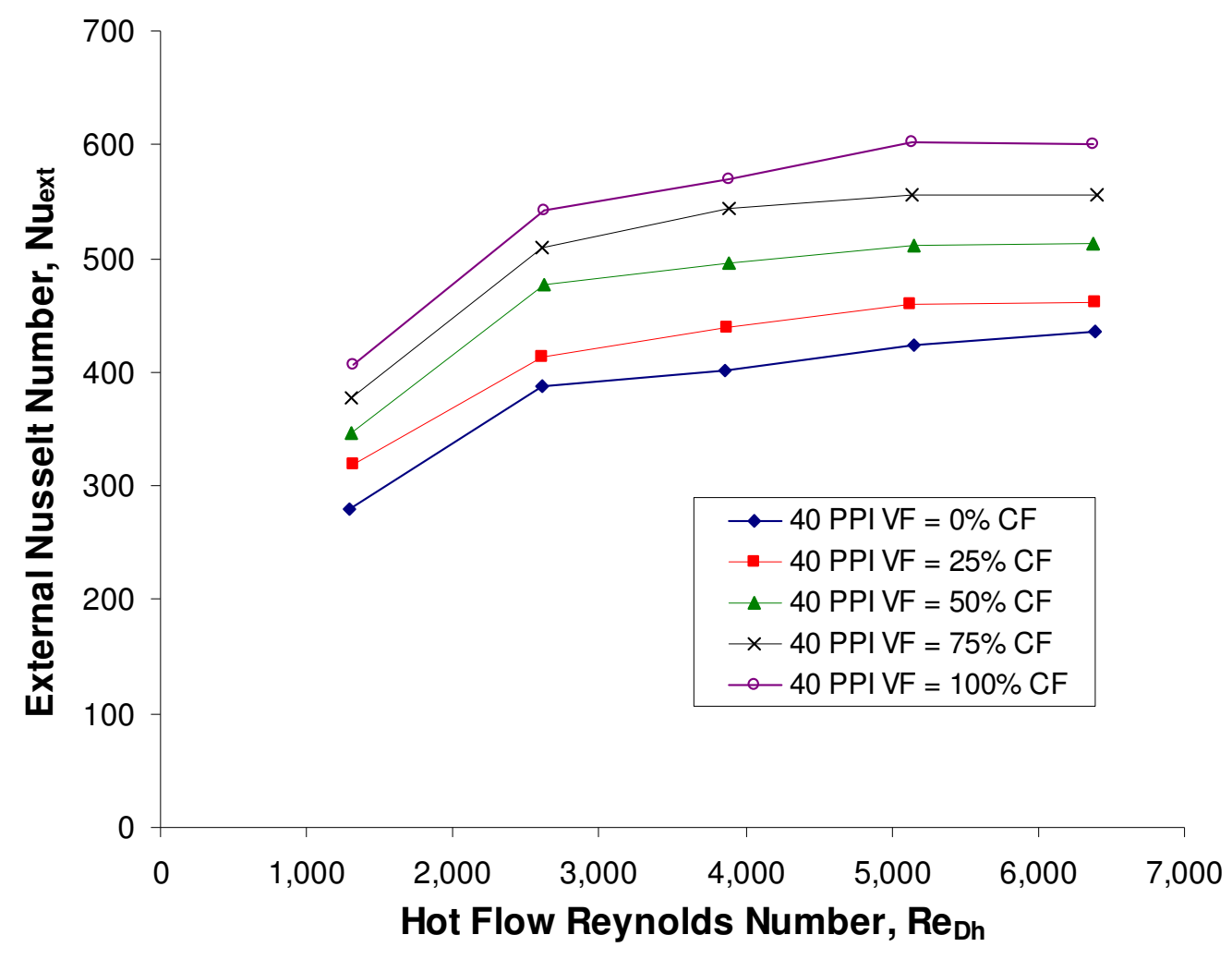

Just like the internal Nusselt number, the external Nusselt number for the 40 PPI model shows similar trends as the 20 PPI model. A given increase in variable-fan flow velocity provides a relatively uniform increase in Nusselt number across all internal Reynolds numbers tested. 


\section{Internal Colburn $\mathbf{j}$ factor}

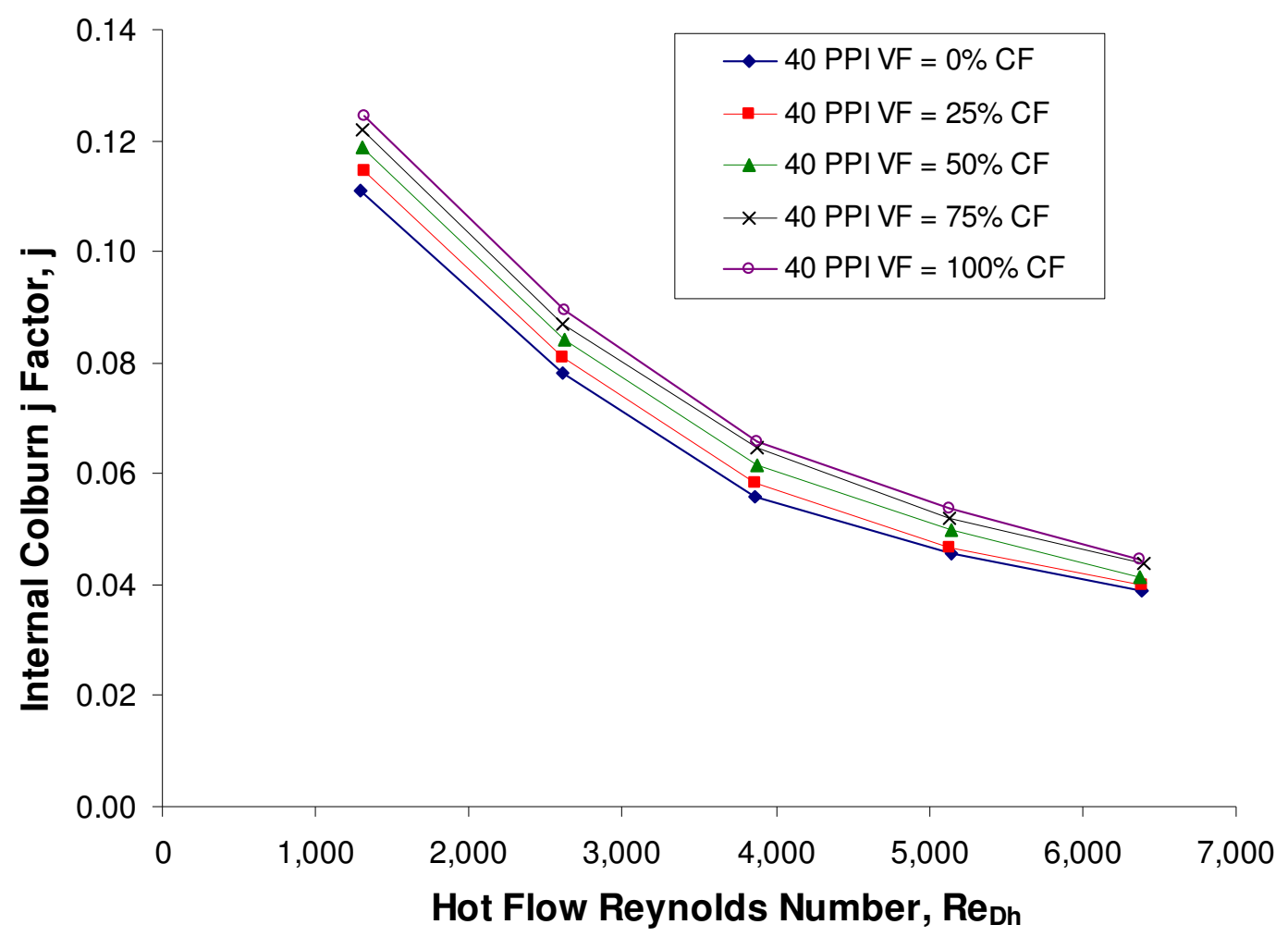

The 40 PPI model's Colburn $\mathrm{j}$ factor shows the same trends as the 20 PPI model. The only difference is the same as seen above for the internal Nusselt number: there is now a change in the $\mathrm{j}$ factor with respect to the variable-fan velocity at a hot-flow Reynolds number of 1,300 . 


\section{Pumping power and thermal resistance}

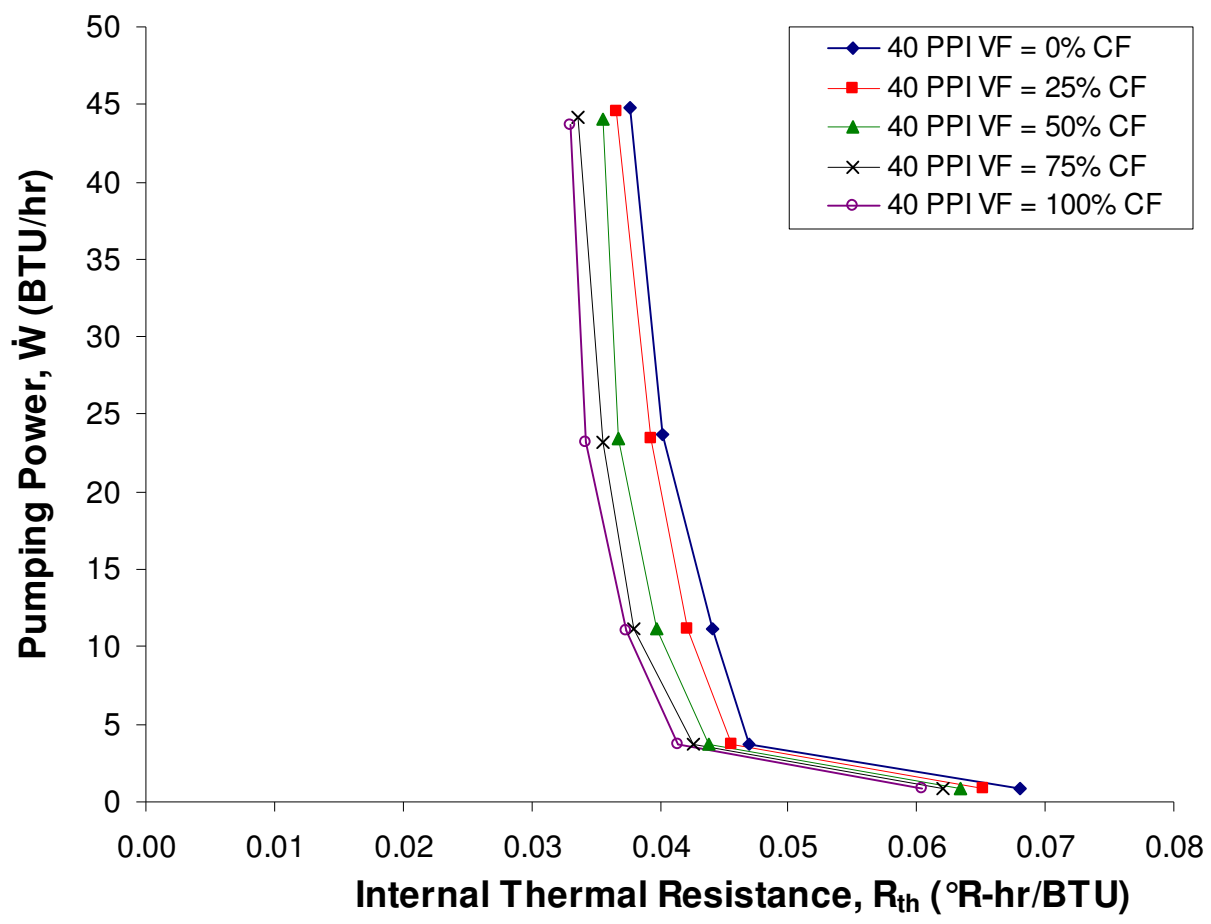

Normalized pumping power and thermal resistance

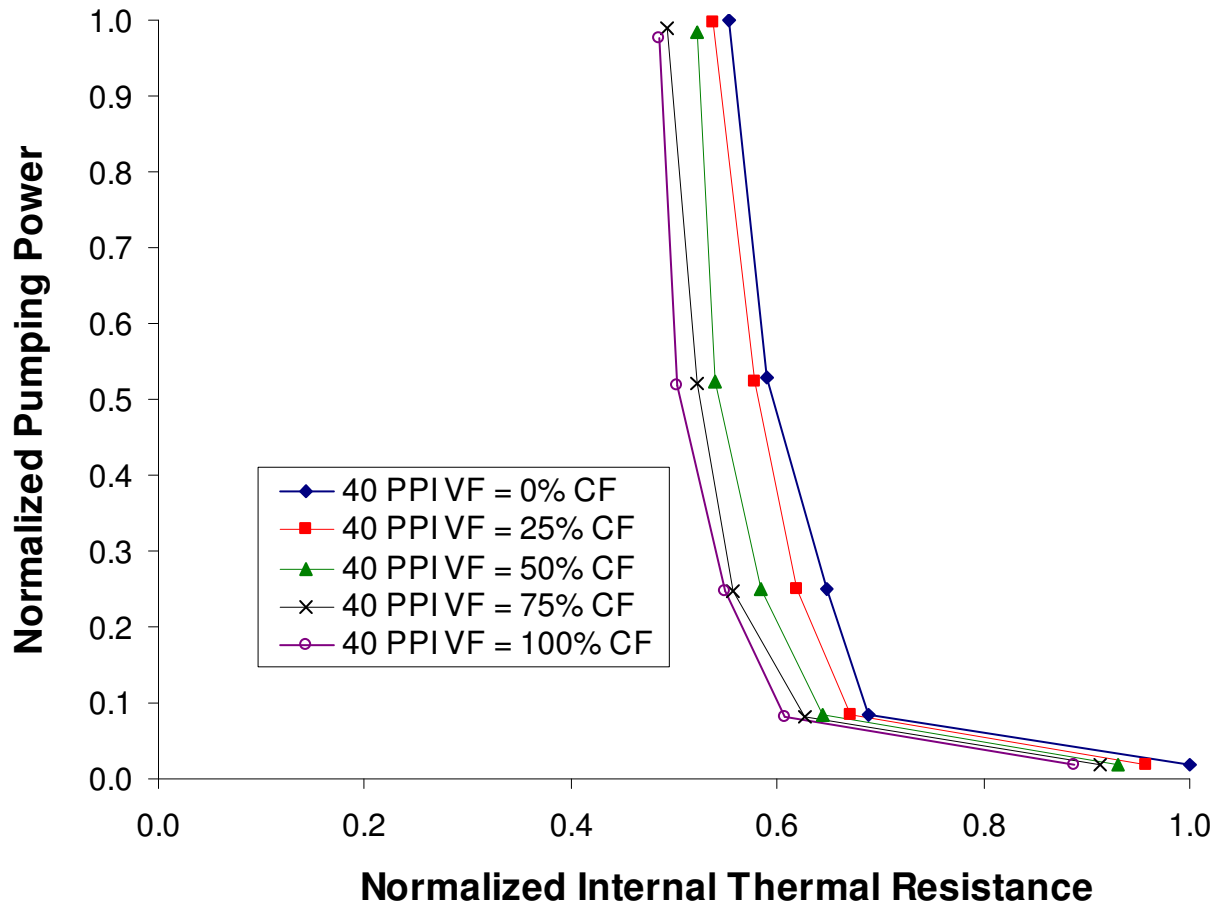




\section{REFERENCES}

${ }^{1}$ Norris, Guy, "Game Changer,” Aviation Week and Space Technology, Vol. 167, No. 14, 2007.

${ }^{2}$ Kandebo, Stanley W., "GE Eyes Variable Cycle for Engine Competition,” Aviation Week, Vol. 138, No. 13, 1993, pp. 28.

${ }^{3}$ Barr, Larine, “Air Force Plans to Develop Revolutionary Engine,” Air Force Research Laboratory Public Affairs, Apr., 2007.

4 “VAATE BAA III - Adaptive Versatile Engine Technology (ADVENT)," Broad Agency Announcement Number 07-01-PRK, Call 01, Air Force Research Laboratory, Propulsion Directorate, Wright-Patterson AFB, OH, 2007.

5 "Duocel Foam Properties," Energy Research Generation, Inc., California. [http://www.ergaerospace.com/foamproperties/introduction.htm. Accessed 1/30/07.]

${ }^{6}$ Salas, Ken I. and Waas, Anthony M., "Convective Heat Transfer in Open Cell Metal Foams," Journal of Heat Transfer, Vol. 129, Sept., 2007, pp. 1217-1229.

${ }^{7}$ Calmidi, V. V. and Mahajan, R. L., "The Effective Thermal Conductivity of High Porosity Fibrous Metal Foams," Journal of Heat Transfer, Vol. 121, May, 1999, pp. 466-471.

${ }^{8}$ Boomsma, K., and Poulikakos, D., "On the effective thermal conductivity of a three-dimensionally structured fluid-saturated metal foam," International Journal of Heat and Mass Transfer, Vol. 44, 2000, pp. 827-836.

${ }^{9}$ Ashby, Michael F., Anthony Evans, Norman A. Fleck, Lorna J. Gibson, John W. Hatchson, Haydn N.G. Wadley, Metal Foams: A Design Guide, Butterworth-Heinemann, Massachusetts, 2000.

${ }^{10}$ Ballestas, Osvaldo, “An Experiment on Leading-Edge Cooling Using Metallic Foam,” Masters Thesis, Department of Aerospace Engineering, California Polytechnic State University, San Luis Obispo, CA, 2005.

${ }^{11}$ Sheridan, Matthew, "An Investigation of High Temperature Leading Edge Cooling Using Metallic Foam," Masters Thesis, Department of Aerospace Engineering, California Polytechnic State University, San Luis Obispo, CA, 2006.

${ }^{12}$ User's Guide: FMA 1700 \& FMA 1800 Mass Flowmeter, Omega Engineering, Stamford, CT.

13 “Norgren Excelon Pressure Regulators," Omega Engineering, Connecticut. [http://www.omega.com/Auto/pdf/R72G_SERIES.pdf. Accessed 9/22/08.]

${ }^{14}$ Boomsma, K., Poulikakos, D., and Zwick, F., "Metal Foams as Compact High Performance Heat Exchangers," Mechanics of Materials, Vol. 35, 2003, pp. 1161-1176.

${ }^{15}$ Boomsma, K., Poulikakos, D., "The Effects of Compression and Pore Size Variations on the Liquid Flow Characteristics in Metal Foams," Journal of Fluids Engineering, Vol. 124, 2002, pp. 263-272. 
${ }^{16}$ Calmidi, V. V., and Mahajan, R. L., "Forced Convection in High Porosity Metal Foams," Journal of Heat Transfer, Vol. 122, 2000, pp. 557-565.

${ }^{17}$ Taylor, John R., An Introduction to Error Analysis: The Study of Uncertainties in Physical Measurements, $2^{\text {nd }}$ ed., University Science Books, Sausalito, CA, 1997. 